Revista lus et Praxis, Año 25, № 3, 2019, pp. 333 - 406

ISSN 0717 - 2877

Universidad de Talca - Facultad de Ciencias Jurídicas y Sociales

La corrupción en el mundo de los negocios. Una aproximación

criminológica teórica y empírica para el caso chileno

Sebastián Salinero Echeverría - Rodrigo Alarcón Soto-Sebastián Galleguillos

Trabajo recibido el 10 de mayo de 2018 y aprobado el 23 de agosto de 2019

\title{
La corrupción en el mundo de los negocios. Una aproximación criminológica teórica y empírica para el caso chileno*
}

\author{
CORRUPTION IN THE BUSINESS WORLD. A THEORETICAL AND EMPIRICAL \\ CRIMINOLOGICAL APPROACH TO THE CHILEAN CASE
}

\author{
Sebastián Salinero EcheVerría** \\ RODRIGO Alarcón SOTO** \\ Sebastián Galleguillos ${ }^{* * *}$
}

\begin{abstract}
RESUMEN
En el último tiempo se ha generado una percepción generalizada de incremento de la corrupción y, con ello, reforzado la desconfianza ciudadana en las instituciones. El objetivo de este artículo es exponer los principales modelos teóricos que contribuyen a explicar la corrupción en el mundo de los negocios, analizando las investigaciones empíricas nacionales existentes que han aportado información y datos sobre la corrupción. Teniendo en consideración dichas contribuciones teóricas en el ámbito de la criminología, el artículo finaliza con la inclusión de un estudio exploratorio con rasgos cuantitativos y cualitativos de la corrupción privada en Chile, buscando indagar en las características de este fenómeno en el país.
\end{abstract}

\section{ABSTRACT}

The corruption scandals that have recently appeared in Chile have had a great media presence. This has generated a widespread perception of increasing corruption levels and mistrust towards institutions. In this article we describe in the introduction the main theoretical models that contribute to the explanation of corruption in the business world, analyzing the Chilean empirical investigations that have provided data on corruption. Later, we explore the private corruption phenomenon in Chile using a mixed method approach, identifying the principal characteristics of private corruption in that country.

Palabras Claves

Corrupción, empresas en Chile, teorías criminológicas, cohecho.

KEYWORDS

Corruption, Chilean companies, criminological theories, bribery.

\footnotetext{
* Trabajo que se enmarca dentro del proyecto Fondecyt 1150148, titulado "Corrupción y actividad empresarial. Análisis conceptual para una nueva Sistematización". Queremos agradecer el trabajo realizado por los siguientes becarios: Camila Muñoz, Josefa Barros, Alejandra Bustos, Sebastián Gómez, Patricio Acuña y César Bustamante.

** Universidad de Talca, Talca/Santiago, Chile. Correo electrónico: ssalinero@utalca.cl

*** INAP Universidad de Chile, Santiago, Chile. Correo electrónico: rodrigo.palarcon@gmail.com

**** Universidad de Talca, Talca/Santiago Chile. Correo electrónico: sgalleguillos@utalca.cl
} 


\section{Presentación y objetivos del trabajo}

Durante los últimos cinco años se ha producido una agudización de las percepciones negativas respecto a la corrupción en Chile 1 .

La diversidad de indicadores y mediciones tienden a señalar un incremento de una percepción negativa respecto al avance de corrupción. No obstante, los instrumentos antes señalados no permiten ahondar en las áreas donde se desarrolla tal problema (sector público o privado, instituciones políticas, judiciales, ciudadanía, etc.), su severidad y las prácticas correctivas realizadas por los agentes sociales para enfrentar la corrupción.

De tal forma, la corrupción se puede manifestar y desarrollar en prácticas sociales que son difíciles de evaluar, cuantificar y describir, las cuales tienen un alto impacto en cada uno de los actores involucrados, sean estos funcionarios públicos, profesionales del sector privado, ciudadanos, organizaciones, entre otros $^{2}$. Por lo tanto, una buena estrategia para aproximarse al problema se debe orientar a:

i. Utilizar una definición de trabajo de corrupción que permita una aproximación homogénea. En este sentido, se propone enfrentar el problema de corrupción compuesta por dimensiones como el cohecho y soborno, los cuales permiten identificar un conjunto de prácticas (observables) que supone la

\footnotetext{
1 Según la encuesta del Centro de Estudios Públicos de marzo 2010, solo un 11 \% de las personas consideraba a la corrupción como un problema central (ubicada en la posición 10 de las prioridades), mientras que, en agosto de 2016, aumentó a un 36 \% las personas que la consideran como un problema al cual el Gobierno debería dedicar mayor esfuerzo, pasando a la tercera posición de prioridades (solo tras delincuencia y salud). Véase: https://cepchile.cl/cep/site/tax/port/all/taxport_20_194_1.html. Por su parte, según la encuesta Adimark de marzo de 2010, un 33 \% desaprobó la gestión del Gobierno respecto al manejo de la corrupción, mientras que en julio de 2016 esta desaprobación se empinó a un $89 \%$ (solo superado por la delincuencia con un $90 \%$ ). Véase: https://www.adimark.cl/es/estudios/ archivo.asp. De acuerdo a la serie de Encuesta Bicentenario UC- Adimark, desde el año 2013 a la fecha ha caído el nivel de confianza en las empresas a la mitad: de un $16 \%$ que manifestaba tener "mucha confianza" y "bastante confianza" en el año 2013, a solo un $8 \%$ en el año 2015. Respecto a la corrupción, un 80 \% sostiene que "Chile hoy es un país corrupto", donde el sector empresarial ocupa el tercer lugar en el listado de instituciones más corruptas, con un $55 \%$ de personas que piensan que son "muy y bastante corruptas" (superado solo por Parlamento y Gobierno). Véase: http:// encuestabicentenario.uc.cl/resultados/. El Informe 2010 de Latinobarómetro con respecto a Chile reflejó que un 48,9 \% sostenía que en el país se ha avanzado "poco" o "nada" en reducir la corrupción en las instituciones del Estado en estos últimos dos años. Este valor subió en el año 2015 a 54,5 \%.Véase: CORPORACIÓN LATINOBARÓMETRO (2010). Finalmente, el informe ¿Cómo va la vida?, publicado por la OCDE en noviembre de 2017, indicó que el 82 \% de los chilenos opina que la corrupción está generalizada en el Gobierno, cifra superior al promedio de la OCDE (56 \%). Véase OECD (2017).
}

2 Es importante destacar que la relevancia de la corrupción reside en gran parte en su naturaleza pluriofensiva. La corrupción afecta no solo intereses relativos a la función pública, sino que también posee un profundo impacto a nivel económico. Al respecto, véase Carnevall y ArTAZA (2017), pp. 54-65. 
participación de un agente que pretende corromper, ya sea a un funcionario público y/o privado, para lograr fines o beneficios propios ${ }^{3}$.

ii. Identificar el área específica dónde se desea evaluar el desarrollo del problema; es decir, el sistema de relaciones y comportamientos a observar. Para ello, el estudio considera relevante estudiar el impacto de este tipo de delito en el mundo de los negocios, específicamente en las relaciones dadas entre los ejecutivos y su entorno de negocios (relación con la competencia, funcionarios del sector público central y local, organizaciones sociales, clientes, entre otros).

iii. Para el levantamiento de la información se necesitan métodos robustos como el método de entrevistas cara-cara, mediante la aplicación de cuestionarios al actor o población objetivo, complementados con técnicas cualitativas basadas en entrevistas en profundidad. Estos instrumentos permiten medir un set de dimensiones relevantes con el fin de visualizar la magnitud del problema, profundizando en las percepciones de los actores y las prácticas desarrolladas contra el soborno en el sector privado.

Mediante la metodología propia de la criminología, la población de estudio consistió en una muestra no representativa de empresas privadas del Gran Santiago, pertenecientes a la Confederación de la Producción y el Comercio (CPC) y seleccionadas por medio de un proceso de muestreo no probabilístico (por cuotas) ${ }^{4}$.

Se aplicó una encuesta con el fin de identificar las particularidades de la corrupción en el mundo de los negocios y los factores que incidirían en su ocurrencia desde la perspectiva empresarial. Junto con lo anterior, se aplicaron una serie entrevistas en profundidad a actores clave, con el objeto de profundizar en las narrativas que circulan dentro del rubro empresarial. Así, también se buscó identificar las acciones preventivas y de protección en las relaciones comerciales, aspectos centrales del quehacer empresarial que pueden incidir en la realización de prácticas corruptas.

\footnotetext{
${ }^{3}$ Se utiliza el cohecho y soborno porque son los delitos que menos problemas tienen. Entre otras razones para afirmar aquello, podemos indicar que el cohecho, en Chile, es el ilícito que tiene mayor peso porcentual dentro de los delitos considerados como funcionarios. También reúne algunas características para ser seleccionado como objeto de referencia: en primer lugar, su conceptualización en el Código Penal ha sido mantenida en el tiempo; esto es, se ha entendido por muchos años de la misma forma y no se ha introducido ningún tipo de cambio en sus especificaciones. En segundo lugar, la conceptualización de este delito es ampliamente entendida por la mayoría de las personas. Lo que se ha entendido por cohecho se ha mantenido inalterable desde la Ley $\mathrm{N}^{0} 19.645$, de 1999, y por soborno desde la Ley № 19.829, de 2002. En tercer término, desde los últimos años hasta la fecha, la corrupción, dentro de la cual se entienden incorporados el cohecho y soborno, es un problema fundamental para la sociedad chilena y ha sido objeto de una variedad de políticas públicas para poder reaccionar ante ella.

${ }^{4}$ En el apartado de metodología se explican en detalle los problemas asociados al trabajo de campo.
} 
El trabajo relevará, además del estudio empírico, los problemas asociados a la investigación del fenómeno de la corrupción, el saber existente a través de una sistematización desde lo teórico y los estudios de campo que se han levantado sobre la temática de la corrupción en nuestro país.

\section{Explicaciones acerca de la corrupción desde la criminología}

En la bibliografía sobre la etiología de la corrupción, la que particularmente se ha desarrollado profusamente en estudios anglosajones, se resaltan un sinnúmero de explicaciones desde el ámbito de la criminología. Estas podrían ser concentradas en cuatro perspectivas explicativas: motivación, oportunidad, aprendizaje y control social.

\subsection{Motivación}

En el sistema anglosajón, la corrupción en el sector privado se enmarca en la definición de delito de cuello blanco organizativo o crimen corporativo, es decir, el que es "perpetrado por organizaciones o individuos que actúan en nombre de organizaciones" ${ }^{\prime \prime}$. En ese marco, la motivación para la mala conducta corporativa está principalmente subordinada a los intereses de la corporación, tales como la codicia y el afán de lucro, aunque hay otros factores, como la supervivencia y los celos, que se han citado por la literatura ${ }^{6}$. Vaughan hace eco de la idea de que la maximización del beneficio es el factor motivador clave en la mala conducta corporativa ${ }^{7}$. Este postulado se basa en la teoría de la anomia de Merton, que enfatiza la competencia y el éxito económico como objetivos culturalmente aprobados que finalmente conducen a la erosión de las normas que respaldan los medios legítimos para lograr estos objetivos ${ }^{8}$. La tensión que se siente entre poder alcanzar los objetivos y los medios que se cuentan para poder lograrlo es lo que caracterizó la teoría de Merton como una teoría general del crimen. En su análisis de la sociedad estadounidense de los años treinta, Merton argumentó que el objetivo del éxito económico era válido para todos los miembros de la sociedad, el "sueño americano", mientras que los medios culturales prescritos para lograr estos objetivos no estaban distribuidos uniformemente

\footnotetext{
${ }^{5}$ Braithwaite (1989), p. 334. La literatura anglosajona con posterioridad ha realizado distinciones más específicas a nivel conceptual, indicando que el crimen corporativo ostenta características que lo hacen distinto de otras formas delictivas de cuello y corbata. Para una revisión sobre las condiciones particulares del crimen corporativo, véase SIMPSON-PIQUero et al. (2002), p. 510.

${ }^{6}$ Braithwaite (1989), p 334; Naylor (2000), pp. 1-35.

7 VAUGHAN (1982), pp. 1377-1402.

${ }^{8}$ Merton (1938), pp. 672-682.
} 
entre todos los miembros y grupos sociales en la sociedad ${ }^{9}$. Esto podría llevar a grupos con menos acceso a medios legítimos para adquirir riqueza a buscar medios alternativos, posiblemente ilegítimos, prácticas apodadas por Merton como "innovación"10. Cloward y Ohlin agregaron a esto que también la disponibilidad de los medios ilegítimos puede no estar distribuida uniformemente en la sociedad ${ }^{11}$. Si bien esta corriente se desarrolló para la explicación del crimen en las clases más bajas de la sociedad, la teoría de la tensión resultó ser muy popular en la explicación del crimen de cuello blanco. Especialmente, cuando las oportunidades para obtener ganancias están amenazadas y la continuación de una corporación está en juego, los agentes corporativos podrían transferirse a medios ilegítimos para obtener ganancias, como ofrecer sobornos para obtener los contratos necesarios u otras practicas análogas a éstas.

Según Vaughan, hay dos procesos donde ocurre la mala conducta empresarial, uno donde los medios legítimos son lisa y llanamente bloqueados debido a la incapacidad de una organización para competir legalmente, y otro donde los medios legítimos se utilizan para entrar en la competencia, pero, una vez allí, estos se vuelven ineficaces. En consecuencia, el objetivo de la maximización de los beneficios es ilusoria, ya que siempre habrá una configuración de objetivos más altos una vez que se alcanzan los de más bajos ${ }^{12}$. Esta idea es consistente con Passas (1997) -basada también en la teoría del grupo de referencia de Merton-, que postula que ciertos individuos en sociedades con alto énfasis en los objetivos económicos siempre se compararán con aquellos con mayores niveles de bienestar, lo que resulta en la privación relativa en todas las partes de una sociedad ${ }^{13}$.

\subsection{Oportunidad}

La teoría de la oportunidad, por su parte, si bien reconoce la importancia de la persona que comete el delito, también llama a considerar el contexto en el cual este es cometido ${ }^{14}$. El desarrollo de esta corriente ha puesto énfasis en las particularidades que implican los delitos de cuello blanco, destacando que

\footnotetext{
${ }^{9}$ Distintos estudios empíricos han buscado explorar esta teoría dentro de los delitos de cuello blanco. Al respecto, véase el test de la teoría institucional de la anomia en la sociedad americana, Schoepfer y PiQuero (2006), pp. 227-235.

10 Huisman y Vande et al. (2010), p. 22.

11 Richard y Lloyd (1961), pp. 282-289; Vold- Bemard et al. (2002), pp. 141 y ss.

12 Vaughan (1982), pp. 1387 y ss.

13 PASSAS (1998), pp. 42-55.

14 Benson y Simpson (2015), p. 96.
} 
existen técnicas y condiciones particulares a través de las cuales se cometen estos ilícitos ${ }^{15}$.

En el ámbito de las oportunidades, la mayoría de los autores en el campo de la criminología estiman la globalización como un elemento criminógeno a considerar. De acuerdo con Passas ${ }^{16}$, la globalización multiplica, intensifica y activa asimetrías que son la raíz del crimen corporativo. Passas define estas asimetrías como "Disyunciones estructurales, desajustes y desigualdades en las esferas de la política, la cultura, la economía y la ley ${ }^{\prime 17}$. Estas son criminógenas porque ofrecen oportunidades ilegales, crean motivos para utilizarlas y hacen posible, en definitiva, que los delincuentes se salgan con la suya. Desde una perspectiva criminológica, la globalización también implica un aumento de las relaciones de interdependencia y una mayor ausencia de guardianes capaces de ejercer vigilancia ${ }^{18}$. Passas advierte que la corrupción corresponde a una fuerza conservadora que mantiene o aumenta las asimetrías ${ }^{19}$. Esta fuerza impide el progreso social, económico y político y facilita la existencia de mercados ilegales. La corrupción, por otro lado, también es una consecuencia de las asimetrías ${ }^{20}$. Empresas que operan en países con una administración de lentitud burocrática se verán tentadas a pagar dinero para tener una alta velocidad y poder desarrollar su giro.

Las asimetrías criminógenas también se pueden encontrar en el campo de la regulación normativa de la corrupción. La naturaleza y la firmeza de la regulación de la corrupción pueden diferir de un país a otro, las que van desde la total ausencia de estándares regulatorios hasta la completa criminalización del fenómeno. Asimetrías en la regulación de la corrupción podrían no solo brindar oportunidades para su existencia, sino que también pueden contribuir a la ambigüedad moral ofrecer y aceptar sobornos. Falta de claridad de los requisitos reglamentarios y los límites de un comportamiento aceptable son una característica típica de la delincuencia de cuello blanco ${ }^{21}$. La confusión sobre qué es y qué no es aceptable, debido a cambios radicales en la sociedad, fue etiquetada por el sociólogo Durkheim como "anomia". De acuerdo con Durkheim, y para

\footnotetext{
15 Benson y Simpson (2015), pp. 99 y ss.

16 PASSAS (1998), pp. 42-55.

17 PASSAS (1998), p. 42.

18 Al respecto, véase Grabosky (2009), pp. 133-134.

19 PASSAS (1998), pp. 42-55.

20 PASSAS (1998), p. 47.

21 Nelken (1994), pp. 355- 392; ZimRing y Johnson (2005), pp. 45 y 793-809.
} 
los criminólogos que han reelaborado su teoría, en un ambiente anómico, se pueden esperar niveles comparativamente altos de delincuencia ${ }^{22}$.

Por otro lado, también se enumeran los procesos organizacionales, la estructura y la complejidad de las transacciones como contribuyentes significativos al crimen corporativo. Aunque estos componentes del sector empresarial fueron diseñados originalmente para la actividad comercial legítima, pueden ser utilizados con propósitos ilegítimos. Las organizaciones a menudo reclutan personas cuyas cualidades y objetivos están alineados con la cultura y necesidades organizacionales, seguido por el refuerzo de esta relación a través de recompensas, dependencia financiera y aislamiento del mundo exterior. La estructura organizativa también reduce la probabilidad de detección y sanción de comportamientos no éticos o ilegales. Además del motivo de la ganancia, Clinard argumenta que una corporación también desea dar forma a su entorno político y comercial. Él agrega que el impulso por las ganancias y el poder no es ilegal en sí mismo, pero, cuando eclipsa todas las demás consideraciones, se obtienen consecuencias potencialmente indeseadas. Clinard entiende la estructura organizacional y los procesos como parte de los principales factores que contribuyen al crimen corporativo, es decir, relaciones y expectativas complejas; factores tales como tamaño, delegación y especialización que llevan a una abdicación de la responsabilidad personal. El autor también argumenta que las jerarquías organizacionales promueven rigidez y timidez en los rangos inferiores. En consecuencia, incluso si aquellos que en la parte inferior de los rangos debían reportar comportamiento no éticos o ilegales, la alta gerencia puede no querer ser informada o conocer de hechos negativos, lo que lleva a la aprobación tácita ${ }^{23}$.

En la dinámica de los procesos organizacionales, también existe la filosofía del acoplamiento flojo de las organizaciones, que es una forma de descentralización en la que las subunidades son parcialmente separadas de la organización matriz y así reciben una mayor autonomía. Aunque una estructura débilmente acoplada permite que una organización se adapte mejor al cambio, también tiene algunas disfunciones que pueden convertirse en un impulso para el comportamiento ilegal ${ }^{24}$. Una estructura dividida y débilmente acoplada puede carecer de control interno. Debido a la autonomía de las subunidades, el comportamiento ilegal puede no llamar la atención de la administración central. Si bien este comportamiento puede ser un efecto secundario, no deseado,

22 Durkheim (1997); George y Bemard et al. (2002), p. 105.

23 Clinard y Yeager (1978), pp. 255-272.

24 Keane (1995), pp. 168-181; Tombs (1995), pp. 132-147. 
el desacoplamiento también puede ser una estrategia deliberada para aislar subunidades que corren un mayor riesgo de ser acusadas de comportamiento ilegales, por ejemplo, porque están operando en un contexto de corrupción, ya sea un mercado o un país con altos niveles de corrupción ${ }^{25}$. Algunos estudios muestran que las corporaciones que ingresan a mercados extranjeros en ambientes corruptos se adaptan al riesgo de corrupción mediante la contratación a corto plazo y la utilización de empresas conjuntas ${ }^{26}$. También otro paso más en la separación de los riesgos de responsabilidad y reputación es la tercerización de actividades cuestionables ${ }^{27}$.

El modelo económico de Becker también podría ser un reflejo de este enfoque oportunista. El argumento se presenta para un marco de elección racional en el crimen corporativo, donde los beneficios de la actividad ilegal se ponderan contra los costos de detección y castigo. La extensión de este marco es el modelo principal-agente según el cual los agentes (es decir, empleados) tienen la discrecionalidad de realizar actividades ilegales, mientras el director (es decir, la empresa, accionistas) mantiene el poder a través de incentivos y estructuras de control que afectan al agente. Las decisiones conjuntas tanto del director como del agente afectan la probabilidad de decidir participar en tales actividad ilegales ${ }^{28}$.

Braithwaite resume: "Dadas las grandes recompensas y los bajos riesgos de detección, ¿por qué tanta gente de negocios adopta el curso económicamente irracional de obedecer la ley?"29. El mismo autor también se plantea una plantilla útil para combinar teorías criminológicas para explicar el crimen corporativo ${ }^{30}$. Él argumenta, primero, a favor de una teoría de oportunidad, por la cual la combinación del bloqueo de objetivos y las oportunidades ilegítimas Ilevan a una subcultura conducente al crimen.

\footnotetext{
25 Gobert y Punch (2003), pp. 156 y ss.

${ }^{26}$ Uhlenbruck-RodríGuez et al. (2006), pp. 402-414. formalmente de propiedad de Chiquita.

${ }^{28}$ Alexander y Cohen (1996), pp. 421-435.

29 Braithwaite (1985), p. 7.

30 BRAithwaIte (1989), pp. 6 y 333-358.
}

27 WINDSOR (2008), pp. 119- 137. Un ejemplo destacado de esta separación de riesgos y reputación fue cuando la gran corporación multinacional de frutas Chiquita tuvo que aceptar una declaración de culpabilidad después de haber sido acusada de proporcionar dinero de pago a la AUC en Colombia -un grupo paramilitar que está en la lista de organizaciones terroristas de los Estados Unidos-y oficialmente salió de Colombia. En cambio, se formó una nueva compañía y una compañía independiente para la exportación de plátanos, Banamex, que tiene como único cliente Chiquita y utilizó todo la infraestructura 


\subsection{Aprendizaje}

En la línea del aprendizaje, conforme a la teoría de la asociación diferencial de Sutherland, el comportamiento criminal se aprende como cualquier otro comportamiento. El criminal aprende tanto las técnicas para cometer un crimen como las motivaciones favorables a ese comportamiento. A través de la asociación diferencial, las técnicas del delito, las racionalizaciones y las actitudes para con el mismo se transmiten. La hipótesis de la asociación diferencial es que el comportamiento criminal se aprende en asociación con aquellos que definen dicho comportamiento favorablemente y aislado de aquellos que lo definen desfavorablemente ${ }^{31}$. Un aspecto central del modelo de la asociación diferencial es que las definiciones favorables para quebrantar la ley deben tener una entidad suficiente o "peso" para arrollar a las definiciones que son desfavorables a la violación de la ley ${ }^{32}$.

A partir de este modelo de asociación, los criminólogos especializados en el estudio de los delitos de cuello blanco enfatizan el efecto acondicionador de la organización en el comportamiento del individuo. Las personas que no tienen una autoimagen desviada se convierten en delincuentes a través de las presiones de la "normalización" de la desviación. Drucker etiquetó esto como el "hombre de la organización" ${ }^{\prime 3}$, que está bajo presión para ajustarse a la imagen de que la individualidad y los estándares éticos personales deben estar orientados al bien de la carrera. Estos procesos de socialización pueden crear una especie de "entumecimiento moral", en el cual actividades no éticas o ilegales parecen ser una parte normal de la rutina diaria ${ }^{34}$.

Según Cohen, los miembros de la organización que están sujetos a las contradicciones entre las normas de comportamiento en la sociedad y las normas que se transfieren en la subcultura organizacional, podrían sufrir de anomia psicológica ${ }^{35}$. En este sentido, Passas incluso afirma: "En situaciones anómicas, los delincuentes están en una mejor posición para neutralizar y racionalizar sus actos, y al mismo tiempo preservar su autoestima"136. Las subculturas organizativas proporcionan a sus miembros las justificaciones apropiadas. Bajo esta teoría, la cultura de los delitos de cuello blanco permea la dinámica del mundo

31 Sutherland (1947); Vold- Bernard et al. (2002), pp. 160 y ss.

32 Benson y Simpson (2015), p. 75.

33 DruCKer (2001), p. 7.

34 Huisman y Vande (2010), p. 25.

35 Cohen (1965), pp. 5-14.

36 PASSAS (1990), pp. 157-178; 166. 
de los negocios, siendo trasmitida entre distintas generaciones de ejecutivos y empleados ${ }^{37}$.

En otra línea, pero dentro de esta misma esfera, los ofensores de cuello blanco generalmente están fuertemente comprometidos con la estructura normativa central, por lo que cada delincuente tiende a cruzar un umbral moral para poder violar las leyes o las normas éticas. Al mantener una identidad de ser un ciudadano respetable, un delincuente de cuello blanco tiene que ajustar el "lente normativo" a través del cual la sociedad ve su comportamiento. En su clásico estudio, Sykes y Matza mostraron que los delincuentes ajustan este lente normativo usando técnicas de neutralización que niegan la gravedad de la ofensa y la reprochabilidad de la acción del delincuente ${ }^{38}$. Como Coleman ha establecido, las técnicas de neutralización no son solo racionalizaciones ex post de los delitos de cuello blanco, también pueden preceder al incumplimiento de las reglas $y$, por lo tanto, facilitan moralmente el incumplimiento ${ }^{39}$. Una

\footnotetext{
37 Benson y Simpson (2015), p. 73.

38 SYKES Y MATZA (1957), pp. 664-670.
}

39 Coleman (1987), pp. 406-439. Este autor construyó una tipología de las técnicas de neutralización utilizadas por criminales de cuello blanco. Una de las técnicas más comunes es la negación del daño. Según el autor, el delincuente de cuello blanco a menudo afirma que sus acciones no dañaron a nadie y que, por lo tanto, no hizo nada malo. La relación de los interesados en el esquema de la corrupción a menudo se presenta como un asunto triangular y la víctima a menudo es más difícil de detectar. Por ello, será fácil de mantener que no se ha hecho daño y que no hay perjudicado o víctima alguna. Una segunda técnica de neutralización utilizada por delincuentes de cuello blanco es afirmar que las leyes que están violando son innecesarias o incluso injustas. Los delincuentes que usan esta racionalización encuentran apoyo en la influyente escuela neoliberal de economía de Chicago, la cual sostiene que los sistemas de mercado solo pueden operar con la máxima eficiencia cuando no existen barreras artificiales como la regulación gubernamental (Friedman 1962, Posner 1976). A la luz de la corrupción, este argumento es interesante, porque es debido a la presión de los negocios internacionales que organizaciones internacionales tales como el Banco Mundial, el FMI, la OCDE y la Unión Europea están forzando a los Estados a prohibir y prevenir la corrupción. Una tercera técnica de neutralización es que la violación de la regulación es necesaria para lograr objetivos económicos o simplemente para sobrevivir. Tanto en el lado activo como en el pasivo de la corrupción, la neutralización puede ser identificada. Aquellos que ofrecen sobornos enfatizarán que esto -a pesar de ser indeseable- resulta necesario para poder hacer negocios. En cambio, aquellos que reciben los sobornos pueden decir que el salario regular no es suficiente para sobrevivir y que el ingreso adicional es necesario para mantener a la familia. Una cuarta técnica de neutralización implica la transferencia de responsabilidad del ofensor a un grupo más grande. Esto será especialmente útil cuando la corrupción sea endémica. Ambos, aquellos que están ofreciendo y que están aceptando sobornos podrían decir que "todos lo están haciendo". La racionalización que lo acompaña es que es injusto condenar a un violador a menos que todos los demás violadores también sean condenados. Finalmente, el quinto método de neutralización es que una persona no es responsable de su comportamiento cuando este se conforma simplemente a las expectativas de otros. Esto se refiere a las actividades de los bandos medios en situaciones de tensión. A través de procesos de socialización, el uso de sobornos podría ser visto como una forma aceptable de cumplir objetivos establecidos por una administración superior. 
racionalización no es una excusa después de los hechos que alguien inventa para justificar su comportamiento, sino que también puede ser una parte integral de la motivación para el acto $^{40}$.

En un estudio sobre qué consideraciones los delincuentes de cuello blanco condenados solían justificar o excusar en su comportamiento, Benson identificó tres patrones generales ${ }^{41}$ : consideraciones orientadas hacia la ofensa, consideraciones sobre el delincuente y finalmente hacia el denunciante. Las consideraciones que se enfocan en la ofensa enfatizan la normalidad y aceptación general del comportamiento ("business as usual"). A su vez, cuando es sobre el delincuente, el sujeto intentará mostrar que no importa cómo sea la ofensa, ya que ella no es indicativa de su verdadero carácter personal. Los ofensores deben demostrar que son individuos ordinarios, comprensibles, que se separan de su delito y enfatizan el carácter de evento único y aislado. Las consideraciones que apuntan al denunciante son expuestas con un ejemplo; el delincuente podría reclamar que los fiscales están motivados por intereses personales en lugar de un deseo de defender los valores sociales o legales y que son perseguidos por razones políticas que nada tienen que ver con la nocividad de su comportamiento.

Sumado a las técnicas de neutralización tradicionales, la literatura norteamericana reciente también ha detectado otras igualmente relevantes, entre las que se pueden mencionar la negación de una víctima, la apelación a que el comportamiento corresponde a un acto de lealtad con la organización a la que se pertenece, la comparación de su conducta con actos previos de buen comportamiento, o mediante la reclamación del derecho a reclamar los frutos de su comportamiento ilegal, entre otros ${ }^{42}$.

\subsection{El control social}

La teoría del control social se centra en las estrategias e instituciones que controlan el alcance del comportamiento, como la influencia de las familias, las escuelas y los sistemas morales que conducen al cumplimiento con las reglas de la sociedad. Esta teoría explica la etiología de la delincuencia de una manera negativa; es decir, se hacen la pregunta inversa que hacía la criminología clásica: ¿por qué no delinquimos, pese a que existen todas las posibilidades para ello?

40 Coleman (1987), p. 411.

${ }^{41}$ Benson (1985), pp. 583-607.

${ }^{42}$ Para una revision de las ocho técnicas de neutralización más importantes que propone Haugh, véase HAUGH (2016), pp. 1255 y ss. 
Es importante destacar en este enfoque la fórmula de Travis Hirschi en su obra Causes of Delinquency (1969), por ser considerada una de las teorías más importantes de la criminología moderna y que más investigación ha producido en los últimos años ${ }^{43}$. Hirschi realizó un estudio sobre la delincuencia juvenil basado en información proporcionada por los propios jóvenes sobre sus actividades en general (incluidas las delictivas, si las había) y sobre sus relaciones con otras personas, especialmente con sus padres, sus amigos y en el ámbito escolar. Los resultados mostraron que aquellos sujetos que tenían más vínculos sociales y que participaban en más actividades convencionales (educativas, recreativas, etc.) cometían menos delitos. Es decir, constató que la inmersión del sujeto en redes de contacto y apoyo social favorecían el control de sus actividades. A partir de estos resultados, Hirschi elaboró una teoría dotada de consistencia interna y coherencia lógica ${ }^{44}$.

La teoría de Hirschi puede sugerir que la adopción de políticas públicas orientadas hacía un Estado que garantice una mayor vinculación entre los diversos sujetos que componen la sociedad, junto con la creación de mayores y mejores redes de contacto que generen actividades sociales, podrán reducir o a lo menos mantener los niveles de delincuencia.

En lo que respecta particularmente a la corrupción, en el ámbito del control social, los Estados son responsables de ejercer el control de las corporaciones al regular los negocios y hacer cumplir estas regulaciones inspeccionando activamente el cumplimiento y sancionando los incumplimientos. El crimen es facilitado por el Estado cuando falta este control social, cuando las agencias reguladoras del gobierno no pueden restringir las actividades comerciales desviadas. Esta falla, que podría deberse a negligencia, también podría ser una estrategia intencional para atraer empresas extranjeras, como lo han sugerido algunos autores ${ }^{45}$.

La corrupción puede ser un factor causal o un resultado de este nexo de relaciones entre el Estado y las empresas, Ilevando a un comportamiento desviado. El concepto de crimen corporativo estatal refleja el cumplimiento de objetivos mutuamente acordados de una agencia pública y una entidad privada logrados a través de actividad ilegal cooperativa ${ }^{46}$.

De esta manera, en la medida en que exista un mayor control social, las posibilidades de conductas ilegales serán menores. En el caso inverso, el

\footnotetext{
${ }^{43}$ HIRSCHI (1969), pp. 11 y ss.

${ }^{44}$ Akers (1999), p. 85 y ss.

45 Huisman- Vande et al. (2010), p. 18.

${ }^{46}$ FRIEDRICHS (2007), p. 147.
} 
comportamiento desviado también será una posible consecuencia de la falta de ley. Por eso, de acuerdo a las teorías de control social, existiría una relación inversamente proporcional entre control y delito.

Un elemento fundamental destacado por la literatura criminológica es que las sanciones formales no funcionan de forma aislada. Como lo sugiere Braithwaite, las consecuencias legales más importantes pueden verse reforzadas con los controles informales ${ }^{47}$. En efecto, la amenaza de la aplicación externa agrega capacidad de control de la delincuencia para agentes de compañía que tienen un sentido moral desinhibido de lo correcto y lo incorrecto, por su comprensión de cómo otros (incluidos sus colegas) probablemente vean su comportamiento, y en la medida en que creen que el descubrimiento de estos actos les causaría vergüenza o, por qué no, también los pudiese afectar al defraudar a personas significativas (es decir, amenazas de sanciones informales) ${ }^{48}$.

\section{La corrupción: Problemas de investigación y estudios empíricos al respecto}

La medición de la corrupción, entendida esta en términos generales, envolvente tanto de la pública como de la privada, es un tema de investigación crecientemente importante $^{49}$. En general, se ha dicho que su medición se puede hacer de tres formas ${ }^{50}$. En primer lugar, se puede hacer objetivamente, con base en las denuncias de corrupción y las investigaciones abiertas por el ministerio público o los jueces de instrucción ${ }^{51}$. En segundo lugar, a través de encuestas

\footnotetext{
47 Braithwaite (1989), pp. 54-68.

48 Simpson-GiBs et al. (2013), pp. 231-278.

49 Robinson (1998), pp. 1-14, y 2 y ss.; Andersson y HeYwood (2009), pp. 746-767; SAmpFord- SHACKLOCK et al. (2016).

${ }^{50}$ Solimano (2008), pp. 57-58, y 59 y ss.

51 En Chile no existen estadísticas propiamente tales sobre denuncias de corrupción. Tanto las policías como el Ministerio Público no reflejan en sus índices sobre delitos conocidos este fenómeno. Lo que estos organismos registran son tipologías delictivas que más bien se asocian a ella. Así, tenemos que Carabineros de Chile no lleva cifras oficiales. Diferente es el caso de la Policía de Investigaciones de Chile, la cual registra la cantidad de investigaciones de estas tipologías delictivas (por región, frecuencia, prefectura policial, mes y día de ocurrencia) y detenidos (por región, frecuencia, prefectura, género, grupo etario, nacionalidad, estado civil, nivel de educación y actividad). Sin embargo, sus registros son tanto vagos como confusos, por cuanto se ignora si se trata de denuncias recibidas directamente o que emanan de ordenes de investigar de los persecutores penales (fiscales); también se desconoce si se trata de detenciones en caso de delito fragrante o se trata de ordenes judiciales. Sin perjuicio de lo anterior, el problema mayor radica, por una parte, en el subregistro, al tratarse de un organismo que no controla de manera unilateral el conocimiento total de los delitos asociados a la corrupción, y, por otra parte, en la posibilidad de que sus estadísticas puedan estar replicadas o repetidas en las cifras de otros organismos, a saber: el Ministerio Público.
} 
de percepción de corrupción a inversores nacionales y extranjeros, expertos o a la ciudadanía en general ${ }^{52}$. Finalmente, a través de encuestas en las que se pregunta a los ciudadanos por sus experiencias directas en el pago de sobornos o en las extorsiones que sufren de parte de funcionarios del Estado (encuestas de victimización $)^{53}$. En la actualidad, hay más de quince instrumentos de medición, de manera global o regional, y muchos de ellos se han sofisticado bastante ${ }^{54}$.

En términos generales, la medición de la corrupción presenta un reto difícil de superar por varias razones. La primera razón es que la corrupción es un fenómeno que conlleva clandestinidad, además de que muchas de sus modalidades pertenecen a lo que se denominan delitos sin víctimas. Ello da lugar a que, probablemente, se descubran menos casos de los que haya realmente. En las mediciones objetivas no se sabe si lo que medimos realmente es la calidad del sistema judicial, la voluntad política de combatir la corrupción o el nivel real de corrupción pública ${ }^{55}$. En Chile, los datos objetivos de corrupción tienen, además, varios problemas específicos. Para empezar, no existe un censo de casos de corrupción (existe una serie de delitos que configurarían la corrupción) ni de sentencias dictadas en la materia. Por otra parte, la existencia de una causa judicial abierta no implica que vaya a haber condena, ni siquiera que haya acusación fiscal.

Como se apuntó anteriormente, la mayoría de las investigaciones sobre la corrupción se han orientado al análisis de las percepciones y valoraciones

El otro organismo que registra cifras sobre el fenómeno es el Ministerio Público. Sus cifras son más confiables, porque se advierte que controla o absorbe, por ser el exclusivo y excluyente actor de ejercer la acción penal pública y de llevar adelante la investigación penal de todas las denuncias de los delitos asociados a la corrupción.

52 En los párrafos siguientes se dará cuenta de estas investigaciones.

${ }^{53}$ En criminología, en general se entiende y reconoce que una de las mejores maneras de mensurar la delincuencia es a través de las encuestas de victimización. Este método cuantitativo es idónea, ya que sus datos no proceden de las agencias del sistema legal, como ocurre con la denuncia, sino de la propia víctima del delito. Además, la encuesta excluye la denominada "cifra negra", permitiendo comprobar si la víctima denuncia o no el delito a las autoridades encargadas de la persecución y si éstas son efectivas.

En el ámbito práctico, en materia de encuestas de victimización, la corrupción sí ha tenido cabida en Chile, más precisamente en la Encuesta Nacional Urbana de Seguridad Ciudadana (Enusc). Desde los albores de esta encuesta, en el año 2003, ya se preguntaba por corrupción a través de preguntas sobre soborno (también denominado "coima") por parte de un funcionario público, la denuncia del mismo delito y la individualización o identificación del participante. Preguntas asociadas a este fenómeno se realizaron hasta la encuesta de 2014, para luego en las últimas versiones desaparecer, desconociéndose la verdadera razón.

54 Global Integrity (2008), pp. 1-81, y 10 y ss.

55 Lambsdorff (1999), pp. 10-15. 
subjetivas que realiza el ciudadano común o algún actor relevante respecto al actuar de otros, sean estos la sociedad en su conjunto, trabajadores públicos o privados, miembros del poder político o económico empresarial, entre otros ${ }^{56}$. No obstante, diversos organismos internacionales (Banco Mundial, Transparencia Internacional, OECD, entre otros) han desarrollado y ampliado proyectos de estudio sobre corrupción con un fuerte acento en modelos comparativos y con atención especial en el comportamiento y evaluación de actores como funcionarios públicos y sector empresarial.

Transparencia Internacional, a través de su oficina nacional (Chile Transparente), viene desde el año 1996 realizando estudios de opinión en materia de corrupción ${ }^{57}$. Para el año 2017, Chile ocupó la posición 26 (67pts.) de los 180 países del Índice de Percepción de la Corrupción. En el año 2016, Chile se encontraba en el lugar 25 (66 pts.), manteniéndose dentro del TOP 25, subiendo en el año 2015 al lugar 23 (70 pts. $)^{58}$. En corcondancia con dichas cifras, la literatura chilena ha constatado cómo casos públicos que envuelven prácticas corruptas han adquirido una mayor permanencia, periodicidad y frecuencia desde la perspectiva ciudadana, impactando en la imagen de quienes se ven envueltos en dichas dinámicas ${ }^{59}$.

Algunas conclusiones de la oficina nacional de transparencia de por qué se arribó a esos resultados en 2016 y se experimentó una baja respecto a años anteriores, va en la línea de que diversos actos de corrupción conocidos en los últimos dos años estarían incidiendo en este bajo desempeño de Chile. Casos como Penta, Caval, Soquimich, Milicogate y Corpesca han incidido y han repercutido en los niveles de confianza de la ciudadanía ${ }^{60}$.

\footnotetext{
${ }^{56}$ Compañías internacionales de auditoría, como KMPG, realizaron en el año 2009 la "Encuesta de fraude y corrupción en Chile". Sobre una muestra de 120 empresas trasnacionales situadas en Chile, se estableció que la inmensa mayoría de los encuestados (92 \%) consideró que la corrupción en el sector público es mayor que en el ámbito privado. También se descubrió que la mayoría de los encuestados (70 \%) desconocía el marco regulatorio contra la corrupción.

57 Mediante su metodología elabora el índice de percepción de la corrupción (IdePC). El IdePC clasifica a los países de acuerdo al nivel de corrupción percibida en autoridades políticas y funcionarios públicos. Las puntuaciones de cada país se adecúan a la escala de 0 a 100, donde valores cercanos a 0 indican países que se perciben con mucha corrupción y puntuaciones cercanas a 100 indican países percibidos como menos corruptos. Utiliza distintas fuentes de información. Una critica a la metodología de Transparencia Internacional puede verse en ANDERSSON (2009), pp. 746-767.

${ }^{58}$ Según datos metodológicos de la encuesta, el intervalo de confianza es 61-70, lo que significa que, con un $90 \%$ de probabilidad, el valor de Chile se encuentra entre esos parámetros.

${ }^{59}$ Maldonado (2018), p. 694.

${ }^{60}$ Véase Índice de Percepción de la Corrupción 2016. Para el año 2017 no hay conclusiones de momento.
} 
Por otra parte, Libertad y Desarrollo ha realizado desde el año 2002 la denominada "Encuesta Anual sobre Irregularidades de Funcionarios Públicos" con el fin de medir la evolución del fenómeno de la corrupción en el tiempo, obteniendo datos comparables. Dicha encuesta busca establecer cuál es la imagen que tienen los encuestados sobre el nivel de corrupción, tanto a nivel país como en las distintas instituciones públicas en particular, lo que genera el Índice de Percepción de la Corrupción ${ }^{61}$.

En su decimoquinta edición, en el año 2017, en la Encuesta de Percepción de Corrupción de LyD $^{62}$ el nivel de percepción de corrupción en Chile se calificó con una nota de 5,37, con un descenso no significativo desde el punto de vista estadístico sobre la medición de 2016 (5,52). Las instituciones que lideran el ranking de percepción de corrupción son las municipalidades, con una nota de 6,84; la Cámara de Diputados, con un 6,36, y la Conadi, institución incorporada en la presente edición de la medición. El alza más relevante en materia de percepción de corrupción se da en Carabineros. En el plano de las acciones de gobierno para el control de la corrupción, se observa una mejora estadísticamente significativa en la evaluación de la contribución de la Ley de Transparencia. La Ley del Lobby, evaluada por primera vez, obtuvo una calificación de 4,3163.

La IV Encuesta Nacional denominada "Auditoría a la democracia. Más y mejor democracia para un Chile inclusivo", realizada por Naciones Unidas, que se basa en la opinión de distintos ciudadanos, obtuvo algunos resultados interesantes de destacar. Por ejemplo, el $1 \%$ declaró haber pagado una coima o hacer un favor a una empresa privada para que le solucionara un problema. A su vez, tratándose del servicio público, la situación obtiene el mismo guarismo y baja con relación a mediciones del año 2010 (5\%) y 2008 (6\%). Respecto de la percepción de instituciones públicas y cuánto está extendida la corrupción en ellas, las peores evaluadas son: los partidos políticos, 69 \% (en 2010 fue el $41 \%$ ); el congreso,

\footnotetext{
${ }^{61}$ La encuesta es aplicada a una muestra de empresarios y ejecutivos del país, por cuanto ellos podrían experimentar niveles más altos de exposición a situaciones de corrupción y tráfico de influencias. Se utilizó una muestra probabilística elaborada a partir del Directorio Nacional de Empresas y Ejecutivos 2014-2015, que incluye a más de 7.000 empresarios y ejecutivos de empresas de todo el país, de acuerdo a una selección aleatoria de las unidades que se encuentran en el mencionado directorio. El tamaño de la muestra en el año 2016 fue de 251 casos, siendo el error estimado de un 6,1\%. El trabajo de campo consistió en el envío de un cuestionario semiestructurado a cada persona de la muestra, acompañado de una carta explicativa y un sobre franqueado con la dirección de Libertad y Desarrollo. Este sobre es devuelto sin remitente para mantener el anonimato de los encuestados y la confidencialidad de la información entregada por ellos, facilitando así la obtención de una tasa de respuestas más elevada y, con ello, un mejor análisis de la situación de corrupción en el país.

${ }^{62}$ Con la encuesta 2017, el tamaño de la muestra fue de 260 casos, siendo el margen de error estimado de $\pm 6 \%$, al $95 \%$ de confianza. El estudio solo abordó casos ocurridos durante 2016 .

63 Véase Libertad y Desarrollo (2017).
} 
63\% (en 2010 fue el $25 \%$ ); el gobierno, 60\% (en 2010 fue el $24 \%$ ), y los tribunales de justicia, $53 \%$ (en 2010 fue el $28 \%)^{64}$.

Por otro lado, desde su creación en 2009, el Consejo para la Transparencia viene haciendo encuestas naciones de transparencia. Los últimos resultados están contenidos en el VIII Estudio Nacional de Transparencia, de 2016, destinado a evaluar la percepción ciudadana respecto de la Ley de Transparencia y Acceso a la Información Pública. En esta oportunidad, el estudio contempló un espacio destinado a recoger las percepciones de las personas en materia de confianza y corrupción, considerando que el año 2015 estuvo marcado por el descubrimiento de irregularidades, casos de corrupción, conflictos de interés y colusión de diversos actores ${ }^{65}$.

Sus resultados son que la percepción que tienen los chilenos de la corrupción en el país mostró que el promedio de 2016 es el mismo que el del año 2015 $(7,0)$-se mide la corrupción con una escala de 1 a 10, donde 1 es "nada" y 10 es "mucho"-. Sin embargo, si miramos la distribución de los casos, no lo es. En 2015, un $18 \%$ colocaba una nota de 10 en la escala (nivel de corrupción: "mucho") aumentando a $27 \%$ en 2016. Lo mismo ocurre con la percepción de la extensión de la corrupción, donde un $60 \%$ (54 \% en 2015) cree que "mucha gente está involucrada" y un 85 \% (84 \% en 2015) cree que por lo general las personas involucradas en actos de corrupción no son castigadas por dichos delitos. A pesar de esta visión sobre el alcance y la impunidad de los casos de corrupción, un 51 $\%$ de los chilenos cree que hoy éstos son más fáciles de detectar que hace unos cinco años atrás, lo que pudiera relacionarse a la existencia de mecanismos de acceso a la información pública para exponer estos casos y, así, combatirlos ${ }^{66}$.

Los autores de esta encuesta sostienen que la ausencia de percepción de justicia, que es casi unánime, inhibe cualquier mejora en materia de transparencia y acceso a la información, minimizando el impacto positivo que debería tener.

A partir de la generalidad de las encuestas como instrumento de investigación del fenómeno de la corrupción se advierte una serie de inconvenientes. Como uno de los fundamentales, se advierte -erradamente- que la corrupción se sitúa,

\footnotetext{
${ }^{64}$ PNUD (2016). La metodología consistió en entrevistas cara a cara con 1532 personas en hogares de todo el país. El método de muestreo fue estratificado (por región y zona urbana/rural), aleatorio y probabilístico en cada una de sus etapas (manzanas-hogar-entrevistado). El error muestral se estima en $+-3 \%$ considerando varianza máxima y un $95 \%$ de confianza.

65 MARKEt OpinION ReseArCh InTERNATIONAL (2017). La metodología consistió en 2853 encuestas cara a cara con una muestra representativa de todos los chilenos de 18 años y más, entre el 27 de septiembre y el 12 de noviembre de 2016, que habitan en Chile continental, con un error muestral de 1,8\% y un nivel de confianza de 9 5\%. En el estudio 2015 se rediseñó la muestra para los años 2015-2018, con una expansión a 400 casos de una región, permitiendo la comparación anual con una región seleccionada.

${ }^{66}$ Véase Market Opinion Research International (2017), pp. 75 y ss.
} 
por contexto general, de manera exclusiva en el ámbito publico, olvidando que los agentes privados son copartícipes de los actos de corrupción, puesto que, en el ejemplo simple, si no hay una dadiva o una coima que se ofrezca o acepte entregar, no hay funcionario público que se corrompa en el sentido literal de la expresión. También se olvida que se pretende estudiar el fenómeno con base en la sola percepción subjetiva de actores que no son incumbentes, esto es, no son ni víctimas ni victimarios, en circunstancias tales que los delitos en general se estudian en, la generalidad de los casos, a través de la pareja criminal.

No obstante lo anterior, la investigación de la corrupción con base en opinión encuentra su razón de ser en la existencia de una serie de antecedentes, que tienen como común denominador la premisa de que es difícil estudiar el fenómeno de la corrupción. A modo de ejemplo de estas dificultades, que seguramente no son las únicas, encontramos que se trata de delitos en que la víctima no está claramente identificada, o bien ella no sabe a ciencia cierta que es víctima; también se trata de delitos que, en muchos casos, son parte de una organización, donde las personas individuales se pierden bajo el velo de la persona jurídica o, cuando no existe aquella, se trata de una agrupación de personas donde es difícil poder determinar la participación de cada una las individualidades. También, como ya lo reconocía Sutherland, se trata de personas que se encuentran bien insertadas en la sociedad, algunas veces dentro de las esferas del poder económico o político, donde las dudas o desconfianza a su respecto son prácticamente impensadas.

\section{El estudio empírico: Objetivos y metodología}

Los objetivos centrales del estudio empírico son i) la determinación de cómo las actividades empresariales pueden generar condiciones para la corrupción y ii) la individualización de qué medidas se pueden adoptar para enfrentar la corrupción.

El método utilizado en esta investigación ha sido el propio de la criminología empírica, en particular una metodología cuantitativa exploratoria basada en una encuesta estructurada con preguntas cerradas realizadas a una muestra $(\mathrm{N}=32)$ no representativa estadísticamente de empresas del sector privado, de diverso tamaño, y que se dedican a los rubros de bienes y servicios.

Además, para apoyar los resultados y obtener información que sea rica en diversidad y precisión, se utilizó una metodología cualitativa consistente en entrevistas semiestructuradas $(\mathrm{N}=4)$, a un grupo de actores relevantes del mundo empresarial con poder decisorio al interior de las compañías, con el fin de explorar dimensiones de análisis potenciales que que la encuesta no pueda abordar. Los criterios de selección de los entrevistados fueron: sector económico, tamaño de la empresa y relevancia en el área de investigación. 
La encuesta se ejecutó bajo la modalidad de un cuestionario autoaplicado, con previo consentimiento informado del encuestado, por una persona con poder de decisión al interior de la empresa (gerente general, legal, de finanzas, etc.), con presencia de uno de nuestros encuestadores, quien bajo modalidad cara-cara solucionaba los inconvenientes o dudas existentes, en caso de ser requerido.

Terminada la encuesta, ésta era depositada en sobre cerrado para posteriormente vaciar los datos y procesarlos con el programa Statistical Package for the Social Sciences (SPSS versión V20.0), programa estadístico informático altamente utilizado en ciencias sociales y aplicadas.

Para la encuesta, las preguntas se construyeron utilizando como criterio las diversas teorías criminológicas discutidas en el apartado anterior. En virtud de aquello, se utilizó parcialmente como modelo la Encuesta Nacional sobre Prácticas contra el Soborno en Empresas Colombianas realizada por la Universidad Externado de Colombia en concierto con Transparencia por Colombia (Capítulo Transparencia Internacional) ${ }^{67}$.

El informe colombiano es de enorme utilidad práctica y constituye el marco de referencia metodológico de la presente investigación, puesto que permite una mirada descriptiva y exploratoria del problema de la corrupción y sus dimensiones, como también delimita un conjunto de prácticas en el entorno de negocios que son relevantes de evaluar y visibilizar.

La experiencia colombiana no solo aportó con parte de su cuestionario, sino además con su modus operandi, ya que también replicamos la unión con la oficina nacional de Transparencia Internacional (Chile Transparente) para ejecutar nuestra propia encuesta, dado que de esa manera entendíamos que superábamos los déficits de confianza que experimentamos en un comienzo y que posteriormente igual perduraron, sumado al desinterés de una gran mayoría de empresas ${ }^{68}$.

\footnotetext{
${ }^{67}$ La encuesta tiene cuatro versiones, que se han realizado con carácter bianual desde 2008, y se denomina "Encuesta Nacional sobre Prácticas contra el Soborno en Empresas Colombianas".

${ }^{68}$ En un comienzo tuvimos muchos problemas para ejecutar la encuesta. Particularmente, estos inconvenientes se pueden traducir en la desconfianza o lisa y llanamente el rechazo a participar en un estudio de esta índole. En efecto, cuando partimos con el trabajo de campo, nos planteamos tomar una muestra representativa de empresas desde las bases de datos asociadas a la Confederación de la Producción y el Comercio (CPC). Sin embargo, desde finales del año 2016 (cuarto trimestre) y en el primer trimestre del año 2017, contando ya con la base de los asociados y disponiendo de diversos becarios de nuestro centro de estudios para poder producir las citas o reuniones y poder materializar la encuesta (cuatr personas), los resultados obtenidos fueron infructuosos. Se llamó en reiteradas ocasiones a más de 1860 empresas y sólo se pudo acordar una sola reunión con éxito. Cabe mencionar que siempre se explicó a los integrantes de la muestra que se trataba de una investigación que llevaba a cabo la Universidad de Talca con Chile Transparente y sólo se quería saber sobre la percepción sobre
} 
También se utilizaron preguntas de creación propia, que respondían a la propia idiosincrasia conceptual de los negocios en Chile, y otras que recogían de mejor forma el marco teórico ya descrito.

No obstante, y a diferencia de los estudios mencionados anteriormente, la presente investigación no tiene pretensiones de representatividad nacional, sino de poder aproximarse al objeto de estudio por medio de las particularidades que ofrece el fenómeno de la corrupción en sus diversas dimensiones.

En síntesis, el estudio es de carácter descriptivo y exploratorio, y busca abrir la discusión sobre un tema trascendente para el país y aproximarse a describir el fenómeno de la corrupción a partir de la percepción subjetiva de las propias empresas que actúan en el sistema de los negocios en Chile.

La metodología que se ofrece facilita la realización de este tipo de investigaciones en la medida en que los estudios descriptivos están diseñados para caracterizar fenómenos, identificar atributos o cualidades de los objetos de investigación, contrastar o ejemplificar teorías. La encuesta posee dos tipos de preguntas: preguntas que buscan conocer percepción sobre algunos de los ítems y preguntas que recogen información sobre prácticas específicas. Por otra parte, la inexistencia de estudios previos sobre este tema en el país aumenta el valor de la encuesta.

\section{Resultados obtenidos}

Para efectos de análisis y comparación, las entidades fueron agrupadas según tamaño de la empresa ${ }^{69}$ (gráfico 1) y tipo de rama de actividad económica ${ }^{70}$ (gráfico 2). De acuerdo a lo anterior, el 56,3\% de los entrevistados trabaja en grandes empresas (200 y más trabajadores), el resto en micro, pequeñas y me-

la corrupción. En consideración a los malos resultados, se determinó que el contacto con nuestros interlocutores fuese hecho por Chile Transparente, tarea que se ejecutó desde mediados de mayo hasta misma época de septiembre. Ese planteamiento tenía dos inconvenientes: uno, que el target muestral era reducido a una cifra no representativa de 100 empresas, y el otro inconveniente era que, sumado a nuestra base de datos, se incorporó otro índice de empresas de Chile Transparente que no garantizaba aleatoriedad.

${ }^{69}$ La pregunta "G.3 Tamaño de la empresa por número de empleados", se reorganizó en dos categorías: i) "Micro, pequeña y mediana" (MiPyMe) corresponde a empresas con hasta 199 trabajadores y ii) la "Gran empresa" es aquella con 200 y más trabajadores (ver Anexo Cuestionario).

${ }^{70}$ La pregunta "G.5 Sector económico al que pertenece la empresa", se reorganizó en dos categorías: i) sector bienes,que considera a los sectores económicos de la agricultura, caza y silvicultura; la explotación de minas y canteras; las industrias manufactureras; la electricidad, gas y agua, y la construcción, y ii) sector servicios, compuesto por el comercio al por mayor/menor, restaurantes y hoteles; el transporte y comunicaciones; los establecimientos financieros y seguros, y los servicios comunales y sociales. Se excluyen aquellos trabajadores con "actividades no bien especificadas" (ver Anexo Cuestionario). 
dianas empresas (MiPyMe). Mientras que el 62,5\% de los entrevistados trabaja en empresas del sector servicios (destacando el sector inmobiliario y financiero), en el sector bienes $(37,5 \%$ ) destacan las empresas de minería y suministro de agua, gas y electricidad.

Respecto a las características sociodemográficas de la población entrevistada, en promedio tienen casi 43 años y son mayoritariamente hombres (61,3\%); tienen una antigüedad en la empresa de 9,4 años en promedio y aproximadamente 6 años de antigüedad en sus cargos. Respecto a estos últimos, un 68,4 \% ocupa cargos de gerente de área, director de área, coordinador de área o encargado de área; un 22,6\% corresponde a dueño, presidente o gerente general, y el 16,1\% restante a subgerentes y asesores de gerencia o presidencia de la empresa (tabla 1).

Respecto al nivel de incidencia de la corrupción, al consultar a los entrevistados sobre si "en los últimos 12 meses, ¿supo de alguien de su entorno cercano a quien le hayan solicitado algún tipo de acción, ayuda, favor, pago u aporte indebido?", un 50 \% de ellos manifestó que "Sí sabían de algún tipo de solicitud", distribuido en un $21,9 \%$ que a los menos supo de este problema " 1 vez" y un $28,1 \%$ que supo "2 o más veces" de estas peticiones (gráfico 3$)^{71}$, lo que pareciera revelar un importante incidencia de este tipo de comportamientos en el mundo de los negocios.

Al abrir el análisis e identificar ¿cuál es el tipo de comportamiento corrupto más utilizado?, según los entrevistados en los últimos 12 meses el uso de la posición para beneficiar a un tercero $(28,1 \%)$, favorecer a un familiar o amigo $(21,9$ $\%$ ) y realizar pago para agilizar trámites $(18,8 \%$ ), son los tipos de solicitudes más realizadas (gráfico 4). Estos datos presentan incidencias relativas diferentes según tipo sector y tamaño empresa: mientras en las empresas de bienes y en la MiPyMe el uso de posición para beneficiar a un tercero y el realizar aporte o la entrega de información privilegiada son las solicitudes más frecuentes, en el sector de servicios y gran empresa el uso de posición para beneficiar a un tercero y el nepotismo de favorecer a un familiar/amigo en obtención de cargos duplican en intensidad los valores del grupo anterior (gráfico 5).

La solicitud de favorecimiento personal de ayuda a un tercero o familiar también correspondió a una práctica destacada prioritariamente durante las entrevistas por actores claves. En este contexto, uno de los entrevistados indicó:

"Probablemente, lo que más habitualmente se ve como corrupción es intentar obtener ciertas ventajas sobre la base de mi poder político, económico

\footnotetext{
${ }^{71}$ Este indicador es una recodificación de la pregunta "B4. En los últimos 12 meses, ¿supo de alguien de su entorno cercano a quien le hayan solicitado... ?", de la cual se contabilizan la cantidad de veces que supo de algún tipo de solicitud ("1 vez" y "2 o más veces").
} 
o de amistades, mediante vínculos conocidos como el clásico 'pituto'. Eso es bastante frecuente (...)".

Al solicitar a los entrevistados que identifiquen cuáles son los comportamientos que más relacionan con la corrupción (gráfico 6), estos ubican en primera posición al abuso de posición o cargo para beneficio propio (14,7%), luego hacer pagos para omisiones o inspecciones de la autoridad fiscalizador $(12,6 \%)$, en tercera y cuarta posiciones ubican al nepotismo: favorecer a familiares o amigos en obtención de cargos y el uso de información privilegiada (ambos con un 10,5\%). Destaca el dato de que en las últimas posiciones se encuentran el robar propiedad ajena y dar contribuciones políticas (ambos con un 1,1\%). Comparados según sector y tamaño de empresa (gráfico 7), se observa que para las empresas del sector bienes el tráfico de influencias (uso de conexiones) aparece en primera posición (13,9\%), mientras que en el sector servicios está ubicado en la octava posición (6,8 \%), y que en la MiPyMe el abuso de poder o cargo se ubica en primera posición $(17,1 \%)$, mientras que en la gran empresa se ubica en octavo lugar $(7,4 \%)$.

En lo que respecta a la etiqueta abuso de posición o cargo en beneficio propio, dicha práctica también fue destacada en las entrevistas al momento de definir qué se entiende por corrupción. Así, uno de los actores clave entrevistados señaló que:

"Corrupción es en el fondo, desde mi punto de vista, la desviación forzada de las resoluciones normales de un cierto asunto. Yo fuerzo a través de mi poder económico mi fuerza, mis recursos, una desviación de lo que debe ser una resolución normal de los asuntos que están sometidos a la consideración del otro, de cualquier público. Puede ser aparato público, a través de una coima o el cohecho, o bien puede ser también con el sector privado con público de interés con los cuales yo me relaciono, obtener y forzar o torcer la voluntad del otro o de lo que normalmente ocurriría, si es que yo me hubiera relacionado sin ese elemento de la corrupción".

A la vez, al solicitar identificar cuáles son las condiciones que incentivan o favorecen la corrupción en los negocios (gráfico 8), casi un 91 \% sostiene estar "muy de acuerdo" y "de acuerdo" con que la deficiente o inexistente política de ética empresarial favorece la corrupción; luego, con un 90,3 \%, se ubican tanto la ambición de enriquecerse lo más rápido posible y la falta de educación cívica de los miembros de la empresa. En cuarta posición están los deficientes controles internos de la empresa (87,5\%). Estas dimensiones parecen identificar comportamientos asociados a mantener privilegios, deficiencia de controles internos en la empresa, condiciones laborales internas y nivel de instrucción del capital humano. 
A nivel comparativo, en el sector bienes, en primer lugar se ubican los deficientes controles internos en la empresa (100\% menciones), mientras que en servicios aparece la falta de educación cívica de los miembros de la empresa $(94,7 \%$ ). A su vez, en la MiPyMe el $100 \%$ de los entrevistados ubica en primera ubicación a la ambición de enriquecerse rápidamente, mientras que en la gran empresa el 94,4 \% ubica a la falta de educación cívica de los miembros de la empresa en primera posición (gráfico 10).

No obstante, al consultar respecto a si las empresas chilenas -comparadas con otras empresas de la región- ${ }^{72}$ están más o menos expuestas o dispuestas a realizar solicitudes de sobornos, los entrevistados expresan: i) respecto a si las empresas chilenas están más o menos expuestas, cerca de un $67 \%$ de los entrevistados sostienen que en Chile las empresas están menos expuestas a este tipo de solicitudes de soborno, y ii) respecto a si están más o menos dispuestas, un $60 \%$ sostiene que las empresas chilenas está menos dispuestas a realizar ese tipo de solicitudes (gráficos 11 y 12).

Si se analiza la percepción sobre la relación de negocios entre el sector privado y público, un 19,2\% de los entrevistados considera que los niveles de corrupción en el sector público han impedido a su empresa ganar alguna licitación o contrato público, mostrando mayores niveles relativos en la MiPyMe y en el sector de bienes (gráfico 13). A la vez, los entrevistados identifican que las principales razones o motivos para ofrecer soborno al sector público (gráfico 14) se sustentan en el temor a perder negocios (30,2\% ); para evitar trámites y procedimientos engorrosos $(22,1 \%)$, y para evitar controles o supervigilancia de instituciones públicas (18,6\%).

Identificadas las posibles motivaciones y las principales causas percibidas por los entrevistados, se les solicita describir el sentido de oportunidad de ocurrencia de este fenómeno; es decir, la probabilidad de ocurrencia del problema de la corrupción en los negocios. De tal forma, frente a la pregunta ¿cuál es la posibilidad de que se presenten actos de corrupción en...? (gráfico 15), casi un $91 \%$ dice que hay una probabilidad "muy alta" y "alta" de corrupción en las municipalidades; un $87,5 \%$, en los gobiernos regionales; un $84,4 \%$, en las empresas públicas vs, un $62,5 \%$ en la empresa privada y un $43,8 \%$ en el gremio empresarial; un $78 \%$ ve alta probabilidad en el Congreso (senadores y diputados), destacando la baja prevalencia de corrupción en Contraloría y Servicio Impuestos Internos (solo un 22,6\%).

\footnotetext{
72 Preguntas B71. “¿Cree Ud. que las empresas chilenas en general... i) están más o menos expuestas a solicitudes de sobornos que las empresas de otros países de la región? y ii) están más o menos dispuestas a pagar sobornos que las empresas de otros países de la región?".
} 
A nivel comparativo, en el sector bienes, las municipalidades y la empresa pública se ubican en las primeras posiciones (91,7\% y 83,3\%), mientras que en el sector servicios el Senado y la Cámara de Diputados lideran el ranking (ambos con un $95 \%$ ). A la vez, en la MiPyMe el $100 \%$ de los entrevistados ve alta probabilidad de corrupción en las municipalidades, mientras que en la gran empresa el Senado, la Cámara de Diputados, gobierno regional y la empresa pública están en primera ubicación, con un 95\% (gráficos 16 y 17).

De tal forma, las instituciones donde se percibe menor posibilidad u oportunidad de desarrollo de corrupción son los organismos contralores y supervisores, los medios de comunicación, las mismas organizaciones y empresas privadas, tendiendo a mirar al sector público como una institucionalidad altamente corruptible.

Frente a lo anterior, se les consultó a los entrevistados sobre formas de afrontar este fenómeno: ¿qué se puede hacer para reducir la corrupción en Chile? (gráfico 19). Estas respuestas priorizan denunciar comportamientos corruptos a las autoridades competentes (30,1\%); participar y apoyar una campaña educativa contra la corrupción (19,4\%); participar en campañas de sensibilización y abstenerse de pagar sobornos por servicios públicos (ambos con 15,1\%). A su vez, frente a la pregunta "¿Cuáles son las formas más efectivas para disuadir actos de corrupción en las empresas?" (gráfico 20) predominan acciones referidas a la autogestión empresarial antes que mecanismos de control externo: un 24,4 $\%$ sostiene necesario tener un sistema interno efectivo de supervisión, el 23,2 $\%$ plantea tener un alto nivel de ética personal y un $17,1 \%$ sostiene seguir el ejemplo de altos directivos.

El estudio cuantitativo y el cualitativo mostraron algunas diferencias en materia de prevención que deben seguir explorándose en nuevas investigaciones. En el primero, una gran parte de los entrevistados apostó únicamente por el autocontrol, en cambio para los entrevistados del segundo se requiere un poderoso control externo y la corrupción debe tener una consecuencia económica importante para los infractores, así como reputacional:

"Yo creo que para que te duela te tiene que doler el bolsillo, lamentablemente es así ehh... te tiene que doler harto, yo soy de la idea, y que no me escuche ninguno de mis compañeros de la universidad (risas), de que les tiene que doler, porque si no les duele, la clase de ética les entra por el oído y les sale por el otro, ehh... (silencio). Porque no solamente... yo creo que es una lástima sí, pero en la medida en que haya también un repudio público, ¿ya?, que sea pública la sanción. Es decir, yo creo que no hay nada peor que te indiquen con el dedo en la calle, yo creo que incluso es peor que el bolsillo, uno lo ve en los entornos en que uno se mueve". 
"Si a un empresario le duele más la sanción social que la sanción pública o la multa económica que afecta su bolsillo o le duele más ir a clase de ética en donde se le ilumine el efecto de ciertos temas teóricos formativos valóricos (....), yo creo que tiendo pensar que más le duele la exposición pública y la sanción económica".

Las principales razones por las cuales no se denuncian los actos de corrupción (gráfico 21) son la falta de evidencia para probar (18,3\%); porque los que denuncian actos de corrupción están sujetos a represalias (16,1\%); porque, aunque se informe, los encargados o autoridades no harán nada (15,1\%), o por la falta de claridad sobre los procedimientos (14\%). Pareciera que todos estos aspectos apuntan o tienden a un visón que normaliza y genera un efecto de tolerancia y aprendizaje institucional de la misma respecto a la corrupción.

Por lo anterior, destaca la importancia de identificar con qué frecuencia son utilizadas ciertas prácticas consideradas favorecedoras de la corrupción (gráfico 22). En este sentido, un 48,4\% sostiene que el uso de regalos se realiza "siempre o casi siempre", mientras que casi un $47 \%$ sostiene que se usan gastos de representación; el 44,8\% apunta a los patrocinios y casi el $42 \%$ al uso de información privilegiada, ubicándose en últimas posiciones la colusión $(19,4 \%)$ y los sobornos $(16,1 \%)$.

El carácter de riesgoso de los regalos también fue un tópico relevado en las entrevistas, el cual fue caracterizado como una práctica de uso común en el pasado:

"El cambio cultural implica que a lo mejor vas a tener que dejar de hacer negocios, que vas a tener que empezar a decir que en realidad 'pucha, muchas gracias por los regalos, pero nosotros no podemos recibir regalos'. Esto implica una tolerancia cero con los regalos: 'muchas gracias, te lo devuelvo y, si no, a una empresa de caridad' (...). Mi política es que la secretaria no recibe regalos, el junior no recibe regalos, nadie recibe regalos".

A nivel comparativo, en el sector bienes, en primer lugar se ubican los gastos de representación (50\%), mientras que en servicios aparece el uso de información privilegiada (57,9\%). A la vez, en la MiPyMe los patrocinios (aportes monetarios a personas) se ubican en primer posición, con un 58,3 \%, mientras que en la gran empresa los regalos, con un 55,6 \%, están en primera posición (gráfico 24).

Asociando a lo anterior, se les consultó a los entrevistados: ¿qué nivel de riesgos representa para las empresas...? realizar un conjunto de prácticas (gráfico 25), donde evaluaron como un riesgo "muy alto y alto"el soborno (cerca de un $94 \%$ ), la colusión (casi 87 \%), los pagos para agilizar o facilitar trámites (78,1\%), el uso de información privilegiada (77,4\%), las contribuciones políticas (casi $69 \%$ ) y, en las últimas posiciones, los gastos de representación (37,5\%) y los regalos (35,5\%). 
Por otro lado, respecto a la pregunta ¿con qué frecuencia son utilizadas las siguientes prácticas anticorrupcción? (gráfico 26), considerando solo el criterio "nunca y casi nunca", un 35,5\% sostiene que en la empresa no se realiza control y listado de lobistas; un 23,3 \% sostiene que "nunca y casi nunca" aplican mecanismos de término de contrato preestablecidos; un 22,6 \% no realiza análisis de idoneidad de contratistas o proveedores. Por el contrario, un $80 \%$ sostiene que "siempre y casi siempre" se implementan sistemas de registros de pago a terceros y un $71 \%$ plantea que se aplican controles internos y auditorías.

Al consultar respecto a la presencia o no de mecanismos de control interno (instructivos, manuales, códigos de ética, etc.) o la presencia de procedimientos para detectar actos de corrupción y la realización o no de investigaciones por actos de corrupción (gráfico 27), se observa que un 87,5 \% de las empresas tiene códigos y/o manuales orientadores; solo un 11,5\% de las empresas tiene procesos para detectar violación de los Códigos, y un $30 \%$ dice haber realizado una investigación por sospecha de corrupción (últimos 12 meses).

"Tengo un reglamento interno, donde se le hace leer a cada trabajador. Pero principalmente que ahí, se le hace un comentario, se le lee cuáles son los reglamentos de la empresa, pero también no se les pide nada más a ellos externo, más que lo que ellos trabajan".

"En ese mismo fenómeno y orden de cosas las empresas han empezado a trabajar muy fuertemente en mecanismos internos de control de buen gobierno, la gobernanza corporativa, hoy probablemente uno de los grandes temas de sostenibilidad de las organizaciones, todos los temas de ética, los códigos de ética que no tienen guardado en un cajón, sino que se puedan bajar se trabajen con la gerencia de personas, recursos humanos y la gerencia de comunicaciones para bajar eso y traducirlo en cultura de probidad e integridad. En muchas compañías están trabajando muy seriamente en eso; todos los temas de cumplimiento 'compliance' hace cuatro años atrás no existían salvo muy pocas empresas más avanzadas, pero hoy día es prácticamente un tema. Todas las grandes empresas ya lo tienen y es un tema para la profesión de los abogados, es nuevo pero es absolutamente vital; todos los temas de transparencia de rendición de cuentas de fortalecimiento del "compliance" internos de las auditorías internas, de programas de mitigación de riesgos, todos esos están ayudando a que la cultura de probidad haya aumentado".

Al consultar si la empresa somete o no a revisión sus actividades comerciales y cierre de negocios o contratos (gráfico 28), un 32,1\% sostiene que la empresa no somete de manera voluntaria a un tercero la valoración del diseño, implementación e impacto del programa para contrarrestar actos de corrupción; un $31,3 \%$ tampoco cuenta con un programa para contrarrestar el soborno, mientras un 15,6 \% sostiene que la empresa no cuenta con una declaración o 
política de rechazo a ofrecimientos o recepción de sobornos. Por contraparte, casi un $91 \%$ sostiene que la empresa sí denuncia a las autoridad competentes los intentos y actos de corrupción que se presentan al interior de su empresa.

A nivel comparativo (gráficos 29 y 30), en el sector bienes un $16,7 \%$ dice que no cuenta con un programa para contrarrestar el soborno, mientras que en servicios este sube a un $40 \%$. Situación inversa a lo que sucede en la MiPyMe respecto a la gran empresa (un $50 \%$ vs. 16,7 \%).

De forma complementaria, se pidió evaluar a los entrevistados sobre ¿qué aspectos desmotivan o motivan para implementar prácticas que contribuyan a prevenir la corrupción? (gráfico 31), donde el aspecto más desmotivante se refiere a que el mercado no reconoce estos esfuerzos (casi un $77 \%$ ), seguido por implica gastos adicionales (casi $71 \%$ ), mientras que el $100 \%$ de los entrevistados consideró como factor motivante el sentido ético en la sostenibilidad de los negocios, la contribución de relaciones de negocio de largo plazo y el mantener estándar de reputación empresarial.

Finalmente, consultados respecto a ¿cuáles de las siguientes medidas son las más importantes para luchar contra la corrupción? (gráfico 32), los entrevistados priorizan implementar un programa de capacitación contra la corrupción para los empleados (14,4\%), fomentar una cultura ética a través de la implementación de transparencia (13,3\%) y realizar programas de formación para altos ejecutivos (10\%). Llama la atención el hecho de que disponer de mejores marcos normativos, clarificar derechos y deberes y tener apoyo legal expedito tengan valores bajo el $3 \%$.

\section{Discusión de resultados}

Lo primero que es relevante destacar es lo complejo de la investigación, desde las ciencias sociales aplicadas, de la corrupción como objeto de estudio. Se advirtió desconfianza generalizada o falta de interés de los actores empresariales a la hora de participar en este tipo de estudios, pese a utilizar todo tipo de técnicas para poder alcanzar los objetivos trazados. Esto no es un acontecimiento aislado, ya que se corresponde con las dificultades que la literatura viene sopesando y manifestando en una serie de estudios, principalmente de corte anglosajón. Esto, se quiera o no, es un preocupante aliciente para la existencia y difícil erradicación del fenómeno de la corrupción.

En segundo término, es importante evidenciar que hay probablemente una gran diferencia entre lo que los actores empresariales perciben y lo que se hace en el mundo de los negocios. En efecto, existe una percepción generalizada de menos exposición, en el contexto comparativo sudamericano de prácticas configurativas de corrupción. Sin embargo, esta percepción se pierde a la hora de conocer el desarrollo diario de los negocios, donde se manifiestan sentimientos 
de existencia latente de corrupción, como aquella que pudo haber afectado o mermado el éxito en los negocios. También se reconoce la existencia de algunas conductas que están en el umbral de lo prohibido, como es el favorecimiento personal definido en la ayuda a una tercera persona o a un familiar para beneficiarlo, además de aquellas conductas de favorecimiento para colaborar con un tercero o con el propio negocio, sea evitando fiscalizaciones de la autoridad o la burocracia del sistema público. Lo interesante -y preocupante a la vez- es que este tipo de conductas muestran cierta habitualidad, lo que implica que no son episodios esporádicos.

Al desentrañar cuáles son las conductas de corrupción y el porqué de aqueIlas, encontramos que los comportamientos identificados pueden ser reducidos a: el abuso de posición o cargo en beneficio propio; el hacer pagos para omitir acciones o inspecciones de la autoridad fiscalizadora; nepotismo, y el uso de información privilegiada. A su vez, para los motivos que fundarían estas conductas se reveló principalmente la existencia de un móvil de carácter económico; la burocracia del sistema; la ineficiencia de la autoridad para ejercer controles, y el requerimiento directo o indirecto de soborno por parte de funcionarios públicos. Probablemente, lo que caracteriza a todas estas variables motivadoras es la existencia de un ánimo de lucro del agente empresarial y un mercado -y su desarrollo- que permiten este tipo de conductas.

Si uno hace una revisión historiográfica sencilla en los medios de comunicación, por los casos más bullados de corrupción en Chile, sin duda encontrará recogida las dimensiones descritas en el apartado anterior: i) denuncia contra Guido Girardi por presionar a la presidenta Michelle Bachelete a que nombrará en cargos públicos a personas de su sector ${ }^{73}$; ii) pagos al alcalde de Hualpén, entre otras cosas, para evitar fiscalizaciones ${ }^{74}$; iii) acusaciones de nepotismo contra Piñera ${ }^{75}$; iv) el caso "Chispas" es un ícono de la información privilegiada ${ }^{76}$.

Los motivos que hemos elevado en este informe y que devienen en el comportamiento constitutivo de corrupción se vinculan con el marco teórico antes descrito. En efecto, Vaughan enfatiza que la maximización del beneficio o afán de lucro es el factor motivador clave en la conducta corrupta ${ }^{77}$. Sin duda, se trata del móvil del sujeto mismo para realizar una conducta desviada, pero ella solo será posible cuando el escenario de oportunidades y/o de carencia

73 La TerCera (2012).

74 Diario U. de Chile (2012).

75 El Siglo (2017).

76 Radio Cooperativa (2006).

77 Vaughan (1982), p. 1380. 
de controles permita esas conductas. Es así que, frente a la ausencia de una normativa punitiva, como la que ocurrió con la colusión por ejemplo, este tipo de conductas serán parte de la escena diaria que podrá ver nuestra sociedad, como sucedió a propósito de los conocidos casos de los pollos o del papel tisú ${ }^{78}$.

En la misma línea anterior, en el testeo de los factores que favorecen la corrupción, los que en algún sentido, pero no exclusivamente, se pueden relacionar con los motivos para los comportamientos corruptos, se erigen: la inexistencia o deficiencia de la ética empresarial; la ambición por enriquecerse y la falta de educación cívica de sus miembros; la deficiencia de los controles internos en la empresa, y la colusión entre miembros de la organización. El análisis que se puede hacer de estos resultados es que los factores endógenos a las compañías, como los vinculados a defectos en la organización, serían vistos como criminógenos de la corrupción por sobre los exógenos, como el marco normativo o la ley, antes aludidos. Ahora, cuando uno realiza un análisis de cara a identificar factores latentes de agrupación, se encuentra grupos de factores como aquellos que tienden a mantener privilegios (intentar mantener trato preferente, acelerar procesos/procedimientos, la posibilidad de perder un negocio/licitación/contrato) y otros factores basados en un marco normativo laxo (deficientes controles internos, colusión entre miembros de la organización).

En otro apartado de cuestiones, es importante destacar que hubo una opinión importante en torno a conductas que no estarían incardinadas con la corrupción, como son: las contribuciones políticas; la entrega de donaciones, regalos o patrocinios, o la entrega de regalos para obtención de favores. Estas conductas, que se presentan como reiteradas en el quehacer de los negocios, son reconocidas por los agentes empresariales como inocuas y, a su vez, como riesgosas. Existe una distorsión latente entre conductas que podrían estar emparejadas con la corrupción, pero igualmente son realizadas por las empresas, dada su probable ambivalencia de no saber si están prohibidas o permitidas, o bien podría tratarse de prácticas culturalmente consensuadas y aceptadas en el mundo de los negocios.

Lo anterior nos permite afirmar que, frente a conductas cuyo contenido moral y/o normativo es ambivalente -pues se manifiesta en ellas una valoración de no saber si trata de una conducta buena o mala, o se desconoce lisa y llanamente si se trata de una de caracter permitida o prohibida-, las compañías prefieren de todas maneras su ejecución. Este hallazgo es concordante con la visión de las

\footnotetext{
${ }^{78}$ Ejemplo de esto es lo que sucedió a propósito de los conocidos casos de los pollos o del papel tisú. Con relación a estos sucesos, no existía tipo penal en la legislación chilena contra la colusión al momento de producirse los hechos. Más aún, se derogaron en el año 2003 los artículos $1^{\circ}$ y $2^{\circ}$ del Decreto Ley $\mathrm{N}^{\circ} 211$, que consideraban punibles las adulteraciones de precios.
} 
empresas, las cuales, como agentes de lucro, persiguen maximizar beneficios y transitan en sus desarrollos por una cornisa entre lo prohibido y permitido. Esta visión, que la teoría no ha advertido del todo bien, se ha colgado originalmente en la anomia por la existencia de asimetrías en la regulaciones, que producirían, entre otras cosas, por ejemplo, ambigüedad moral al ofrecer o aceptar sobornos.

Conductas como contribuciones políticas, donaciones o regalos, entre otras, en el mundo de los negocios se han tenido como históricamente aceptadas en el rubro, pero no para la sociedad como un todo, la cual las mira con recelo debido a que podrían constituir moneda de cambio para obtener favores o, en general, lograr algún tipo de ventaja indebida. Así, si bien en determinados casos podría constituir un ilícito penal (soborno o cohecho), en otros casos esa conducta podría generar controversia sobre su naturaleza debido a que el límite es bastante difuso. No obstante, lo que no podemos negar es que esas conductas son una falta moral no solo a nivel social, sino en una visión no consecuencialista, esto es, deontológica. Conforme a este enfoque, como indica Green ${ }^{79}$, lo que hace que una conducta sea ilícita moralmente es la violación intrínseca de un deber o una regla moral autónoma, más allá de las consecuencias de la conducta en sí. Además, se requiere que esa conducta tenga -o pretenda tener- un impacto negativo en una persona o grupo de personas. De esta manera, ineludiblemente estas conductas constituyen una falta moral socialmente reconocida que la legislación no ha actualizado en sus contenidos y, a juicio de algunos filósofos de Derecho penal, como Michael Moore, defensor del moralismo jurídico, justifican su establecimiento en leyes penales y su castigo ${ }^{80}$.

En otro ámbito de cuestiones, para las formas más efectivas de disuadir los actos de corrupción se prefieren conductas de autocontrol, como lo son la existencia de un sistema interno efectivo de supervisión, tener un alto nivel de ética personal, el ejemplo personal de altos directivos, miedo a sanciones internas, etc. Las conductas preventivas relacionadas con la imagen o reputación de las empresas y el miedo a sanciones legales en la encuesta encontraron una representación marginal; sin embargo, en las entrevistas lograron un lugar significativo.

En lo que respecta a las herramientas para controlar y poder reducir la corrupción en Chile, existe preferencia por las campañas educativas en general y la denuncia de ese tipo de conductas a las autoridades. Es paradójico que herramientas como las denuncias a la prensa, que han ayudado a revelar escándalos en el último tiempo, figuren con escasa incidencia. No obstante esto, la reputación empresarial y la confianza para construir relaciones de negocios,

${ }^{79}$ Green (2013), p. 74.

${ }^{80}$ Por todos, MOORE (1997). 
las que sí podrían verse mermadas por la prensa, motivan unánimemente la adopción de prácticas para prevenir la corrupción.

La autoeducación y el autocontrol son percibidos, en general, como medidas importantes en la lucha contra la corrupción. La implementación de programas de capacitación para los empleados, la realización de programas de formación para altos ejecutivos, el fomento de la cultura ética a través de sistemas de integridad y transparencia, y la implementación de auditorías externas anotan en conjunto las preferencias más importantes.

La primacía del autocontrol por sobre el control externo de las autoridades (mediante marcos normativos rígidos, fiscalizaciones y otras acciones) encuentra su explicación en dos fundamentos. Uno bastante simplista, que se traduce en la conveniencia o en un estado de acomodo, ya que, de esa forma, al no estar normados y/o fiscalizados, no se detectan posibles irregularidades en la compañías y quedan excluidos de posibles sanciones, y el otro, en que de una manera u otra el Estado ha trasladado la corresponsabilidad de regulación a los particulares ( $v$. gr., compliance) y este hecho ha sido observado no solo como un traspaso de autoridad o competencia, sino también como la posibilidad del empresariado de adoptar sus propias normas regulatorias. Sin embargo, frente a la imposibilidad de poder superar el estado acomodaticio de los agentes de negocios, es importante describir que la corresponsabilidad de las empresas en su autorregulación no implica de modo alguno un traslado de potestades o una renuncia a la regulación normativa externa por parte del Estado. Esta corresponsabilidad se traduce en que las compañías tienen una obligación moral que resulta del posible yerro en la marcha de sus negocios y las obliga no sólo a reconocerlo, sino también a aceptar sus consecuencias. Por su parte, el Estado a través de los órganos competentes, tiene una obligación de control, fiscalización y de regulación irrenunciable de las diversas compañías que se desarrollan en la sociedad e interactúan con sus miembros.

Finalmente, es destacable que exista una opinión de que la corrupción no es una característica privativa de los órganos de la administración del Estado, o sea, exclusivamente en el sistema público, ya que se reconoce que el fenómeno también encuentra un nicho poderoso para situarse en el sector privado.

\section{Conclusiones}

Hemos logrado una aproximación a la corrupción en el ámbito de los negocios a partir de los datos proporcionados por ejecutivos incumbentes en estas estructuras organizativas. Aparentemente, se trata de un medio idóneo de conocimiento científico, el que debería ser relacionado con otros medios, como se evidencia en la experiencia comparada, y con estudios cualitativos que permitirían una mayor caracterización de este tipo de delincuencia. 
En cuanto a los objetivos planteados, y teniendo presente el carácter exploratorio de nuestro trabajo, especialmente que sus resultados no pueden ser interpretados de modo alguno como representativos, interesa destacar que la corrupción en el ámbito privado del mundo de los negocios existe y obedece a una serie de motivos y factores que la favorecen y que se relacionan entre sí.

\section{BiBLIOGRAFÍA CITADA}

AleXAnder, Cindy, y Cohen, Mark (1996): "New Evidence on the Origins of Corporate Crime", en: Managerial and Decision Economics (№ 17), pp. 421-435.

AKERS, Robert (1999): Criminological Theories (Chicago, Roxbury Publishing Company).

Andersson, Staffan, y Herwood, Paul (2009): "The Politics of Perception: Use and Abuse of Transparency International's Approach to Measuring Corruption", en: Political Studies (No 57), pp. 746-767.

Benson, Michael (1985): "Denying the Guilty Mind: Accounting for Involvement in White Collar Crime", en: Criminology ( $\left.N^{\circ} 23\right)$, pp. 583-607.

Benson, Michael, y Simpson Sally (2015): "Understanding white-collar crime. An opportunity perspective", en: New York: Routeledge, pp. 1-306.

Braithwaite, John (1989): "Criminological Theory and Organizational Crime", en: Justice Quarterly ( ${ }^{\circ}$ 6), pp. 333 - 358.

Press).

(1989): Crime, Shame and Reintegration (New York, Cambridge University

(1985): "White Collar Crime", en: Annual Review of Sociology (№ 11), pp. 1-25.

CARnevali, Raúl, y ArtazA, Osvaldo (2017): "La naturaleza pluriofensiva y transnacional del fenómeno de la corrupción. Desafíos para el Derecho Penal", en: Revista lus et Praxis (№ 22), pp. 53-90.

COHEN, Albert (1965): "The sociology of the deviant act anomie theory and beyond", en: American Sociological Review (Vol. 30, № 1), pp. 5-14.

ColEmAn, James (1987): "Toward an Integrated Theory of White-Collar Crime", en: American Journal of Sociology (Vol. 93 № 2), pp. 406-439.

Corporación Latinobarómetro (2010): "Informe 2010". Disponible en: http://www.latinobarometro.org/documentos/LATBD_INFORME_ LATINOBAROMETRO_2010.pdf. [visitado el 5 de octubre de 2019].

Clinard, Marshall, y Yeager, Peter (1978): "Corporate Crime", en: Criminology (Vol. $16 \mathrm{~N}^{\circ}$ 2), pp. 255-272. 
DiARIO U. DE ChILE (2012): “Formalizan a alcalde de Hualpén por corrupción pública y lavado de dinero". Disponible en: http://radio.uchile.cl/2012/01/27/formalizan-a-alcalde-de-hualp\%C3\%A9n-por-corrupci\%C3\%B3n-p\%C3\%BAblicay-lavado-de-dinero/ [visitado el 5 de octubre de 2019].

Durkheim, Emile (1997): The division of labor in society (New York, Free Press).

DRUCKER, Peter (2001): The Essential Drucker (New York, Harper Business).

El Siglo (2017): "Le recuerdan a Piñera los familiares que contrató". Disponible en: http://www.elsiglo.cl/2017/11/10/le-recuerdan-a-pinera-los-familiaresque-contrato/ [visitado el 5 de octubre de 2019].

FrIEDRICHS, David (2007): Trusted Criminals: White Collar Crime in Contemporary Society, $3^{\text {rd }}$ edition (Belmont, Thomson/Wadsworth).

Gobert, James, y Punch, Maurice (2003): Rethinking corporate crime (Cambridge, Cambridge University Press).

Global Integrity y UndP (2008): A Users' Guide to Measuring Corruption (Oslo, UNDP Oslo Governance Centre).

Grabosky (2009): "Globalization and White-Collar Crime", en: Simpson S.S., Weisburd D. (eds), The Criminology of White-Collar Crime (Springer, New York), pp. 133-134.

GreEN, Stuar (2013): Mentir, hacer trampas y apropiarse de lo ajeno. Una teoría moral de los delitos de cuello blanco (Buenos Aires, Marcial Pons).

HAUGH, Todd (2016): "The criminalization of compliance", en: Notre Dame Law Review (Vol. 91), pp. 1255 y ss.

HIRSCHI, Travis (1969): Causes of Delinquency (Berkeley, University of California Press).

Huisman, Wim, y VANDE, Walle (2010): "The Criminology of corruption". Disponible en: https://expertise.hogent.be/files/6109339/9th_chapter_Criminology_of_ Corruption.pdf [visitado el 5 de octubre de 2019].

Keane, Carl (1995): "Loosely Coupled Systems and Unlawful Behaviour: Organization Theory and Corporate Crime", en: F. Pearce y L. Snider (eds.), Corporate crime; contemporary debates (Toronto, University of Toronto Press), pp. 168-181.

LAmBSDORFF, Johann Graf (1999): "Corruption in Empirical Research" en: Review. $9^{\text {th }}$ International Anti-Corruption Conference, Durban, South Africa. Disponible en: http://www1.worldbank.org/publicsector/anticorrupt/d2ws1_jglambsdorff. pdf [visitado el 5 de octubre de 2019].

La Tercera (2012): “Andrés Velasco Ilamó al senador Guido Girardi el 'Iíder del clientelismo'". Disponible en: http://www.latercera.com/noticia/ 
andres-velasco-llamo-al-senador-guido-girardi-el-lider-del-clientelismo/ [visitado el 5 de octubre de 2019].

LiberTad y Desarrollo (2017): “Encuesta de corrupción 2017: Percepción y hechos". Disponible en: https://lyd.org/wp-content/uploads/2017/10/TP-1315ENCUESTA-CORRUPCION-2017.pdf [visitado el 5 de octubre de 2019].

Maldonado, Francisco (2018): "Delitos cometidos en torno al desarrollo de los procesos electorales: Consideraciones sobre sus fundamentos y sistematización", en: lus et Praxis (Año 24, №3), pp. 693-762.

Market Opinion Research International (2017): “Estudio Nacional de Transparencia Novena Medición. Análisis de Resultados". Disponible en: https://www.consejotransparencia.cl/wp-content/uploads/estudios/2018/02/Estudio-Nacionalde-Transparencia-2017.pdf [visitado el 5 de octubre de 2019].

Merton, Robert (1938): "Social structure and anomie", en: American Sociological Review (No3), pp. 672-682.

Moore, Michael (1997): Placing blame (Oxford, Clarendon Press).

NAYLOR, R. T. (2000): "Economic and Organized Crime: Challenges for Criminal Justice", en: Strategic Issues Series, pp. 1-35.

Nelken, D. (1994): "White-Collar Crime" en: M. Maguire, R. Morgan y R. Reiner (eds.), The Oxford Handbook of Criminology (Oxford, Oxford University Press), pp. 355-392.

OeCD (2017): “¿Cómo va la vida en Chile?”. Disponible en: https://www.oecd.org/ statistics/Better-Life-Initiative-country-note-Chile-in-Espagnol.pdf [visitado el 5 de octubre de 2019].

PASSAS, N. (1998): "Structural Analysis of Corruption: The Role of Criminogenic Asymmetries", en: Transnational Organized Crime, (4 (1)), pp. 42-55.

(1990): "Anomie and corporate deviance", en: Crime, Law and Social Change (14(2)), pp. 157-178.

PNUD (2016): “IV Encuesta Nacional". Disponible en: http://www.cl.undp.org/content/dam/chile/docs/gobernabilidad/undp_cl_gobernabilidad_PPTencuesta_final_2016.pdf.pdf [visitado el 5 de octubre de 2019].

Radio CoOperativa (2006): "El Caso 'Chispas'". Disponible en: http://www.cooperativa.cl/el-caso-chispas/prontus_nots/2006-01-12/080740.html [visitado el 5 de octubre de 2019].

RichaRD, Cloward, y LLOYD, Ohlin (1961): "Delinquency and Opportunity: A Theory of Delinquent Gangs", en: The British Journal of Sociology (Vol. 12, No 3), pp. 282-289. 
RoBinson, Mark (1998): "Corruption and Development: An Introduction", en: The European Journal of Development Research (Volume 10), pp 1-14.

SAmpFord, Charles; SHaCklock, Arthur; Connors, Camel, y Galtung, Fredrik (2016): Measuring Corruption (USA, Routledge).

Schoepfer, Andrea, y PIQUero, Nicole (2006): "Exploring white-collar crime and the American dream: A partial test of institutional anomie theory", en: Journal of Criminal Justice (Vol. 34, № 3), pp. 227-235.

Simpson, Sally, y PiQuero, Nicole (2002): "Low self-control, organizational theory, and corporate crime", en: Law and Society Review, p. 509-548.

Simpson, S.; Gibbs, C.; Rorie, M.; Slocum, L. A.; Cohen, M. A., y Vandenbergh, M. (2013): "An empirical assessment of corporate environmental crime-control strategies", en: The Journal of Criminal Law and Criminology (Vol. 103, № 1), pp. 231-278.

Solımano, Andrés (2008): "La corrupción: Motivaciones individuales, fallas del Estado y desarollo", en Solimano, Andrés; Tanzi, Vito, y Del Solar, Felipe, Las termitas del Estado, Fondo de Cultura Económica (Santiago, CIGLOB), pp. 57-88.

Sutherland, Edwin (1947): Principles of Criminology, 4º (Filadelfia, Lippincott).

SYKES, Gresham, y MATZA, David (1957): "Techniques of Neutralization: A Theory of Delinquency", en: American Sociological Review (Vol. 22, № 6), pp. 664-670.

TOMBS, Steve (1995): "Corporate Crime and New Organizational Forms", en: F. Pearce y L. Snider (eds.), Corporate Crime; contemporary debates (Toronto, University of Toronto Press), pp. 132-147.

Treisman, Daniel (2007): "What have we learned about the causes of corruption from ten years of cross-national empirical research?", en: Annual Review of Political Science ( $\left.\mathrm{N}^{\circ} 10\right)$, pp. 211-244.

Uhlenbruck, Klaus; Rodríguez, Peter; DoH, Jonathan, y Eden, Lorraine (2006): "The impact of corruption on entry strategy: Evidence from telecommunication projects in emerging Economies", en: Organizational Science (17(3)), pp. 402-414.

VAUGHAN, Diane (1982): "Toward Understanding Unlawful Organizational Behavior. Michigan", en: Law Review (№ 80), pp.1377-1402.

Vold, George; Bernard, Thomas, y SiPES, Jeffrey (2002): Theoretical Criminology, $5^{\circ} \mathrm{Ed}$. (New York, Oxford University Press).

WINDSOR, Duane (2008): "The sustainable peace roles of international extractive industries", en: G.G.S. Suder (ed.), International Business under Adversity. A 
Role in Corporate Responsibility, Conflict Prevention and Peace (U.K., Edward Elgar Publishing), pp. 119-137.

ZIMRING, F. E., y JOHNSON, D. T. (2005): "On the comparative study of corruption", en: British Journal of Criminology ( $\left.N^{\circ} 45\right)$, pp. 793-809.

\section{PÁGINAS WEB}

https://cepchile.cl/cep/site/tax/port/all/taxport_20_194_1.html

https://www.adimark.cl/es/estudios/archivo.asp

http://encuestabicentenario.uc.cl/resultados/

http://www.latinobarometro.org/documentos/LATBD_INFORME_ LATINOBAROMETRO_2010.pdf

https://www.oecd.org/statistics/Better-Life-Initiative-country-note-Chile-inEspagnol.pdf 


\section{Anexo: Gráficos}

\section{Características sociodemográfica}

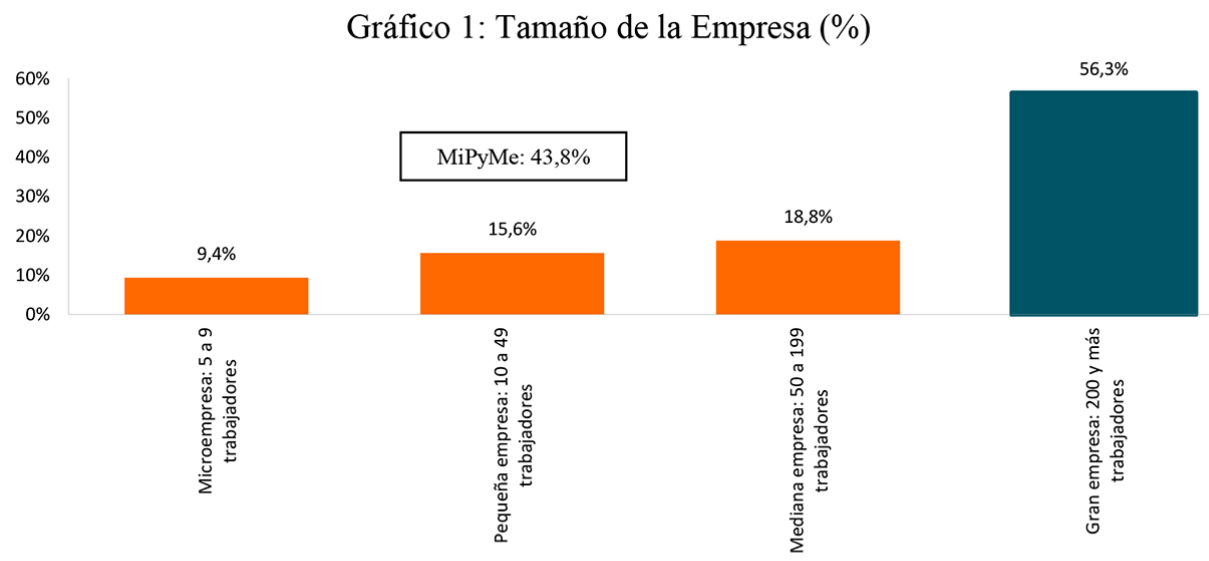

Gráfico 2: Rama Actividad Económica de la Empresa (\%)

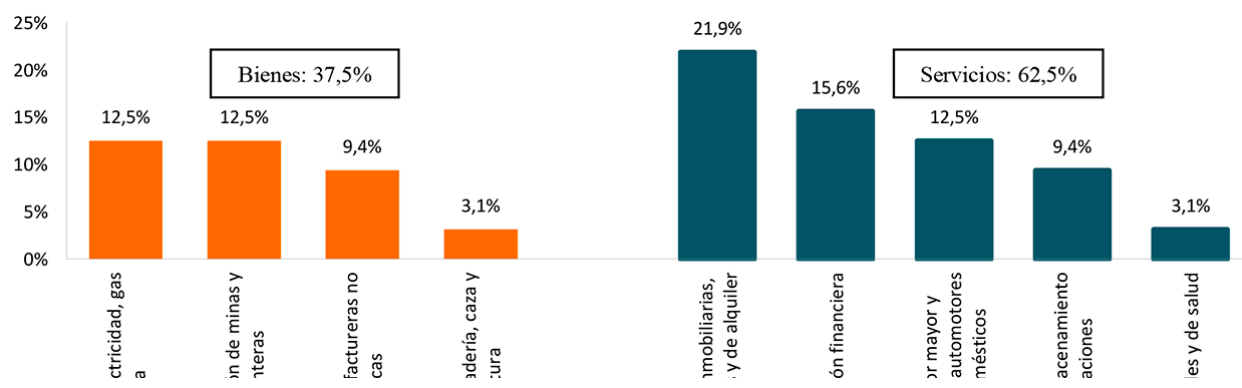


Tabla 1: Datos del informante según cargo en la empresa (promedio años y porcentajes según sexo)

\begin{tabular}{|c|c|c|c|c|}
\hline Cargo & $\begin{array}{c}\text { Dueño, presidente, } \\
\text { gerente general, } \\
\text { director general }\end{array}$ & $\begin{array}{c}\text { Vicepresidente, } \\
\text { subgerente, } \\
\text { asesor presidencia } \\
\text { o gerencia }\end{array}$ & $\begin{array}{c}\text { Gerente área, } \\
\text { director área, } \\
\text { coordinador área } \\
\text { o encargado área }\end{array}$ & Total \\
\hline $\begin{array}{c}\text { Antigüedad en } \\
\text { la empresa } \\
\text { (promedio años) }\end{array}$ & 9,3 & 10,2 & 9,2 & 9,4 \\
\hline $\begin{array}{c}\text { Antigüedad en } \\
\text { el cargo } \\
\text { (promedio años) }\end{array}$ & 8,6 & 6,5 & 5 & 6,1 \\
\hline $\begin{array}{c}\text { Edad } \\
\text { (promedio años) }\end{array}$ & 42,1 & 46,4 & 42,2 & 42,8 \\
\hline$\%$ (Total) & $22,6 \%$ & $16,1 \%$ & $61,3 \%$ & $100,00 \%$ \\
\hline Masculino & $57,1 \%$ & $40 \%$ & $68,4 \%$ & $61,3 \%$ \\
\hline Femenino & $42,9 \%$ & $60 \%$ & $31,6 \%$ & $38,7 \%$ \\
\hline
\end{tabular}

\section{Incidencia corrupción}

Gráfico 3: B4. En los últimos 12 meses, ¿supo de alguien de su entorno cercano a quien le hayan solicitado... ?

(\% agrupados según cantidad tipo de solicitud)

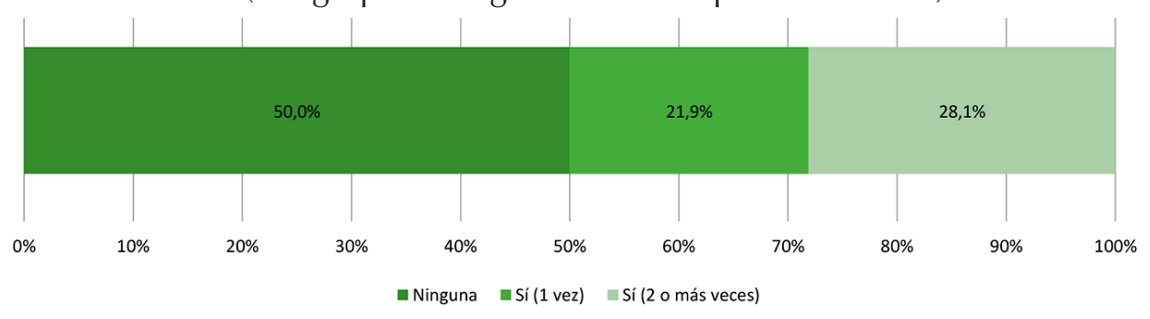

a/ La categoría "Sí" se desglosa en "1 vez" y "2 o más veces" en que la persona supo de algún tipo de solicitud. 
Gráfico 4: B4. En los últimos 12 meses, ¿supo de alguien de su entorno cercano a quien le hayan solicitado... ? (\%)

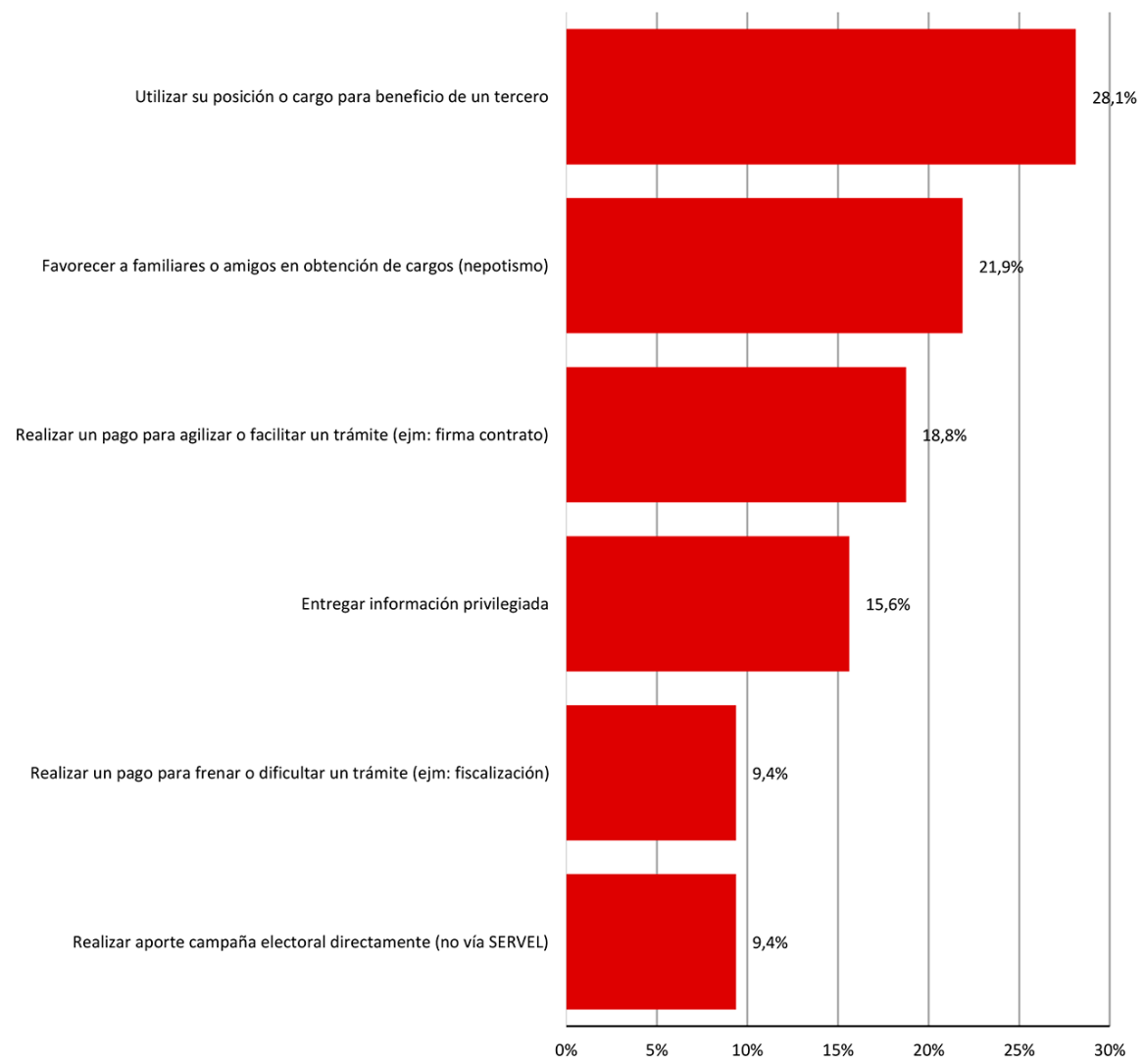

a/ Solo se presenta la categoría "Sí" (la diferencia corresponde a la categoría "No", que agregada suma $100 \%$ ). 
Gráfico 5: B4. En los últimos 12 meses, ¿supo de alguien de su entorno cercano a quien le hayan solicitado...?

según sector y tamaño empresa (\%)

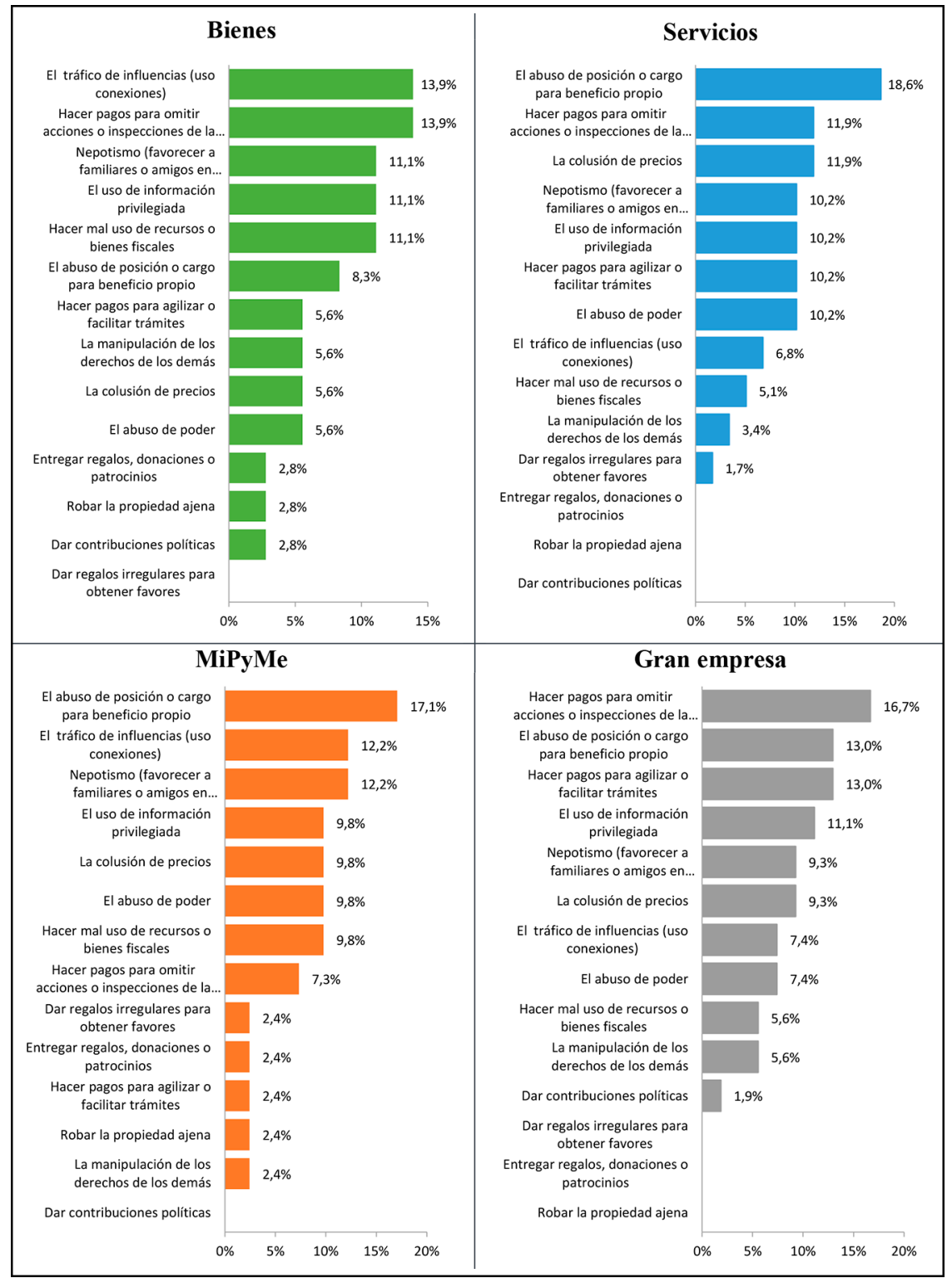

a/ Solo se presenta la categoría "Sí" (la diferencia corresponde a la categoría "No", que agregada suma $100 \%$ ). 


\section{Comportamientos relacionados con corrupción}

Gráfico 6: Ranking Agregado B1. Cuáles son los tres tipos de comportamiento más relacionados con la corrupción ${ }^{\text {a/ }}(\%)$

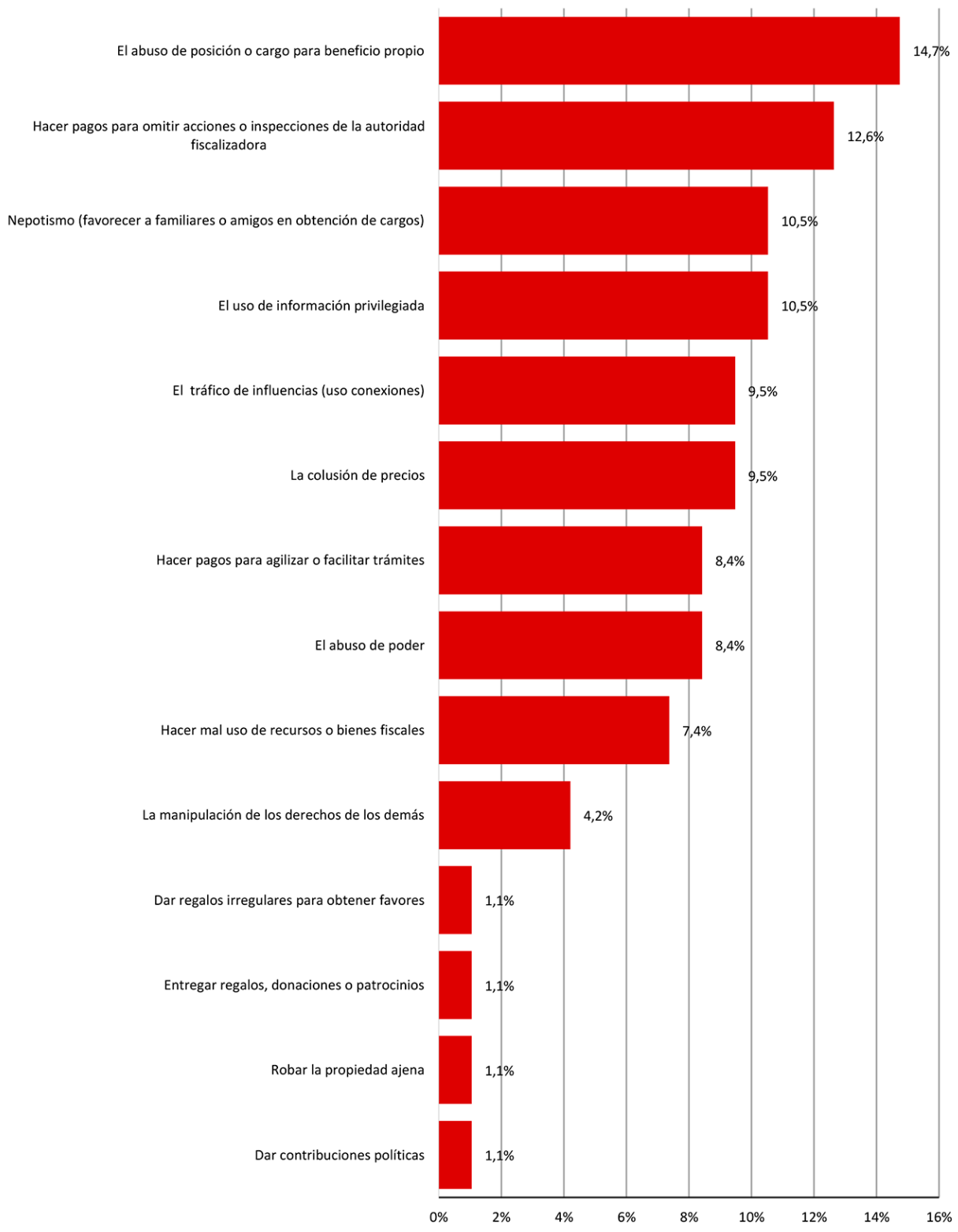

a/ Multirespuesta, ordenado según total de casos agregados. 
Gráfico 7: Ranking Multirespuesta B1. Cuáles son los tres tipos de comportamiento más relacionados con la corrupción según sector y tamaño empresa (\%)

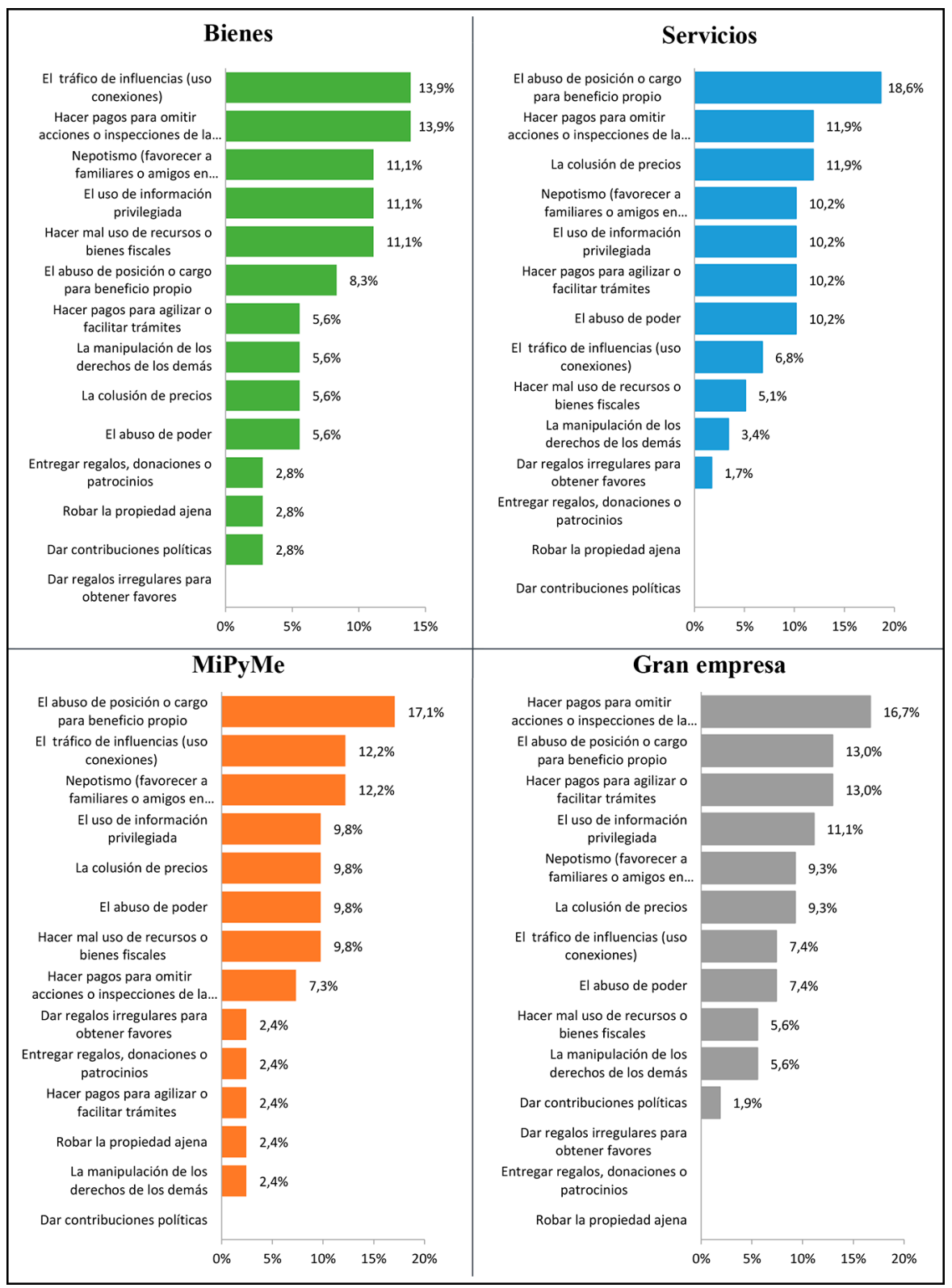

a/ Multirespuesta, ordenado según total de casos agregados. 


\section{Factores que favorecen la corrupción}

Gráfico 8: B2. ¿Las condiciones que incentivan la corrupción en los negocios, son...? (\%)

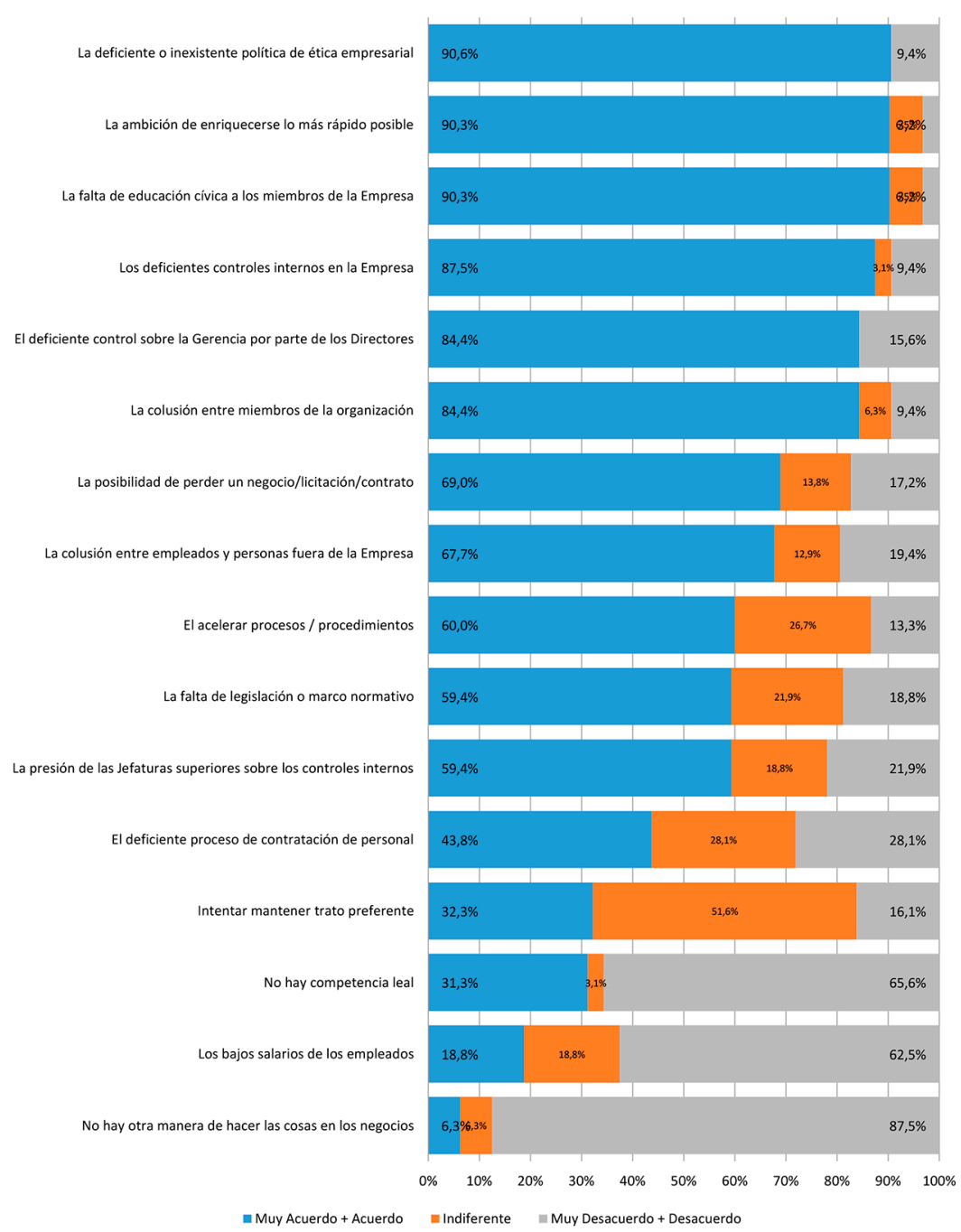

a/ Las categorías de respuesta se reagruparon en Muy de acuerdo + Acuerdo, Indiferente y Muy en desacuerdo + desacuerdo. 


\section{Gráfico 9: B2. ¿Las condiciones que incentivan la corrupción en los} negocios son...? según sector (\%)

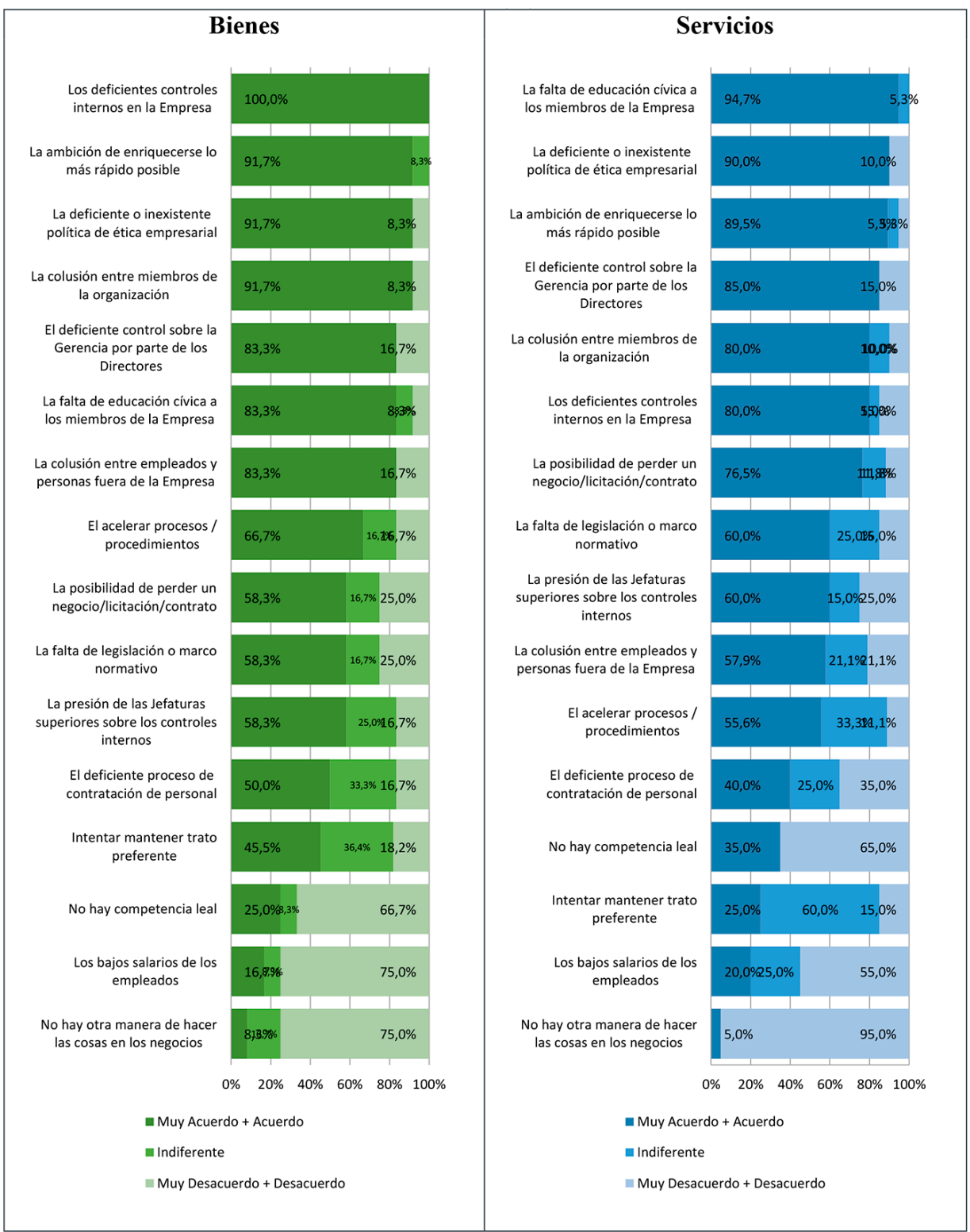

a/ Las categorías de respuesta se reagruparon en Muy de acuerdo + Acuerdo, Indiferente y Muy en desacuerdo + desacuerdo. 
Gráfico 10: B2. ¿Las condiciones que incentivan la corrupción en los negocios, son...? según tamaño empresa ${ }^{a /}(\%)$

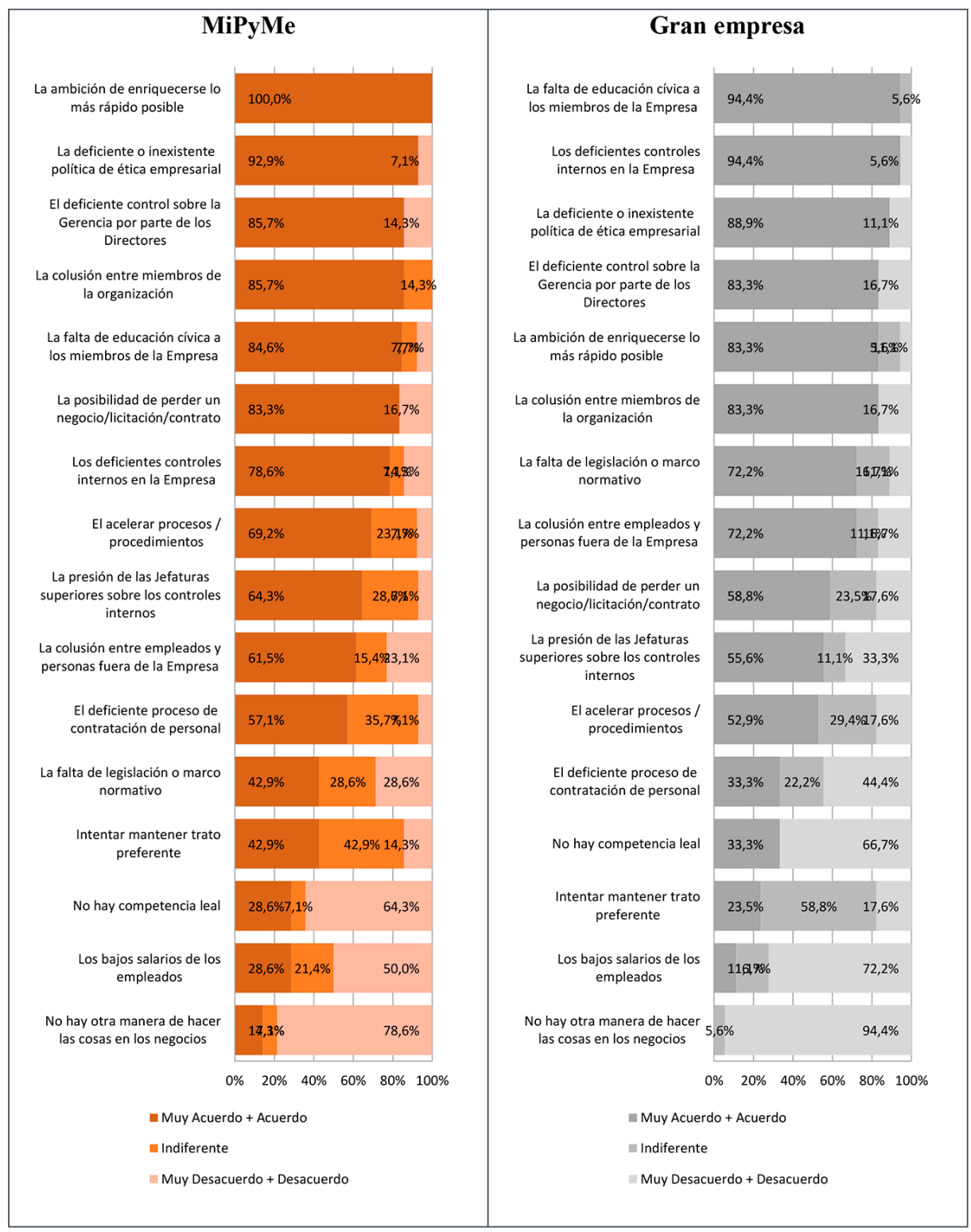

a/ Las categorías de respuesta se reagruparon en Muy de acuerdo + Acuerdo, Indiferente y Muy en desacuerdo + desacuerdo. 


\section{Corrupción en empresas}

\section{Expuestas}

Gráfico 11: B71. ¿Cree Ud. que las empresas chilenas en general... están más o menos expuestas a solicitudes de sobornos que las empresas de otros países de la región? (\%)

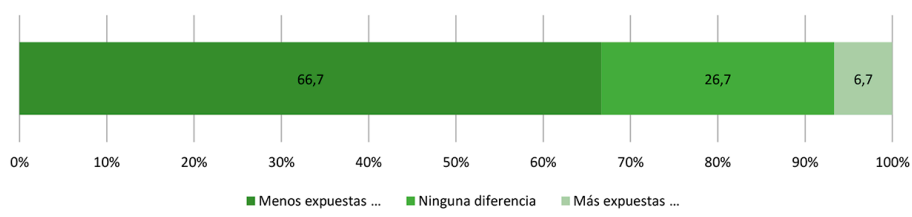

\section{Dispuestas}

Gráfico 12: B72. ¿Cree Ud. que las empresas chilenas en general... están más o menos dispuestas a pagar sobornos que las empresas de otros países de la región? (\%)

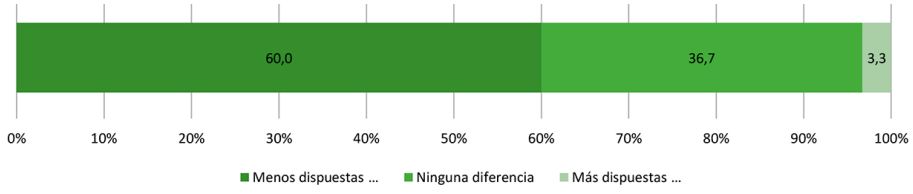

\section{Impacto corrupción en negocios}

Gráfico 13: E2. En los últimos 12 meses, ¿cree Ud. que la corrupción le ha impedido ganar a su empresa alguna licitación o un contrato público? según sector y tamaño empresa (\%)

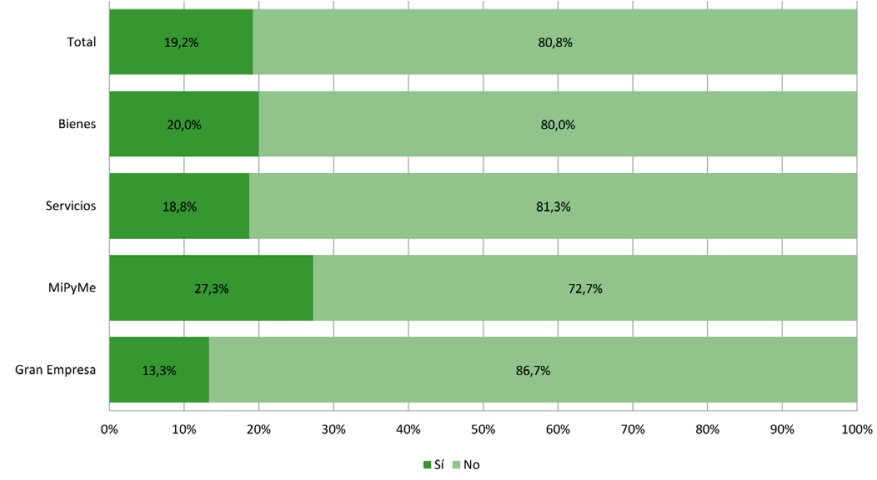

Las columnas suman $100 \%$. 


\section{Motivos para ofrecer soborno al sector público}

Gráfico 14 : Ranking Agregado E4. ¿Cuáles situaciones considera Ud. son los tres principales motivos de presión para dar u ofrecer sobornos? (\%)

motivos de presión para dar u ofrecer sobornos? (\%)

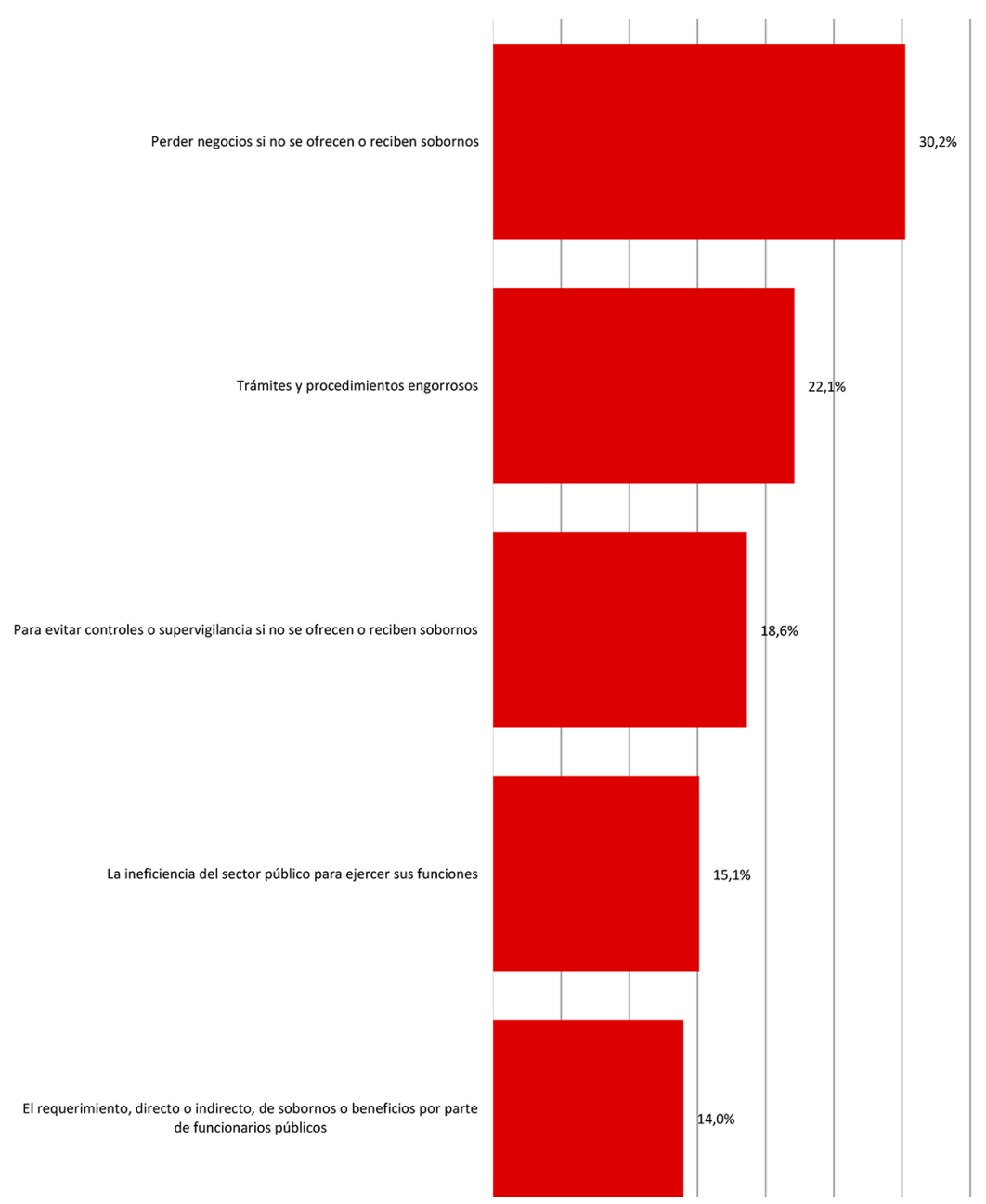

Multirespuesta, ordenado según total de casos agregados. 


\section{Probabilidad de actos de corrupción en instituciones}

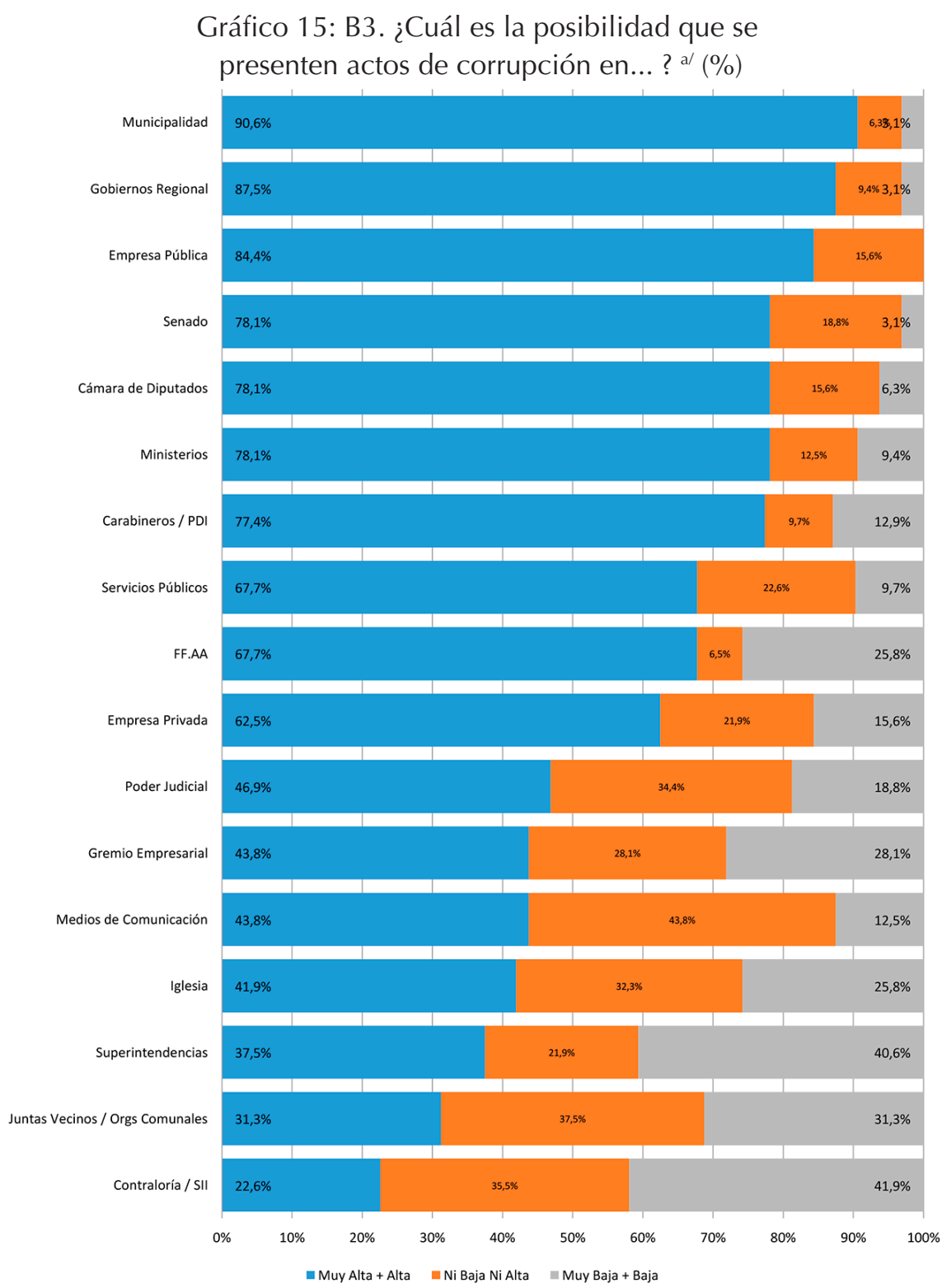

Las categorías de respuesta se reagruparon en Muy Alta + Alta, Ni baja ni alta y Muy Baja + Baja. 
Gráfico 16: B3. ¿Cuál es la posibilidad que se presenten actos de corrupción en... ? según sector $(\%)$

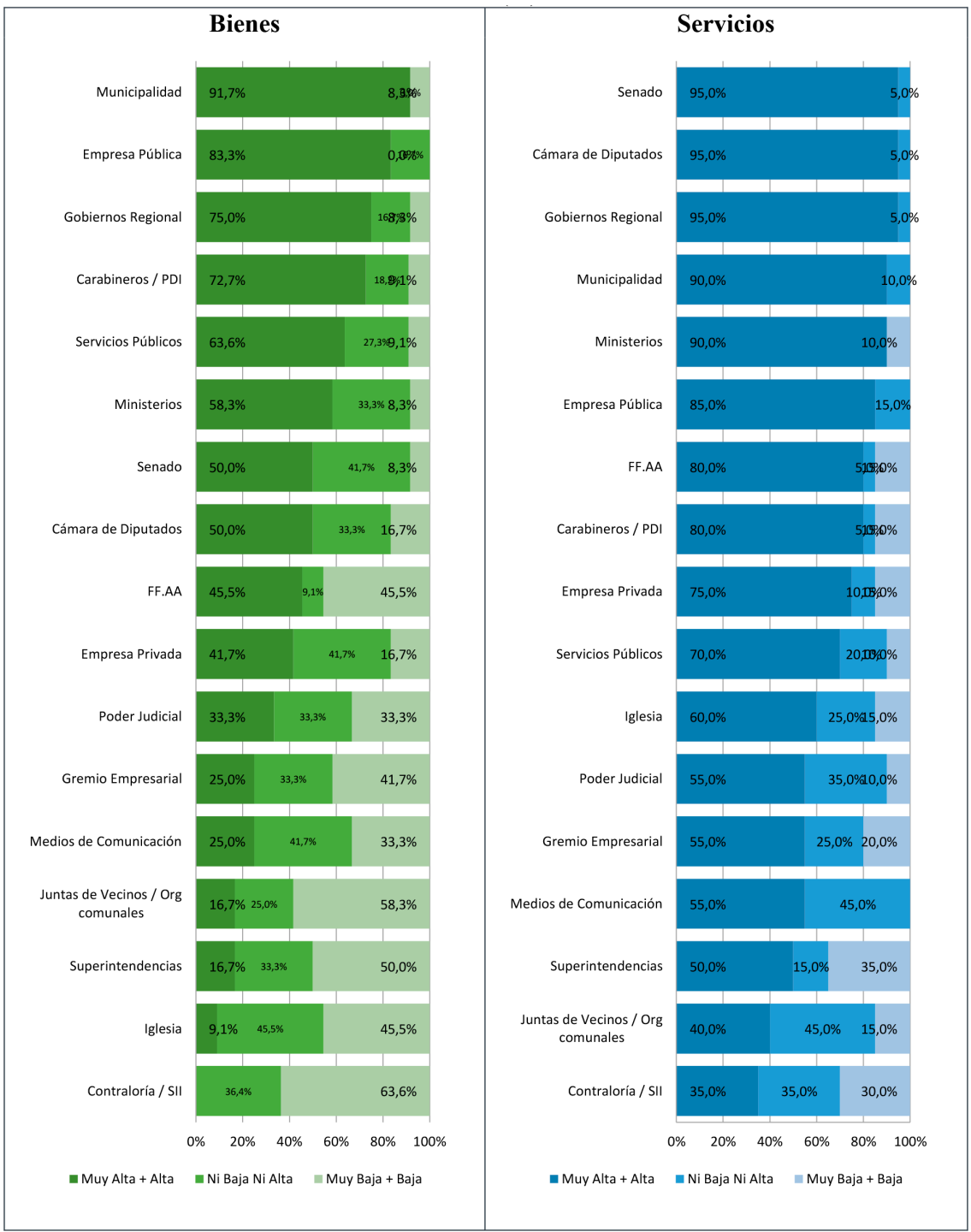

Las categorías de respuesta se reagruparon en Muy Alta + Alta; Ni baja ni alta y Muy Baja + Baja. 
Gráfico 17: B3. ¿Cuál es la posibilidad que se presenten actos de corrupción en... ? según tamaño empresa ${ }^{a /}(\%)$

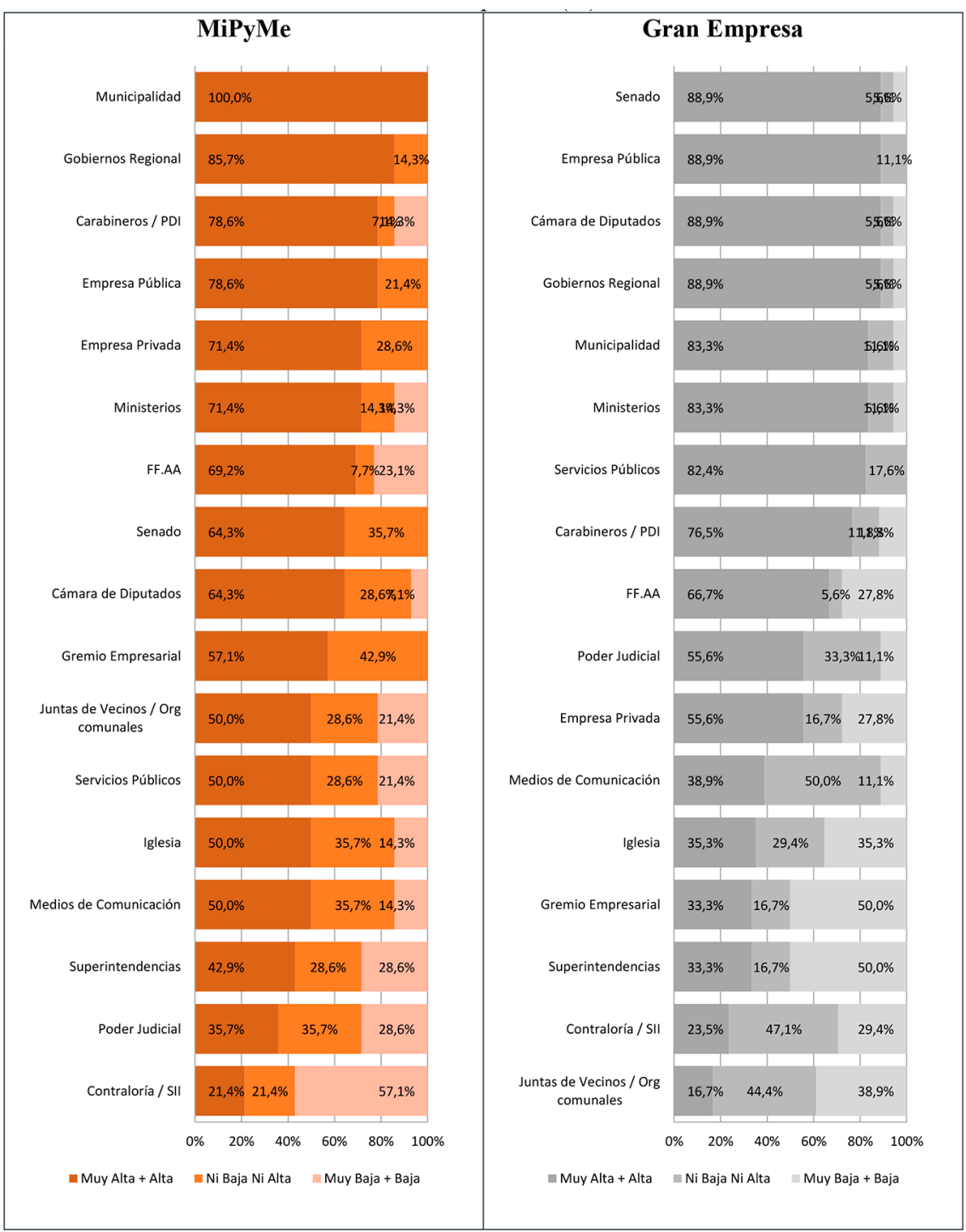

Las categorías de respuesta se reagruparon en Muy Alta + Alta, Ni baja ni alta y Muy Baja + Baja. 


\section{Estrategia para la reducción de la corrupción Chile}

Gráfico 19: Ranking Agregado C7. ¿Qué se puede hacer para reducir la corrupción en Chile? (\%)

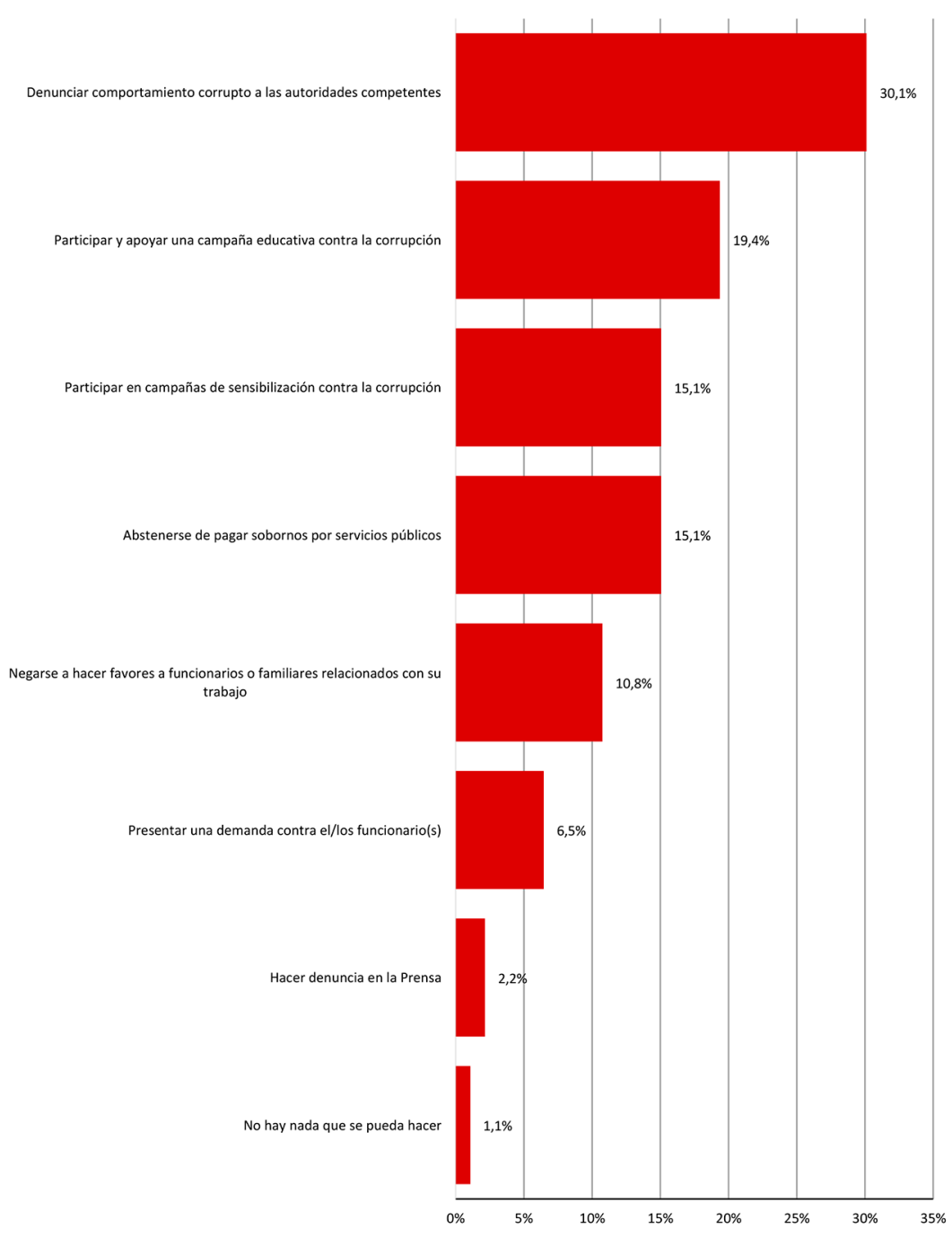

Multirespuesta, ordenado según total de casos agregados. 


\section{Estrategia para la reducción corrupción empresa}

Gráfico 20: Ranking Agregado C6. ¿Cuáles son las formas más efectivas para disuadir actos de corrupción en las Empresas? (\%)

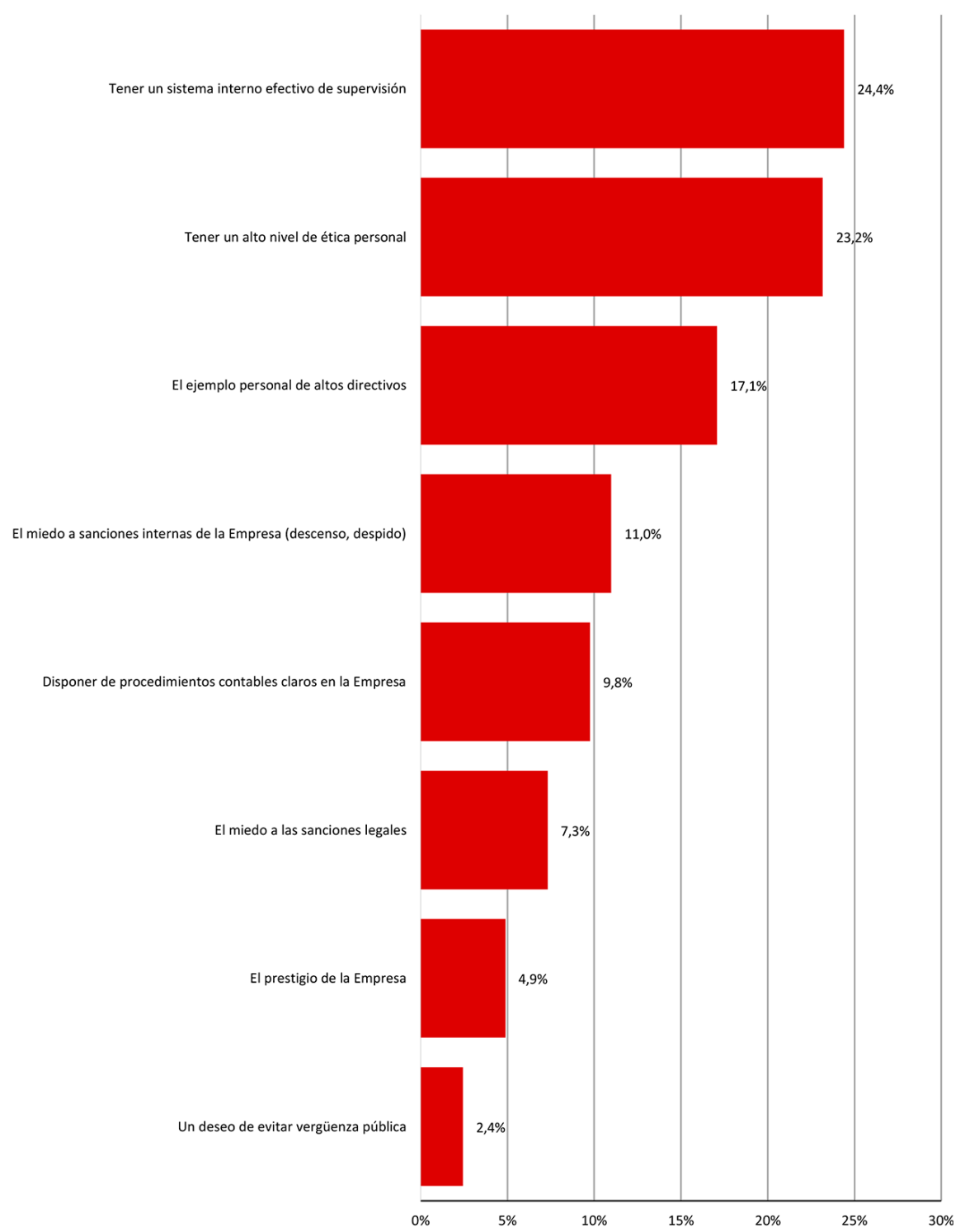

Multirespuesta, ordenado según total de casos agregados. 


\section{Razones para no denunciar actos corrupción}

Gráfico 21: Ranking Agregado C8. ¿Cuál considera Ud. como las tres principales razones para NO informar los actos de corrupción? (\%)

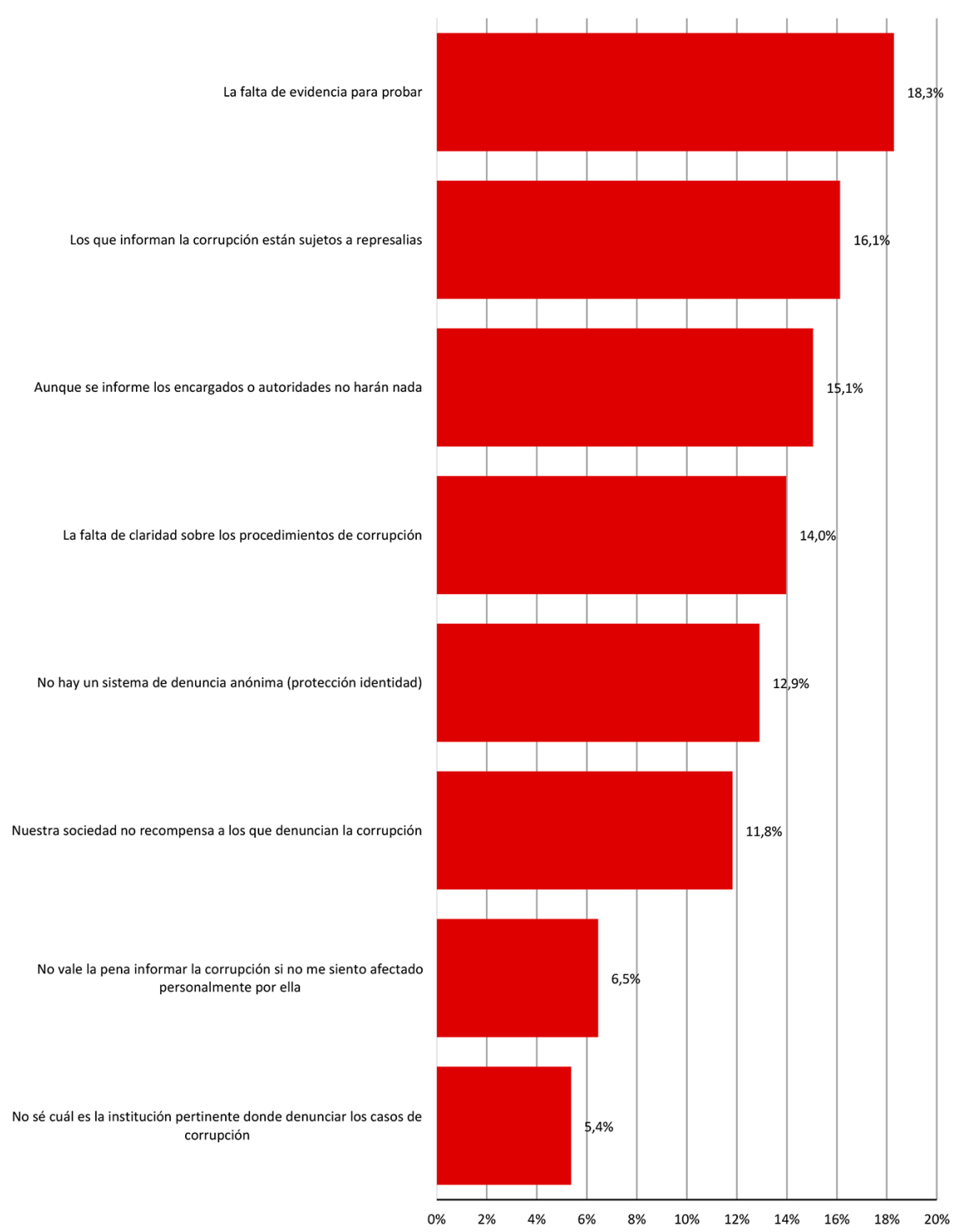

a/ Multirespuesta, ordenado según total de casos agregados. 


\section{Prácticas anti corrupción utilizadas por empresas}

Gráfico 22: D1. ¿Con qué frecuencia son utilizados

(u ofrecidos) por las empresas...? (\%)

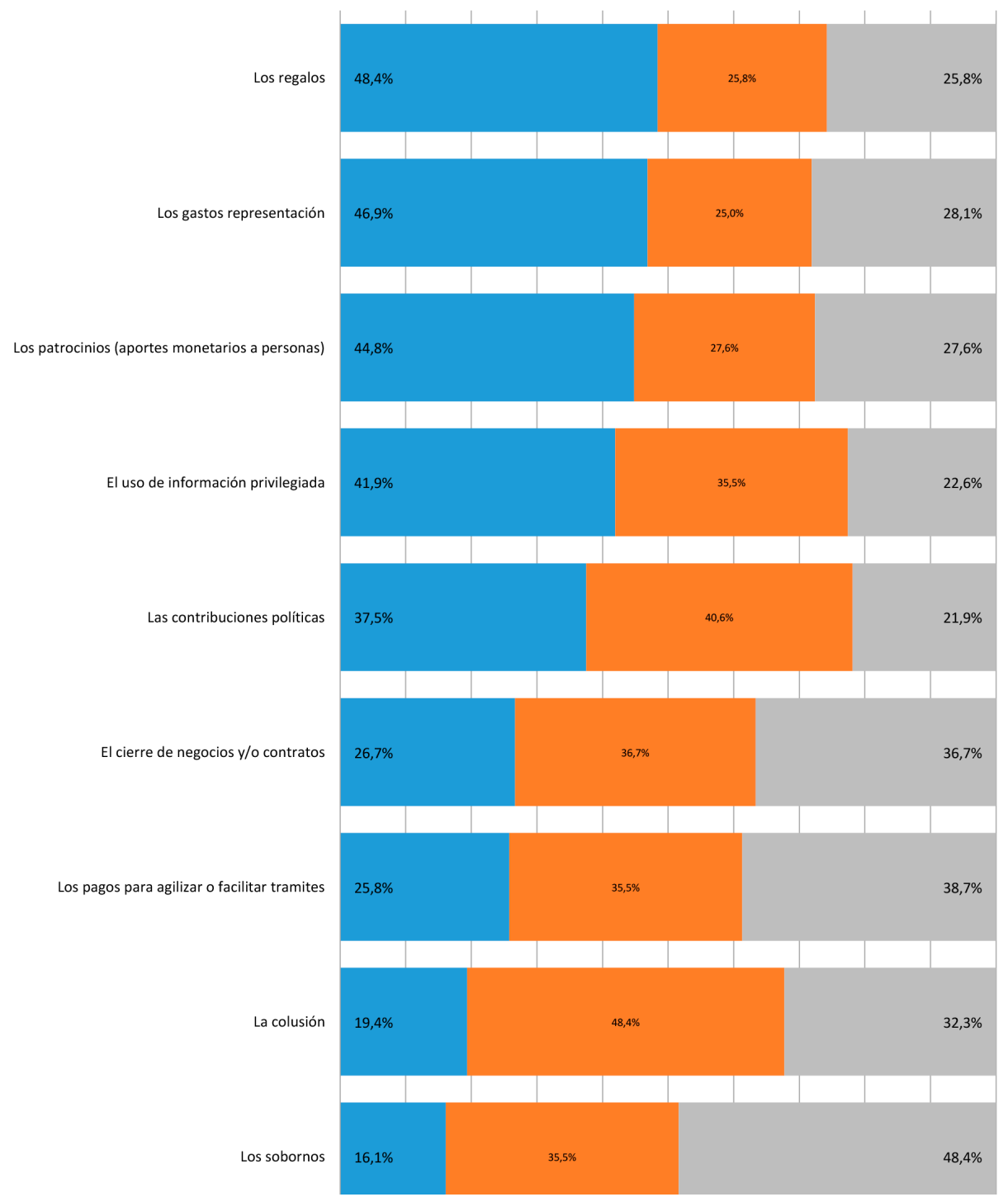

Las categorías de respuesta se reagruparon en Siempre + Casi siempre, Ocasionalmente y Nunca + Casi nunca. 
Gráfico 23: D1. ¿Con qué frecuencia son utilizados (u ofrecidos) por las empresas...? según sector $(\%)$

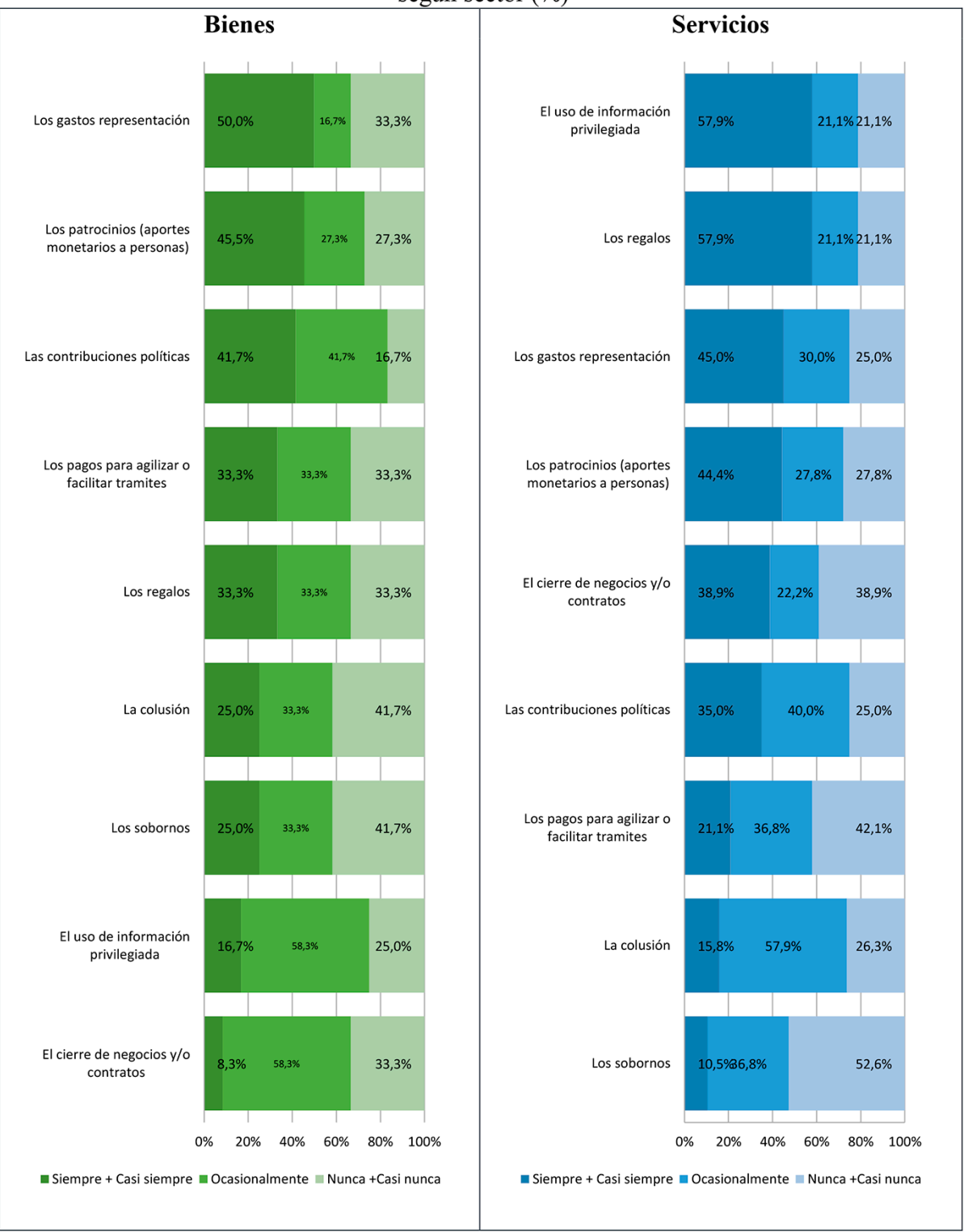

Las categorías de respuesta se reagruparon en Siempre + Casi siempre, Ocasionalmente y Nunca + Casi nunca. 
Gráfico 24: D1. ¿Con qué frecuencia son utilizados (u ofrecidos) por las empresas...?

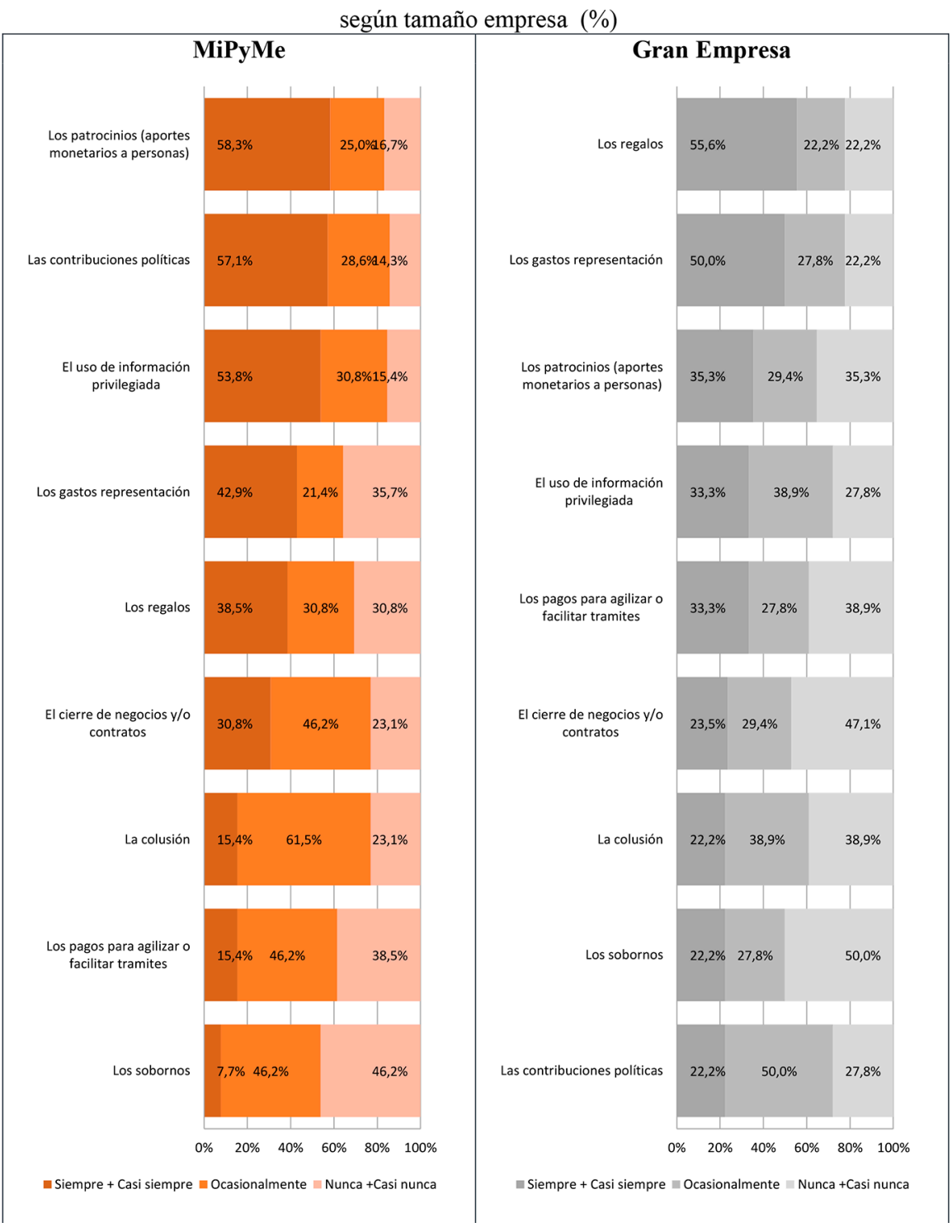

Las categorías de respuesta se reagruparon en Siempre + Casi siempre; Ocasionalmente y Nunca + Casi nunca. 


\section{Riesgos prácticas corruptas utilizadas por empresas}

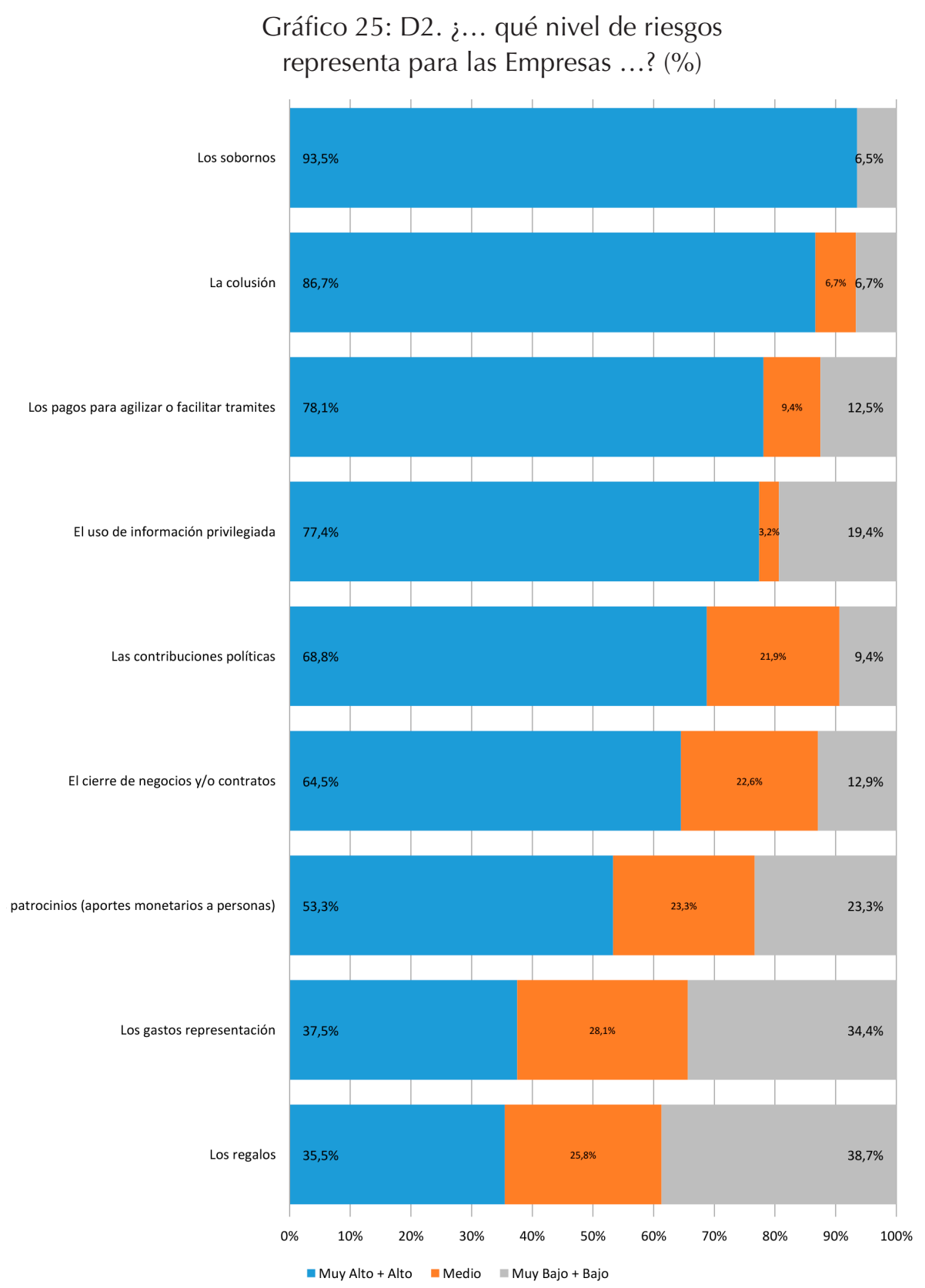

Las categorías de respuesta se reagruparon en Muy Alto + Alto, Medio y Muy Bajo + Bajo. 


\section{Uso prácticas anticorrupción}

Gráfico 26: D3. ¿Con qué frecuencia son utilizadas las siguientes prácticas anticorrupcción? (\%)

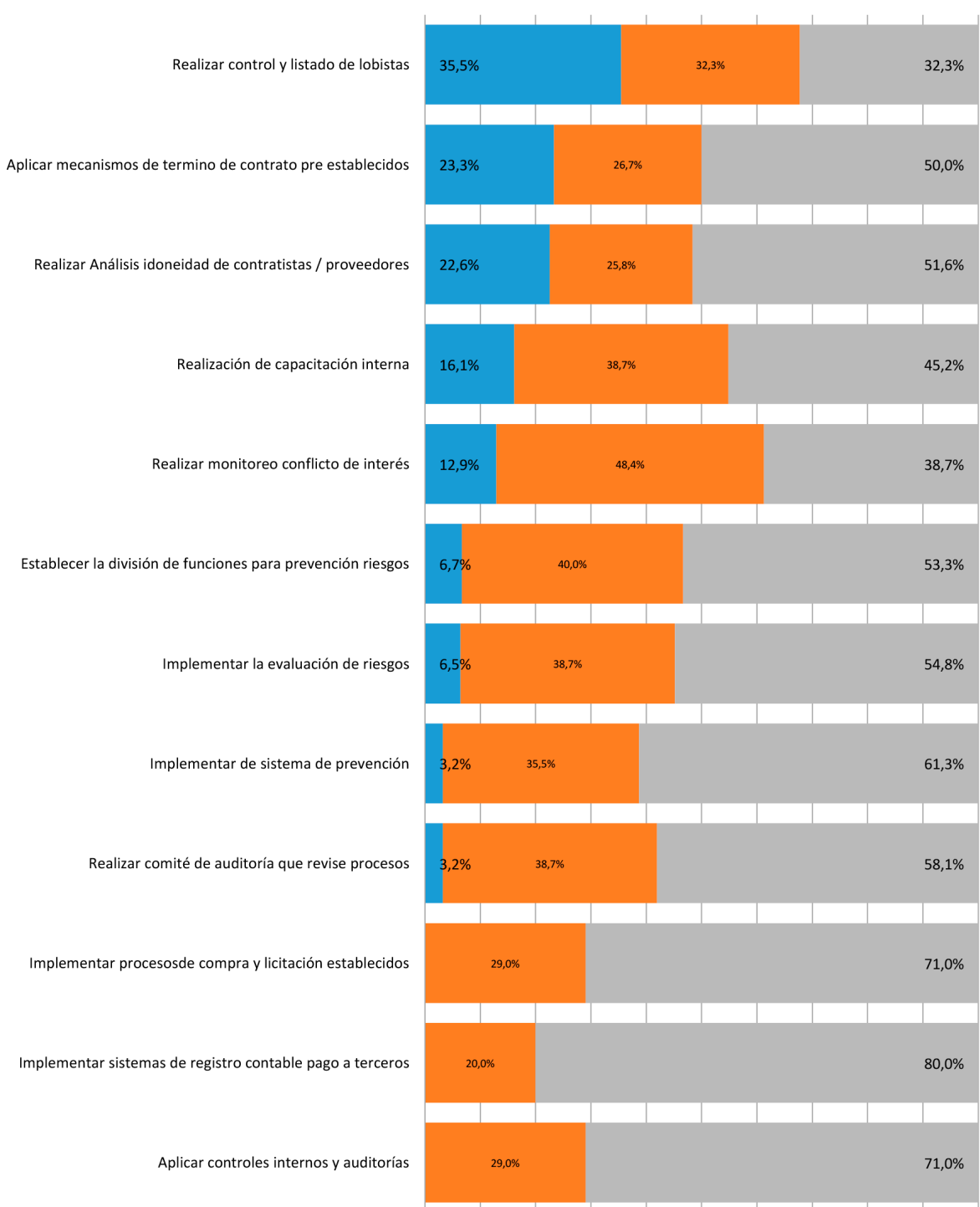

Las categorías de respuesta se reagruparon en Nunca + Casi nunca, Ocasionalmente y Siempre + Casi siempre. 


\section{Presencia de marcos normativos / procedimeintos contra la corrupción}

Gráfico 27: C2. Presencia de códigos / manuales internos + C3. Procedimientos para detectar violación códigos $+\mathrm{C} 4$. Ha realizado investigación por corrupción (últimos 12 meses) (\%)

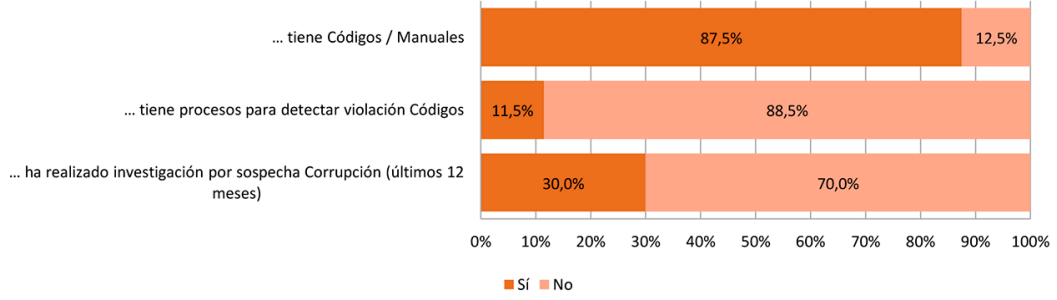

\section{Procedimientos frente a cierre negocios o contratos}

Gráfico 28: C9. Respecto a las actividades comerciales y cierre de negocios o contratos, ¿su empresa...? (\%)

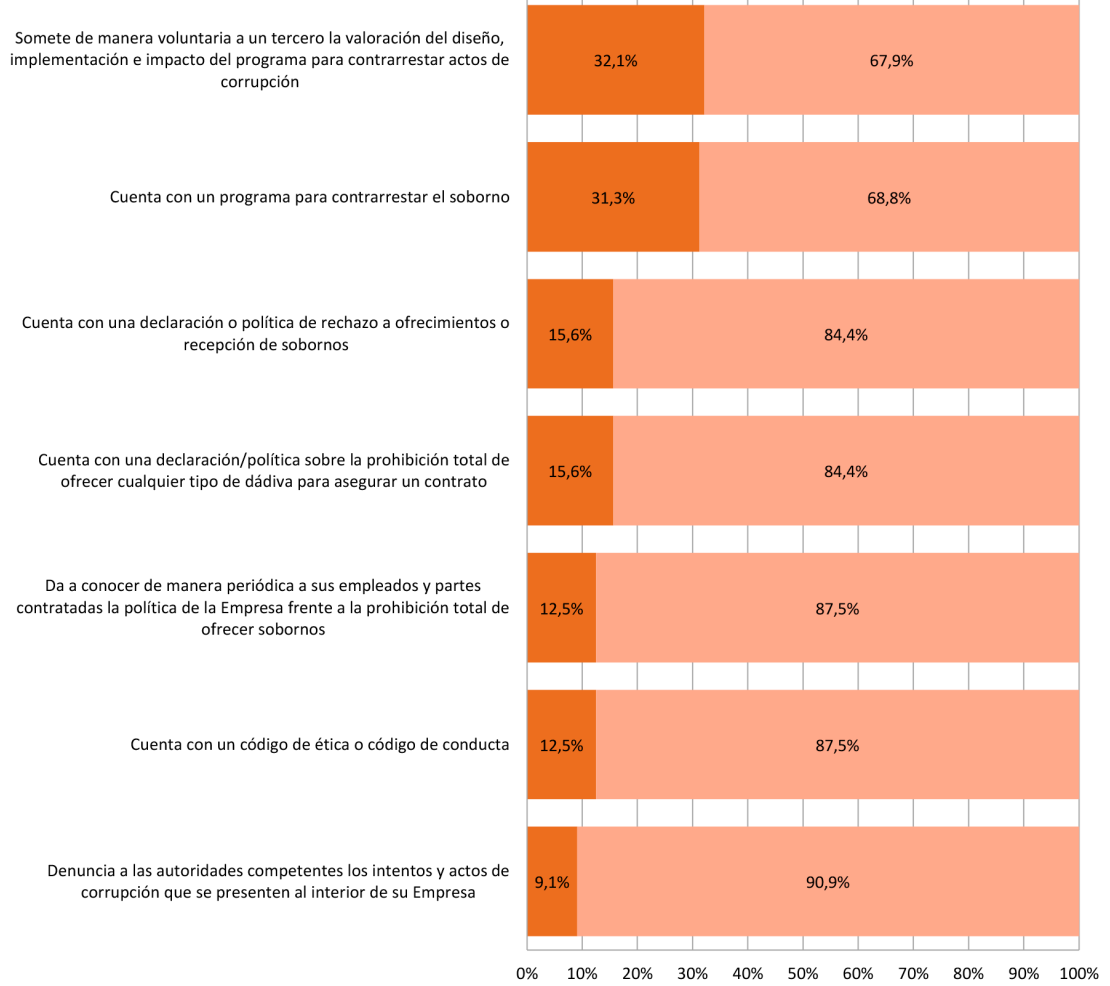




\section{Gráfico 29: C9. Respecto a las actividades comerciales y} cierre de negocios o contratos, ¿su empresa...? según sector $(\%)$

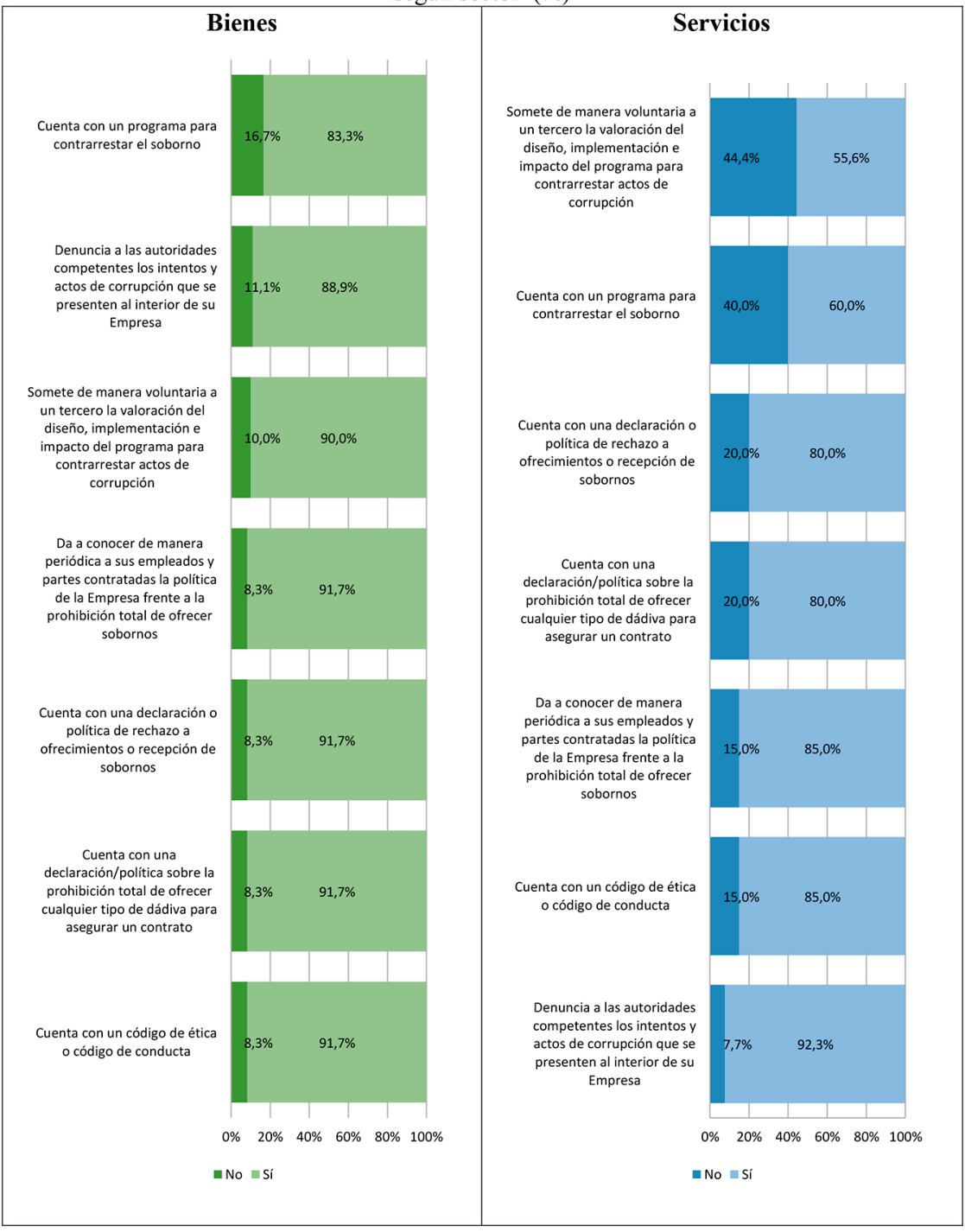




\section{Gráfico 30: C9. Respecto a las actividades comerciales y cierre de negocios o contratos, ¿su empresa...?}

según tamaño empresa (\%)

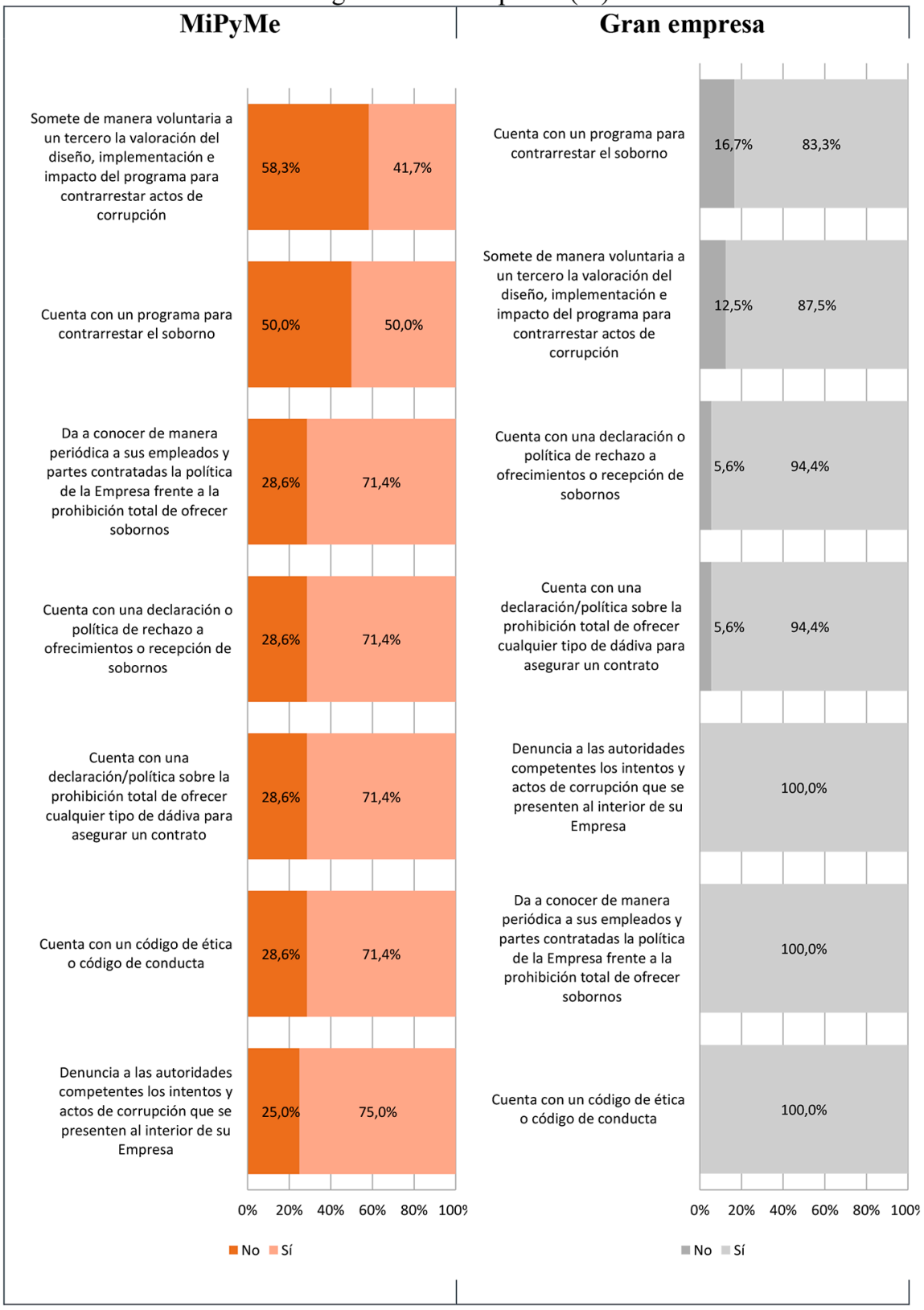




\section{Factores que motivan / desmotivan implementar prácticas prevención corrupción}

Gráfico 31: D4. ¿Qué aspectos desmotivan o motivan para implementar prácticas que contribuyan a prevenir la corrupción? (\%)

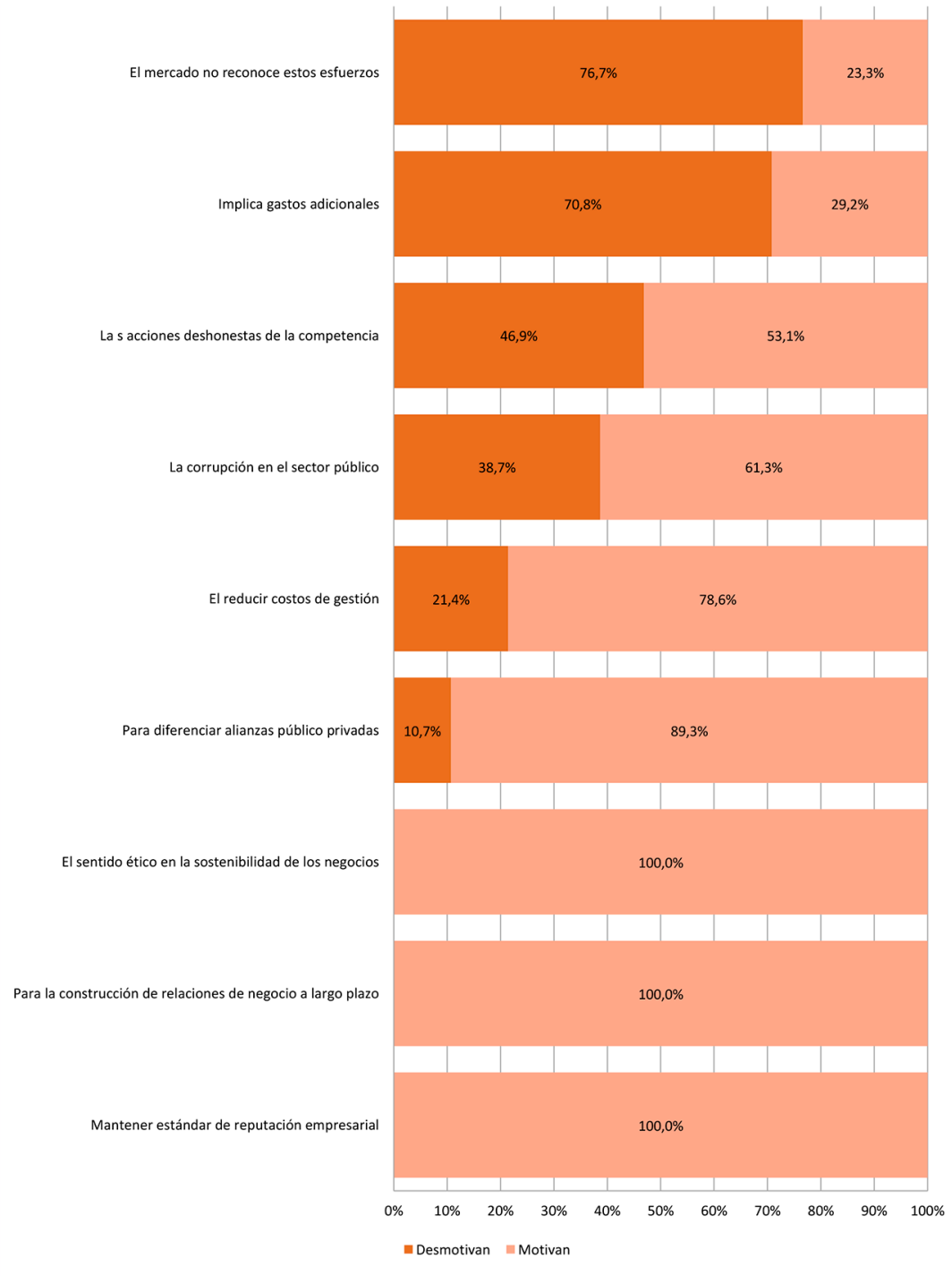




\section{Medidas más importantes para luchar contra la corrupción}

Gráfico 32: Ranking Agregado C1. ¿Cuáles de las siguientes medidas son las más importantes para

luchar contra la corrupción? (\%)

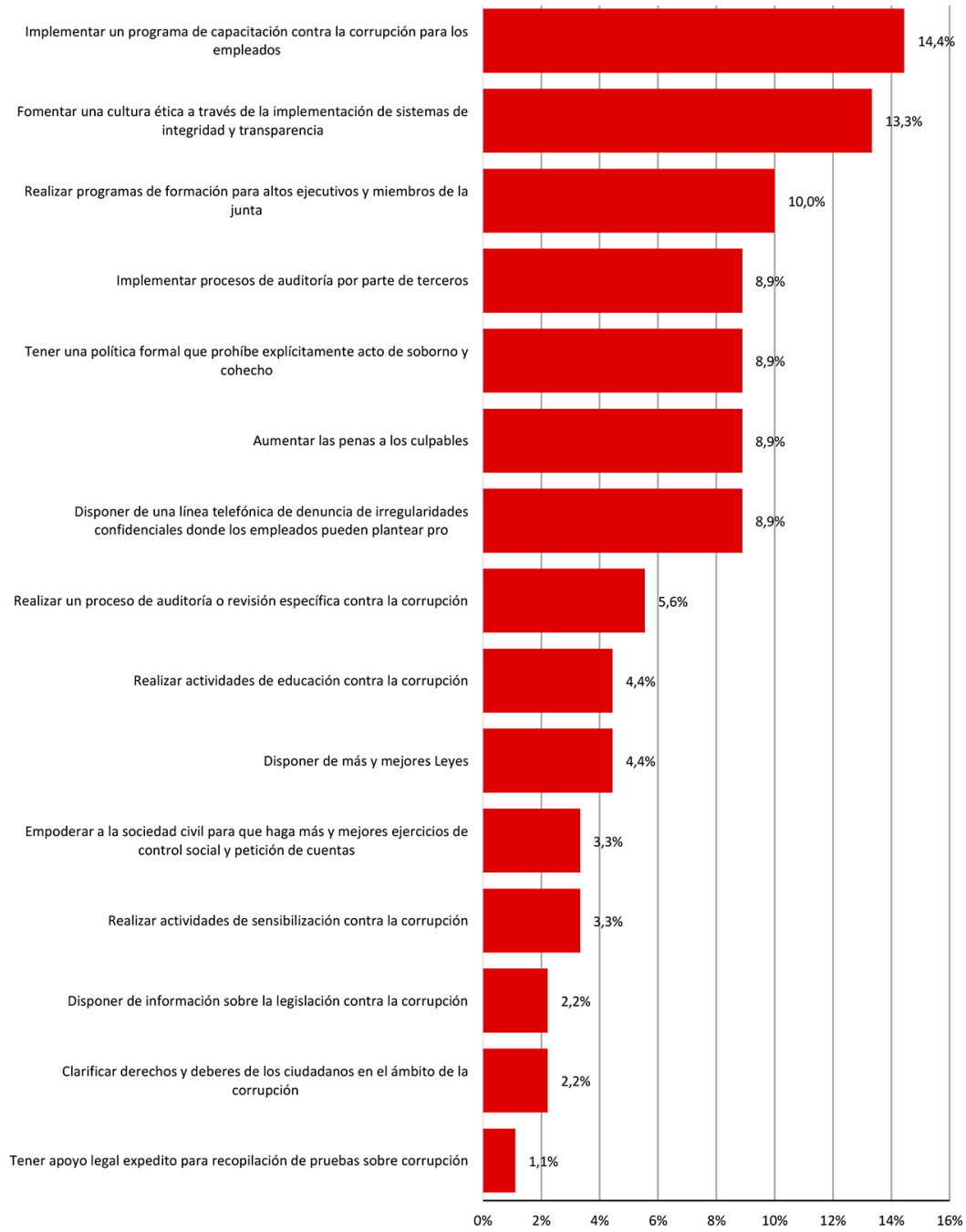

a/ Multirespuesta, ordenado según total de casos agregados. 


\section{Anexo Cuestionario \\ Formulario encuesta autoaplicada estudio sobre la corrupción en el mundo de los negocios}

La Universidad de Talca (UTAL) y Chile Transparente (ChT) están realizando un estudio sobre la corrupción en el mundo de los negocios y las prácticas del empresariado para erradicarla, en el marco del Proyecto de Investigación Fondecyt $N^{\circ} 1150148$, estudio para el cual su empresa fue seleccionada en la muestra a través de un procedimiento científico.

Las respuestas son totalmente anónimas y los datos serán objeto de tratamiento estadístico en el que no se identificará a las empresas ni a quien responde los cuestionarios.

Esta encuesta está diseñada para ser autoaplicada, es decir, para que Ud., como representante de la empresa, vaya marcando las distintas respuestas o llenando los casilleros indicados.

Para resolver alguna duda o comentario, estará presente un "Encuestador / Asistente" designado por la UTAL y ChT durante todo el tiempo que requiera el levantamiento de la información.

Una vez finalizado el proceso de llenado de la encuesta, el encuestador retirará el cuestionario y revisará que haya sido debidamente completado.

Finalmente, el encuestador pondrá en sobre sellado el cuestionario con el fin de resguardar la confidencialidad de la información.

Desde ya le agradecemos su colaboración y le reiteramos la confidencialidad de los datos y su uso exclusivamente para fines de estudio y diagnóstico.

\section{Instrucciones:}

- Favor conteste todas las preguntas del cuestionario.

- Respete el flujo o saltos entre las preguntas (especialmente señaladas).

- Siga las instrucciones de llenado de respuesta descritas en cada pregunta.

- Ante cualquier duda, consulte al asistente.

\section{Folio encuesta $N^{\circ}$ :}

\section{A. Datos iniciales}

\section{A.1 Por favor, ¿me puede decir cuál es su cargo en la empresa?}

* Utilice referencia de cargo siguiendo el siguiente ejemplo de niveles jerárquicos:

1. Dueño, presidente, gerente general, director general.

2. Vicepresidente, subgerente, asesor presidencia o gerencia.

3. Gerente área, director área, coordinador área o encargado área.

[Responden solo personas con 1 o más años de antigüedad en la empresa] A.2 Antigüedad en la empresa

en años

A.3 Antigüedad en el cargo

A.5 Edad $\square$ (en años)
A.4 Sexo
1 Masculino
A.5 Edad años)
Femenino 


\section{B.- Percepción sobre la corrupción}

B.1 Del siguiente listado de tipos de comportamientos, según su opinión, ¿cuáles son los tres tipos de comportamientos más relacionados con la corrupción?

[Marque tres alternativas según orden de importancia

Ej.: si Ud. considera que en $1^{\circ}$ lugar debe estar el ítem 4 "El uso información privilegiada", marque con una $X$ en la celda ' $1{ }^{\circ}$ lugar'. Si considera como $2^{\circ}$ opción el ítem 2 "El abuso de poder", marque con una $X$ en la celda " ${ }^{\circ}$ lugar", etc.]

1. Hacer mal uso de recursos o bienes fiscales.

2. El abuso de poder.

3. La colusión de precios.

4. El uso de información privilegiada.

5. Dar contribuciones políticas.

6. La manipulación de los derechos de los demás.

7. Robar la propiedad ajena.

8. Nepotismo (favorecer a familiares o amigos en obtención de cargos).

9. Hacer pagos para agilizar o facilitar trámites.

10. Hacer pagos para omitir acciones o inspecciones de la autoridad fiscalizadora.

11. El tráfico de influencias (uso conexiones).

12. Entregar regalos, donaciones o patrocinios.

13. El abuso de posición o cargo para beneficio propio.

14. Dar regalos irregulares para obtener favores.

15. Otra. Cuál:

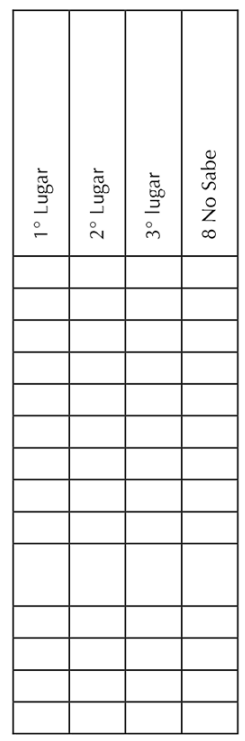

B.2 Según su opinión, ¿̇cuán de acuerdo o en desacuerdo está Ud. con las siguientes afirmaciones?

"Las condiciones que incentivan la corrupción en los negocios son...".

\section{[Marque para cada ítem solo una alternativa]}

1. Los deficientes controles internos en la empresa.

2. La colusión entre miembros de la organización.

3. Los bajos salarios de los empleados.

4. La colusión entre empleados y personas fuera de la empresa.

5. No hay otra manera de hacer las cosas en los negocios.

6. No hay competencia leal.

7. La deficiente o inexistente política de ética empresarial.

8. La falta de educación cívica a los miembros de la empresa.

9. La presión de las jefaturas superiores sobre los controles internos.

10. La ambición de enriquecerse lo más rápido posible.

11. El deficiente control sobre la gerencia por parte de los directores.

12. El acelerar procesos / procedimientos.

13. El deficiente proceso de contratación de personal.

14. Intentar mantener trato preferente.

15. La falta de legislación o marco normativo.

16. La posibilidad de perder un negocio/licitación/contrato.

17. Otra. Cuál:

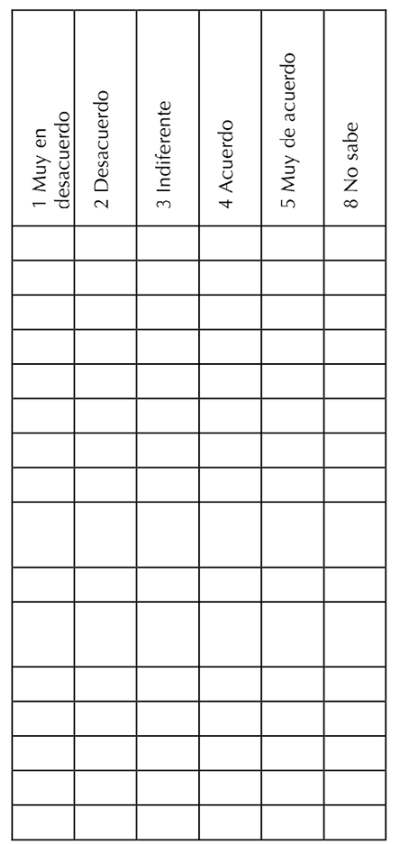


B.3 A continuación se incluye un listado de instituciones públicas y privadas. Al respecto, ¿cuál es la posibilidad que se presenten actos de corrupción en...?

[Marque para cada ítem solo una alternativa]

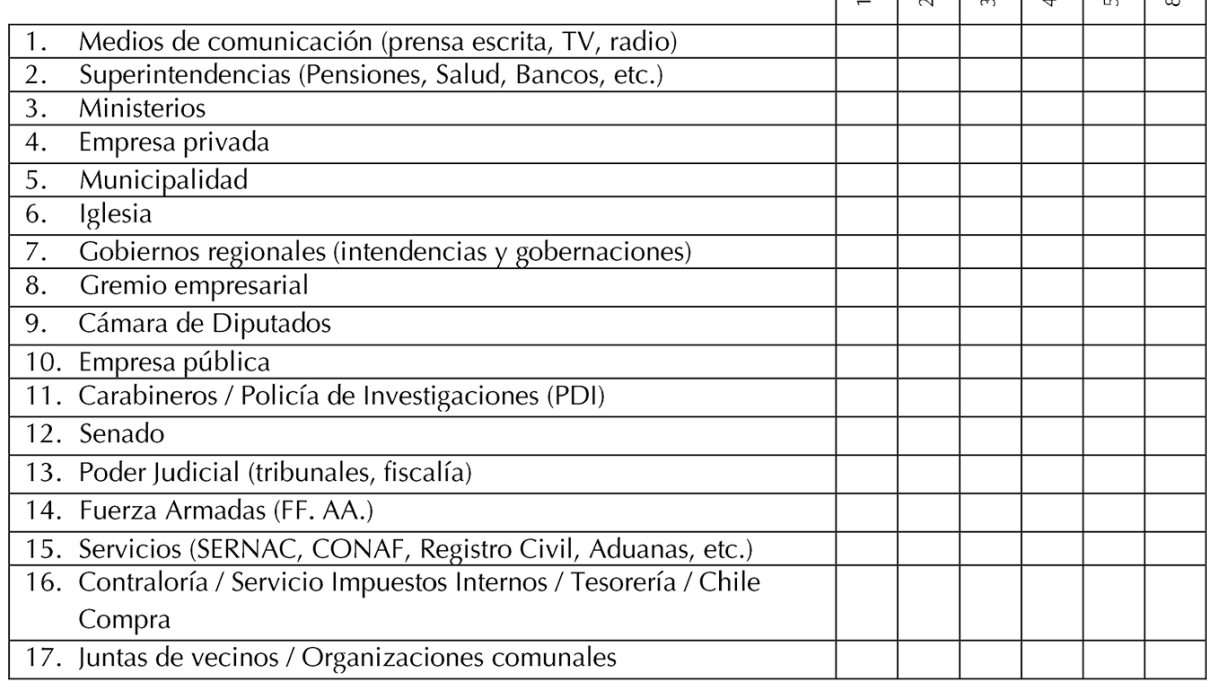

B.4 En los últimos 12 meses, ¿supo de alguien de su entorno cercano a quien le hayan solicitado...?

\section{[Marque para cada ítem solo una alternativa]}

1. Realizar un pago para agilizar o facilitar un trámite (ej.: firma contrato).

2. Entregar información privilegiada.

3. Realizar aporte campaña electoral directamente (no vía SERVEL).

4. Favorecer a familiares o amigos en obtención de cargos (nepotismo).

5. Realizar un pago para frenar o dificultar un trámite (ej.: fiscalización).

6. Utilizar su posición o cargo para beneficio de un tercero.

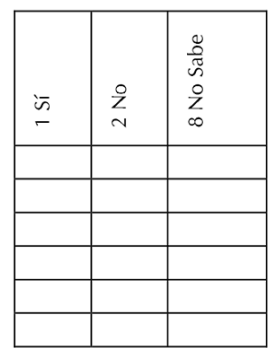

Simarcó a lo menos un "sí", pasar a B.5 Si marcó todas "no" o "no sabe" pasar A B.7

B.5 ¿Sabe si esa persona realizó alguna denuncia o queja en...?

[Marque para cada ítem solo una alternativa,

solo si respondió a lo menos un 'sí' en pregunta B.4 anterior]

1. Ministerio Público o Fiscalía.

2. Ente fiscalizador $y / o$ regulador.

3. Jefatura superior en la empresa.

4. Contraloría / Tesorería / Servicio Impuestos Internos (SII).

5. Carabineros o Policía de Investigaciones.

6. Organismo internacional.

7. Organismo no gubernamental (ONG).

8. Prensa (escrita, TV, radio)

9. Líder político /dirigente comunal / Congreso.

10. Redes dociales (Twitter, Facebook).

11. Otro. ¿Cuál:

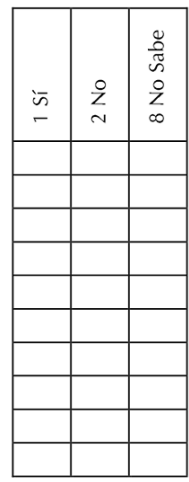


B.6 ¿Sabe Ud. por qué razón esa persona NO denunció?

[Solo si en B.5 marcó 'no' o 'no sabe' en todas las preguntas marque las razones que considere]

1 Miedo a represalias

2 Trámite demasiado tedioso

3 Las denuncias no tienen efecto

4 No sabía a quién denunciarlo

5 No tenía pruebas

6 Otro, Cuál:

8 No sabe

9 No responde

B.7 Desde una perspectiva comparativa, ¿cree Ud. que las empresas chilenas en general...?

[Marque para cada ítem solo una alternativa

solo si respondió 'no' o 'no sabe' en pregunta B.4 anterior] otros países de la región?

... están más o menos dispuestas a pagar sobornos que las empresas de otros países de la región?

\section{Medidas contra la corrupción}

C.1 Según su opinión, ¿cuáles de las siguientes medidas son las más importantes para luchar contra la corrupción en la empresa?

\section{[Marque tres alternativas según orden de importancia}

Ejm: si Ud. considera que en $1^{\circ}$ lugar debe estar el ítem 4 "Aumentar las penas a los culpables", marque con una $X$ en la celda " $1^{\circ}$ lugar". Si considera como $2^{\circ}$ opción el ítem 8 "Disponer de más y mejores leyes", marque con una $X$ en la celda " $2^{\circ}$ lugar", etc.]

1. Implementar un programa de capacitación contra la corrupción para los empleados.

2. Disponer de una línea telefónica de denuncia de irregularidades confidenciales donde los empleados pueden plantear problemas.

3. Realizar un proceso de auditoría o revisión específica contra la corrupción.

4. Aumentar las penas a los culpables.

5. Realizar programas de formación para altos ejecutivos y miembros de la junta.

6. Clarificar derechos y deberes de los ciudadanos en el ámbito de la corrupción.

7. Tener una política formal que prohíbe explícitamente acto de soborno y cohecho.

8. Disponer de más y mejores leyes.

9. Establecer una cláusula estándar en los contratos con los subcontratistas que prohíbe sobornos.

10. Realizar actividades de sensibilización contra la corrupción.

11. Disponer de información sobre la legislación contra la corrupción.

12. Implementar procesos de auditoría por parte de terceros.

13. Disponer de información sobre las instituciones en que se puede denunciar.

14. Tener apoyo legal expedito para recopilación de pruebas sobre corrupción.

15. Tener apoyo legal expedito en la elaboración y presentación de los documentos.

16. Realizar actividades de educación contra la corrupción.

17. Disponer de mecanismos jurídicos expeditos para realizar denuncias.

18. Empoderar a la sociedad civil para que haga más y mejores ejercicios de control social y petición de cuentas.

19. Fomentar una cultura ética a través de la implementación de sistemas de integridad y transparencia.

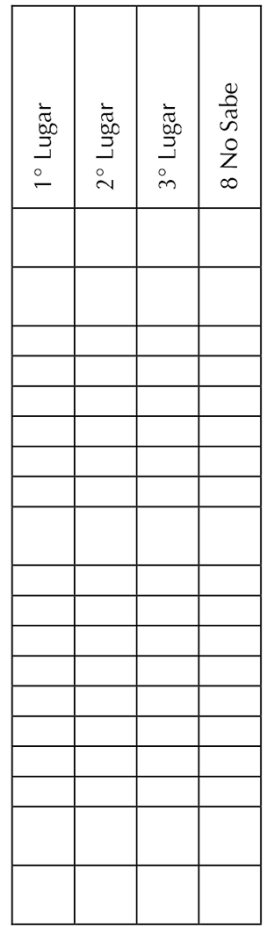

20. Otro. Cuál: 
C.2 ¿Su empresa tiene códigos, manuales, documentos con el conjunto de normas de conducta interna que orienten a los empleados sobre actos de corrupción (pago de sobornos, cohecho)? [Marque solo una alternativa]

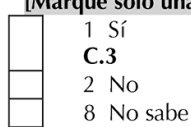

C. 3 iSu empresa tiene procesos que permitan detectar la violación de estos códigos? [Marque solo una alternativa]

C.4 En los últimos 12 meses, ¿su empresa realizó alguna investigación interna por sospechas de corrupción? [Marque solo una alternativa]
1 Sí, con base en una denuncia interna
2 Sí, con base en una denuncia externa
3 No, ninguna investigación
8 No sabe

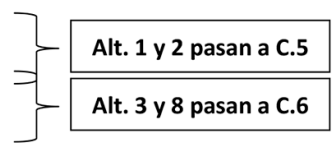

C.5 ¿A qué institución pertenecía(n) la(s) persona(s) involucrada(s) en el caso de corrupción? [Marque solo una alternativa

solo si respondió alternativas 1 o 2 en pregunta C.4 anterior]

1. Empresa de la competencia

2. Municipalidad

3. Ente fiscalizador $y / 0$ regulador

4. Gobierno regional

5. Chile Compra

6. Poder Judicial

7. Senado

8. Servicio Impuestos Internos / Tesorería / Contraloría

9. Carabineros / PDI/FF. AA.

10. Cámara de Diputados

11. Ministerio Público

12. Servicio de Aduanas

13. Servicio de Registro Civil

88. No sabe

C.6 Según su opinión, ¿cuáles son las formas más efectivas para disuadir los actos de corrupción en las empresas?

\section{[Marque tres alternativas según orden de importancia}

Ej.: si Ud. considera que en 1! lugar debe estar el ítem 4 "El prestigio de la empresa", marque con una $X$ en la celda " $1^{\circ}$ lugar". Si considera como $2^{\circ}$ opción el ítem 5 "Miedo a las sanciones legales", marque con una $X$ en la celda " $2^{\circ}$ lugar", etc.].

1. El miedo a sanciones internas de la empresa (descenso, despido).

2. Tener un alto nivel de ética personal.

3. Tener un sistema interno efectivo de supervisión.

4. El prestigio de la empresa.

5. El miedo a las sanciones legales.

6. Disponer de procedimientos contables claros en la empresa.

7. El ejemplo personal de altos directivos.

8. Un deseo de evitar vergüenza pública.

9. Otro. Cuál:

C.7 Según su opinión, ¿qué se puede hacer para reducir la corrupción en Chile? [Marque tres alternativas según orden de importancia Siga el ejemplo de la pregunta C.6 anterior]

1. Abstenerse de pagar sobornos por servicios públicos

2. Negarse a hacer favores a funcionarios o familiares relacionados con su trabajo.

3. Denunciar comportamiento corrupto a las autoridades competentes.

4. Participar y apoyar una campaña educativa contra la corrupción.

5. Hacer denuncia en la prensa.

6. Presentar una demanda contra el/los funcionario(s).

7. Participar en campañas de sensibilización contra la corrupción.

8. No hay nada que se pueda hacer.

9. Otro. Cuál:
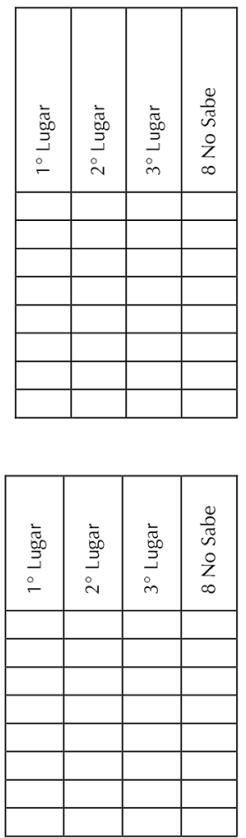
C.8 Algunas personas NO están dispuestas a reportar actos de corrupción debido a varias razones. Del siguiente listado, ¿cuáles considera $U d$. como las tres principales razones para $\mathrm{NO}$ informar los actos de corrupción?

\section{[Marque tres alternativas según orden de importancia}

\section{Siga el ejemplo de la pregunta C.6 anterior]}

1. Nuestra sociedad no recompensa a los que denuncian la corrupción.

2. La mayoría de las personas que cometen corrupción sólo lo hacen debido a las dificultades económicas.

3. Los que informan la corrupción están sujetos a represalias.

4. Aunque se informe, los encargados o autoridades no harán nada.

5. No vale la pena informar la corrupción si no me siento afectado personalmente por ella.

6. No hay un sistema de denuncia anónima (protección identidad).

7. La falta de evidencia para probar.

8. La falta de claridad sobre los procedimientos de corrupción.

9. No sé cuál es la institución pertinente donde denunciar los casos de corrupción.

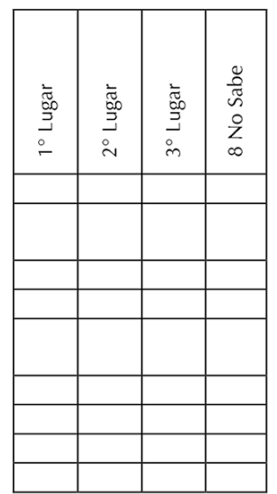

C.9 Respecto a las actividades comerciales y cierre de negocios o contratos, ¿su empresa...?

\section{[Marque para cada ítem solo una alternativa]}

1. Cuenta con un código de ética o código de conducta.

2. Cuenta con una declaración/política sobre la prohibición total de ofrecer cualquier tipo de dádiva para asegurar un contrato.

3. Cuenta con una declaración o política de rechazo a ofrecimientos o recepción de sobornos.

4. Cuenta con un programa para contrarrestar el soborno.

5. Somete de manera voluntaria a un tercero la valoración del diseño, implementación e impacto del programa para contrarrestar actos de corrupción.

6. Da a conocer de manera periódica a sus empleados y partes contratadas la política de la empresa frente a la prohibición total de ofrecer sobornos.

7. Denuncia a las autoridades competentes los intentos y actos de corrupción que se presenten al interior de su empresa.

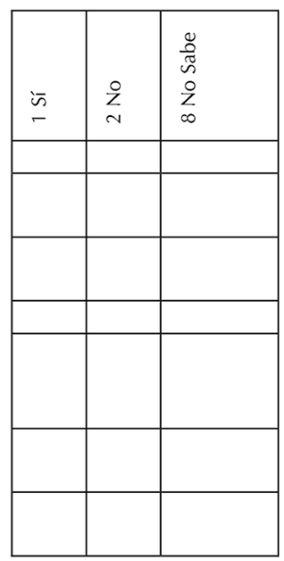

\section{Prácticas anticorrupción}

D.1 Respecto a las siguientes prácticas, consideradas comúnmente como actos de corrupción, según su opinión, ¿con qué frecuencia son utilizados (u ofrecidos) por las empresas...? [Marque para cada ítem solo una alternativa]

1. Las contribuciones políticas

2. Los patrocinios (aportes monetarios a personas)

3. Los regalos

4. Los gastos de representación

5. Los pagos para agilizar o facilitar tramites

6. Los sobornos

7. El cierre de negocios y/o contratos

8. El uso de información privilegiada

9. La colusión

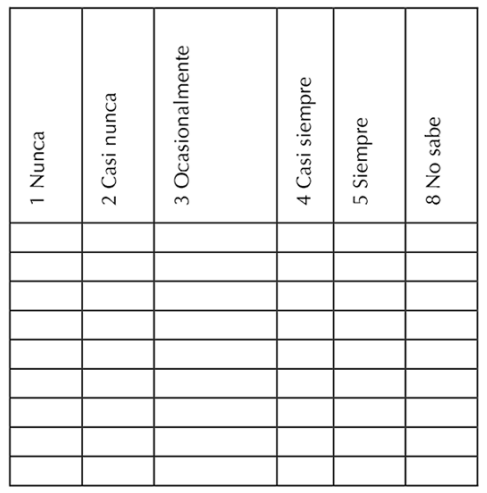


D.2 ¿Y según su opinión, qué nivel de riesgos representan para las empresas...?

\section{[Marque para cada ítem solo una alternativa]}

1. Las contribuciones políticas

2. Los patrocinios (aportes monetarios a personas)

3. Los regalos

4. Los gastos de representación

5. Los pagos para agilizar o facilitar tramites

6. Los sobornos

7. El cierre de negocios y/o contratos

8. El uso de información privilegiada

9. La colusión

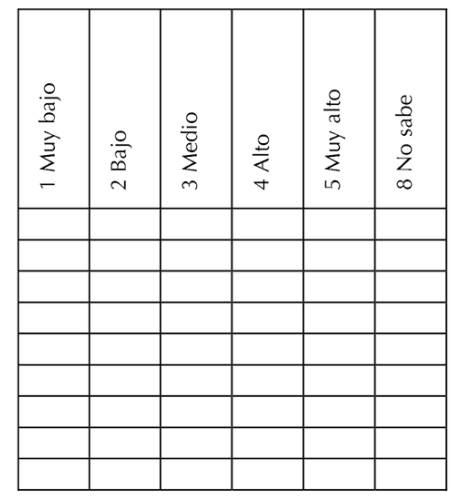

D.3 Respecto a las siguientes prácticas Anticorrupción, según su opinión, ¿con qué frecuencia son utilizadas (o se realizan) por las empresas?

\section{[Marque para cada ítem solo una alternativa]}

1. Implementar la evaluación de riesgos

2. Realizar monitoreo conflicto de interés

3. Aplicar controles internos y auditorías

4. Implementar sistemas de registro contable de pago a terceros

5. Realizar comité de auditoría que revise procesos

6. Establecer la división de funciones para prevención riesgos

7. Realizar análisis idoneidad de contratistas / proveedores

8. Aplicar mecanismos de término de contrato preestablecidos

9. Implementar procesos de compra y licitación establecidos

10. Realizar control y listado de lobistas

11. Realización de capacitación interna

12. Implementar de sistema de prevención

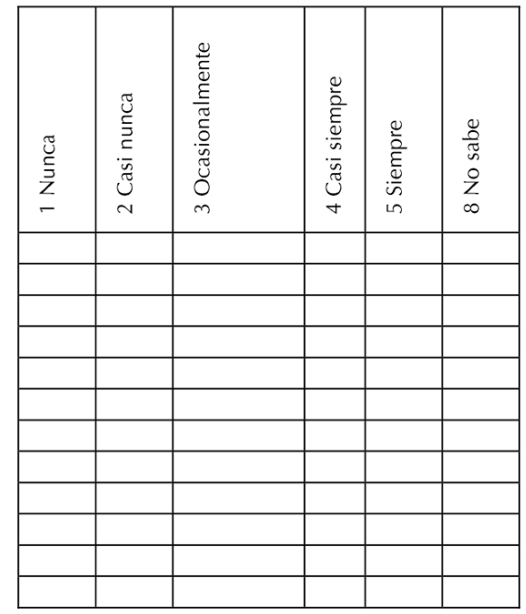

D.4 Según su opinión y experiencia, del siguiente listado de frases, ¿cuáles desmotivan o motivan a su empresa para implementar prácticas que contribuyan a prevenir la corrupción? [Marque para cada ítem solo una alternativa]

1. La corrupción en el sector público

2. El reducir costos de gestión

3. Implica gastos adicionales

4. Mantener estándar de reputación empresarial

5. Para diferenciar alianzas público-privadas

6. Para la construcción de relaciones de negocio a largo plazo

7. Las acciones deshonestas de la competencia

8. El sentido ético en la sostenibilidad de los negocios

9. El mercado no reconoce estos esfuerzos

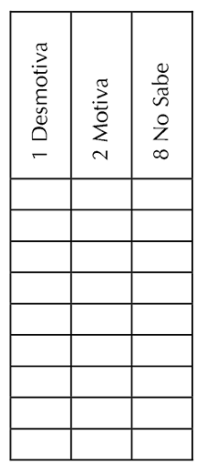




\section{E. Evaluación entorno negocios con sector público}

E.1 En los últimos 12 meses, ¿su empresa ha participado en alguna licitación pública o en un proceso público de adjudicación de contratos?

[Marque solo una alternativa]

1 Sí

2 No

8 No sabe
E.2 En los últimos 12 meses, ¿cree Ud. que la corrupción le ha impedido ganar a su empresa alguna licitación o un contrato público?
[Marque solo una alternativa]
1 Sí
2 No
8 No sabe

* Considerar al sector público compuesto por instituciones como Poder Judicial, Congreso, ministerios, servicios, superintendencias, gobierno regional, municipalidades, empresas públicas, universidades públicas.

E.3 Respecto a la ejecución de trámites de licitación o contrato con el sector público, ¿su empresa...?

\section{[Marque para cada ítem solo una alternativa]}

1. Cuenta con un conducto regular para llevar a cabo la ejecución de cualquier tipo de trámite requerido frente a entidades públicas.

2. Tiene una posición de rechazo frente al pago de comisiones indebidas para agilizar los trámites.

3. Identifica las situaciones en las que es común el pago de comisiones indebidas para agilizar los trámites.

4. Da a conocer a sus empleados y terceros su posición frente al rechazo al pago de comisiones indebidas para agilizar los trámites.

5. Cuenta con una política de prohibición total para ofrecer y recibir pagos para agilizar cualquier tipo de trámite.

\begin{tabular}{|c|c|c|}
\hline in & $\stackrel{\circ}{z}$ & $\underset{\infty}{2} \frac{8}{\tilde{n}}$ \\
\hline & & \\
\hline & & \\
\hline & & \\
\hline & & \\
\hline & & \\
\hline
\end{tabular}

E.4 Respecto a la ejecución de trámites de licitación o contrato con el sector público, ¿cuáles situaciones considera Ud., son los tres principales motivos de presión para dar u ofrecer sobornos?

[Marque tres alternativas según orden de importancia

Ej.: si Ud. considera que en $1^{\circ}$ lugar debe estar el ítem 1 "Trámites y procedimientos engorrosos", marque con una $X$ en la celda " $1^{\circ}$ lugar". Si considera como $2^{\circ}$ opción el ítem 5 "Perder negocios si no ofrecen o reciben sobornos", marque con una $X$ en la celda " $2 \circ$ lugar", etc.]

1. Trámites y procedimientos engorrosos

2. Para evitar controles o supervigilancia si no se ofrecen o reciben sobornos

3. La ineficiencia del sector público para ejercer sus funciones

4. El requerimiento, directo o indirecto, de sobornos o beneficios por parte de funcionarios públicos

5. Perder negocios si no se ofrecen o reciben sobornos

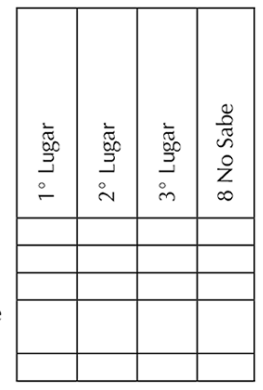

E.5 A menudo se dice que las empresas utilizan aportes irregulares, lobby, regalos $\mathrm{u}$ otros beneficios a funcionarios del sector público para obtener alguna ventaja para sus negocios. ¿En qué medida las siguientes prácticas tienen un impacto en los negocios...?

"Realizar aportes, regalos u otros beneficios...".

[Marque para cada ítem solo una alternativa]

\begin{tabular}{|c|c|c|c|c|c|c|}
\hline 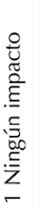 & 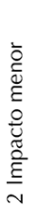 & 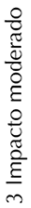 & 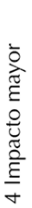 & 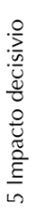 & 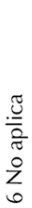 & $\begin{array}{l}\stackrel{8}{ } \\
\tilde{w} \\
0 \\
Z \\
\infty\end{array}$ \\
\hline & & & & & & \\
\hline
\end{tabular}

a los parlamentarios para afectar sus votos.

... a los funcionarios de Gobierno para influir en el contenido de los decretos del Gobierno.

... a los funcionarios de los gobiernos locales o regionales para afectar a sus votos o el contenido de los decretos / leyes del Gobierno.

\section{F. Evaluación situación de conflictos internos}

F.1 Con relación a los resultados económicos y comparándose con el año pasado, en su opinión, esta empresa está... [Marque solo una alternativa]

$\square 5$ Mucho mejor $\square 4$ Mejor $\square 3$ Igual $\square 2$ Peor $\square 1$ Mucho peor $\square 8$ No sabe 
F.2 Para enfrentar las situaciones de dificultad económica, ¿su empresa ha tenido que hacer alguna de las siguientes adecuaciones...?

[Por favor, mencione todas las que corresponda

y marque solo una alternativa por cada una]

1. Ajustar sistemas de vacaciones (adelantar, postergar).

2. Declarar cotizaciones previsionales sin pagarlas o simplemente no declararlas.

3. Ajustar las jornadas de trabajo (acortar o alargar).

4. Ajustar la producción (aumentar/disminuir).

5. Ajustar cantidad de trabajadores (despedir o contratar trabajadores).

6. Comenzar a trabajar por turnos.

7. Renegociar deuda (repactar deuda actual o adquirir nueva deuda).

8. Hacer que los trabajadores realicen nuevas tareas.

9. Ajuste de salario (rebajar o mantener los salarios).

10. Cambiar los rubros de producción (hacer cosas distintas de las habituales).

11. No ha pasado por situaciones de dificultad económica.

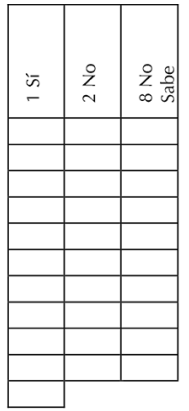

F.3 Durante los últimos 12 meses, ¿ha habido situaciones de conflicto laboral colectivo en su empresa, ya sea huelga, paro u otro cualquiera?
1 Sí. ¿Cuántos?
$\square 2$ No $\square 8$ No sabe

* Por conflicto laboral se entiende un conflicto entre trabajador y empleador por causas propias del proceso de trabajo. Puede involucrar a uno o a más trabajadores.

F.4 ¿Cuál fue la principal medida que tomó la empresa para enfrentar el último conflicto?

\section{[Marque solo una alternativa]}

1 Diálogo directo con los trabajadores.

2 Despido de trabajadores involucrados.

3 Solicitar mediación de la Inspección del Trabajo.

4 Cierre temporal o aviso de cierre temporal de la empresa.

5 Suspensión de conversaciones hasta término de movilizaciones de trabajadores.

6 Ninguna medida.

8 No sabe.

F.5 ¿Trabaja su empresa con contratistas o subcontratistas? [Seguir flujo respuesta]

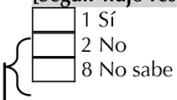

F.7 Cómo es la relación de trabajo con la empresa subcontratista:

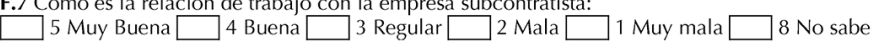

F.8 $i$ Actualmente existe algún sindicato en su empresa? [Seguir flujo respuesta]
1 Sí. ¿Cuántos?
2 No
8 No sabe
$\rightarrow$ Pase a F.9
\}
Pase próximo Módulo $\mathrm{G}$
F.9 Cómo es la relación de trabajo con los sindicatos:
5 Muy Buena
4 Buena
3 Regular
2 Mala
1 Muy mala $\square 8$ No sabe

G. Caracterización de la empresa

\section{G.1 Ciudad Santiago G.2 Razón social de la empresa}

G.3 Tamaño de la empresa por número de empleados [Marque solo una alternativa]

1 Microempresa: 5 a 9 trabajadores

2 Pequeña empresa: 10 a 49 trabajadores

3 Mediana empresa: 50 a 199 trabajadores

4 Gran empresa: 200 y más trabajadores

8 No sabe

G.4 Indique la cantidad total de establecimientos que posee la empresa a nivel nacional

* Se entiende por establecimiento la unidad física en la que opera la empresa. Usualmente se conoce como local, sucursal, faena, etc.

G.5 Sector económico al que pertenece la empresa

¿Cuál fue la actividad económica principal de la empresa, de acuerdo a su mayor valor de facturación durante

los últimos 12 meses? 
[Marque solo una alternativa del conjunto de alternativas siguientes $\rightarrow->$ letras a-r]

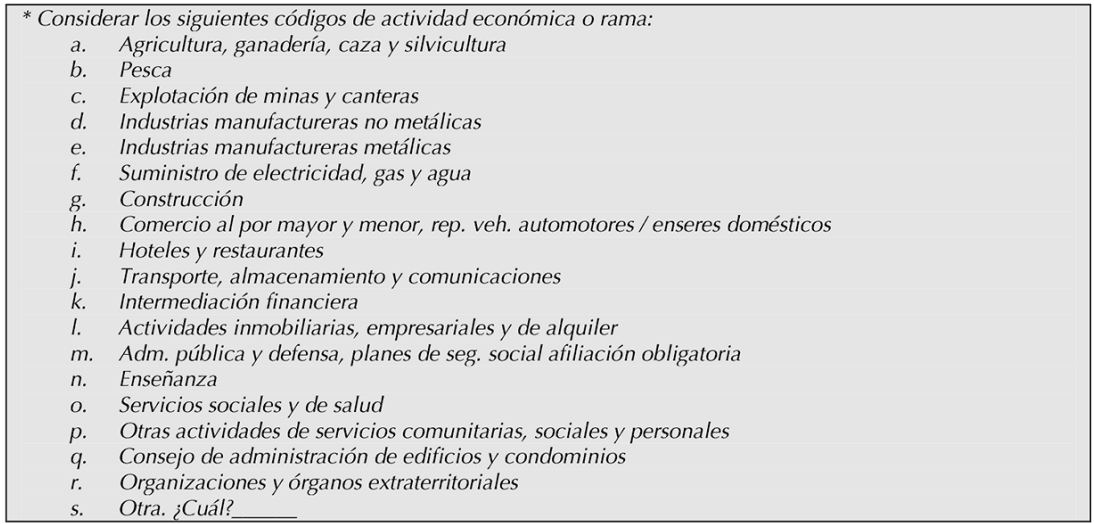

\section{* G.6 ¿Cuál es el origen de la} empresa?

1 Capital nacional

2 Capital extranjero

3 Ambos
G.7 ¿Cuál es el volumen de ventas anual de su empresa a nivel nacional (monto en UF)? [Marque solo una alternativa]

1 Desde 0,01 UF a 2.400 UF (micro)

2 Desde 2.400,01 UF a 25.000 UF (pequeña)

3 Desde 25.000,01 UF a 100.000 UF (mediana)

4 100.000,01 UF y más (gran empresa)

8 No sabe

* En G.6 marque el porcentaje (\%) de participación cuando el capital sea "Ambos" o compartido.

Ej.: $30 \%$ capital nacional y $70 \%$ capital extranjero.

Antes de entregar al asistente

recuerde completar todas las preguntar del cuestionario

gracias por su colaboración 
